\title{
BACKGLOCKEN, BACKDECKEL UND BACKHAUBEN. ARCHÄOLOGISCHE ANGABEN ZUR ERNÄHRUNGSKULTUR SÜD- UND MITTELEUROPAS
}

\author{
TIVADAR VIDA \\ Forschungszentrum für Humanwissenschaften \\ der Ungarischen Akademie der Wissenschaften \\ Archäologisches Institut \\ Úri u. 49, H-1014 Budapest, Ungarn \\ Institut für Archäologiewissenschaften, Eötvös Loránd Universität \\ Múzeum krt. 4/B, H-1088 Budapest, Ungarn \\ vida.tivadar@btk.mta.hu
}

Gewidmet für Károly Mesterházy

\begin{abstract}
Baking bells (or baking lids) were actually very simple ovens that were suitable for baking bread, meat and fish This method of food preparation was practiced since prehistory in the Mediterranean world and we can find descriptions of baking bells in the Bible and in the works of the writers of antiquity. This individual mode of baking bread became especially widespread during late antiquity. In some regions, the use of baking bells survived either owing to a general stagnation (as in the Balkans or the Alpine lands), or to unusual living conditions (as in the Roman military camps of the Augustan period and in the medieval Ottoman-period border forts in Hungary). Their increasingly frequent use in late antiquity was a reflection of economic decline and the disappearance of urban bakeries. At the same time, the adoption of baking bells by the Barbarian peoples (such as the Avars and the ancient Hungarians) settling on the fringes of the Mediterranean world can be seen as a cultural advance and the adoption of local traditions. Baking bells were still used in the Carpathian Basin as late as the $19^{\text {th }}$ century and they can be found in some areas of the Balkans even today.
\end{abstract}

Keywords: baking lid, bread baking, Avars, ancient Hungarians, lifeways, diet

„tunc placentam imponito: testo caldo operito, pruna insuper et circum operito."

(M. P. Cato, De agricultura 76.)

\section{EINLEITUNG, PROBLEMSTELLUNG}

Die Frage nach der Funktion, der Verbreitung und dem Ursprung von Backglocken stellte sich mir während meiner Erforschung der awarenzeitlichen Siedlungskeramik (7.-8. Jahrhundert) im Karpatenbecken. ${ }^{2}$ Bei Siedlungsgrabungen und Landbegehungen kamen in den vergangenen Jahrzehnten in Ungarn Fragmente von Backglocken in großer Zahl ans Tageslicht, deren Bestimmung, ${ }^{3}$ Verbreitung und Chronologie bereits viele Diskussionen in

\footnotetext{
${ }^{1}$ Die vorliegende Arbeit habe ich als Stipendiat des Deutschen Akademischen Austauschdienstes (1993) angefangen und als Stipendiat der Alexander-von-Humboldt-Stiftung (2002) am Institut für Vor- und Frühgeschichtliche Archäologie und Provinzialrömische Archäologie der Ludwig-Maximilians Universität in München beendet. Ich möchte meinen Kollegen für ihre Kommentare und für die mir zur Verfügung gestellten Daten danken: Volker Bierbrauer, Michael Mackensen, Salvatore Ortisi, László Vajda (München); Csanád Bálint, Imre Holl, Katalin Jankovits, Gyöngyi Kovács, Gyula Siklósi, Béla
}

Miklós Szőke, Miklós Takács, Gábor Vékony (Budapest), Otto-Herrmann Frey (Marburg), Franz Glaser (Klagenfurt), Sabine Ladstätter, Hajnalka Herold (Wien), Ion Stanciu (Cluj/Kolozsvár), Ivan Mirnik (Zagreb), Archer Martin (Rom), K. Kalogeropoulos (Agia Paraskevi). Für die sparchliche Korrektur meines Manuskripts und zahlreiche Hinweise bin ich Prof. Dr. Amei Lang (München) dankbar.

${ }^{2}$ VIDA 1996, 323-364.

${ }^{3}$ SzÖKe 1980; BÁlint 1991; FiedLer 1994; VidA 1996. 
der archäologischen Forschung ausgelöst hatten. ${ }^{4}$ Die Suche nach Parallelen von awarenzeitlichen Backglocken hat bald zur Einsicht geführt, dass die Fragestellung nur in einem breiteren chronologischen und geographischen Rahmen als dem Karpatenbecken im Frühmittelalter untersucht werden kann. Der Gefäßtyp an sich ist den Keramikforschern nicht unbekannt - Backglocken werden ja auf dem Balkan und in Äthiopien ${ }^{5}$ noch heute verwendet und ähnliche Gefäße sind auch in Zypern, Italien und Marokko bekannt. ${ }^{6}$ Das Backprinzip ist nämlich uralt, ${ }^{7}$ denn diese Art, Fladenbrot zu backen, war jahrhundertelang, vor der Einführung der Backöfen und der Verbreitung der städtischen, industriellen Produktion, vorherrschend und ist in einigen Regionen, die von der genannten Entwicklung nicht betroffen waren, bis in die Gegenwart erhalten geblieben. Das Brotbacken unter einem Backdeckel oder einer Backglocke war wohl ziemlich allgemein eine rein private Angelegenheit der Haushaltungen. Im süd- und mitteleuropäischen Raum hat das Backen von Brot, Fladen (seltener Teig oder Fleisch) unter einer Backglocke oder einem Backdeckel eine bis heute andauernde, jahrtausendelange Tradition, was durch schriftliche Quellen, ethnographische Daten und zum Teil archäologische Funde belegt und bewiesen ist. ${ }^{8}$

Mit der zusammenfassenden Erforschung der Backglocken beschäftigten sich in Ungarn vor den 1970er Jahren in erster Linie Ethnographen, vor allem auf Grund von Funden aus dem 18.-20. Jahrhundert. Damals waren nur einige prähistorische Funde bekannt und es fehlten dokumentierte Backglocken- und Backdeckelfunde aus archäologischen Kontexten in ganz Europa von der römischen Kaiserzeit bis zum 14. Jahrhundert. ${ }^{9}$ Die Forschung war also trotz der zahlreichen schriftlichen Quellen aus der Antike und dem Mittelalter nicht in der Lage, die von den Ethnographen formulierte Hypothese, dieser Objekttyp sei seit vorgeschichtlicher Zeit ununterbrochen gebraucht worden, lückenlos mit archäologischen Daten zu untermauern. In den letzten Jahrzehnten haben aber zahlreiche Siedlungsausgrabungen in Süd- und Mitteleuropa neue, verifizierte Daten in großer Zahl geliefert, die eine besser fundierte Darstellung des kontinuierlichen Gebrauchs von Backglocken und Backdeckeln im untersuchten Raum von der Bronzezeit bis heute ermöglichen (s. Fundliste).

Das so lange tradierte Backprinzip - das Backen unter einem umgekehrten Gefäß - bedeutet aber nicht, dass man in allen Fällen und in allen Regionen oder Haushaltungen Keramik verwendete, die in der gleichen Technik hergestellt war und die gleiche Form hatte. ${ }^{10}$ Demzufolge mussten unsere Untersuchungen auf alle Keramiktypen erweitert werden, unter denen in den verschiedenen Perioden möglicherweise gebacken wurde, ob in einfachen Bauernhaushaltungen oder in den Küchen der Vornehmen. In der vorliegenden Studie werden auch zahlreiche Gefäßtypen behandelt, bei denen die Backglockenfunktion noch nicht erwogen wurde. Vermutlich wird künftige Forschung die Richtigkeit meiner Feststellungen bestätigen.

Gegenstand der Analyse im engeren Sinne ist die Frage, wann und unter welchen Bedingungen Backglocken und Backdeckel in den Regionen Europas gebraucht worden waren. Ich möchte klären, mit welchem Verfahren sie in den einzelnen Gebieten hergestellt, wie sie geformt und verwendet wurden. Ich untersuche, bei welchen europäischen Völkern und zu welcher Zeit diese Tradition erschien und worauf ihr Erscheinen bzw. ihr Verschwinden in den einzelnen historischen Epochen zurückgeführt werden kann. Des Weiteren soll Klarheit darüber geschaffen werden, welche Brotsarten mit Backglocken und Backdeckeln gebacken werden konnten und ob der Verzehr dieser Brotsarten im Zusammenhang mit den Ansprüchen bestimmter gesellschaftlicher Schichten, der geographi-

${ }^{4}$ Am Anfang bereitete es besondere Schwierigkeiten, dass es für die Gefäßtypen mit der gleichen Funktion in den verschiedenen Sprachen unterschiedliche Bezeichnungen gibt. So habe ich sie gesammelt und möchte das nicht unerwähnt lassen: sütöbura, sütőharang, sütőfedő, cserepulya, vörsnyeg, ceszt, puplika, buretó, bujdosó, hőkürtő (ungarisch), cloche, couvercle pour cuire le pain, moule (französisch), Backdeckel, Backhaube, Backglocke, Lappenschüssel, Lappenbecken (deutsch), baking-bell, baking-cover, cooking-bell, curfew (englisch), vršnik, pekva, črepulje (serbisch, kroatisch, bosnisch, montenegrisch), coperchio per la cottura del pane, teglie per la cottura del pane, testo (italienisch), clibanus, testum (lateinisch), tiesto (spanisch), ţest (rumänisch), gastra (neugriechisch), ponitse (neugriechisch, pomakischer Dialekt).

${ }^{5}$ FisSEHA 2002, 129.

${ }^{6}$ Cubberley 1988, 99.

${ }^{7}$ In der vorliegenden Arbeit handelt es sich nur um die süd- und mitteleuropäische Verbreitung von Backglocken und Back- deckeln und um die archäologischen Funde, die die Theorie ihres organischen Weiterlebens untermauern. Es muss aber festgehalten werden, dass das Backprinzip auch auf anderen Kontinenten (Afrika, Amerika, Asien) bekannt war, wo es aber in der Regel mit einigen Volksgruppen oder kleineren geographischen Regionen zusammenhängt und das für den Balkan beobachtete, jahrhundertelange Fortbestehen nicht nachgewiesen werden kann.

${ }^{8}$, „Nur im Südosten Europas hat die Backglocke sich seit vorgeschichtlichen Zeiten lückenlos in größeren Gebieten gehalten.“ STOKAR 1951, 141; RŐMER 1966, 390; GAVAZZI 1978; BUtURA 1989 , 274-275, Fig. 75-76; CUBBERLEY 1995, 58.

${ }^{9}$ RÓMER 1966, 398.

${ }^{10}$ In der ungarischen ethnographischen Fachliteratur sind eigentlich nur die Parallelen und Vorläufer der nicht scheibengedrehten, stark gemagerten Backglocken aus schlecht bearbeitetem Material untersucht worden. Diese Gefäße sind in bäuerlichen Haushalten und in provisorischen Quartieren gebraucht worden. 


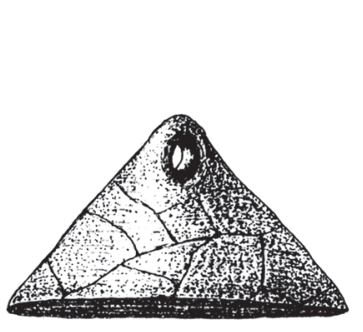

I A

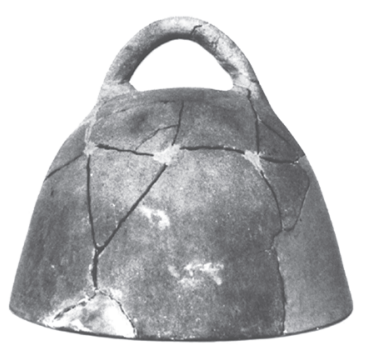

I B

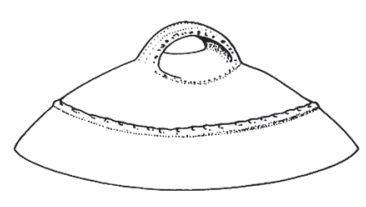

I C

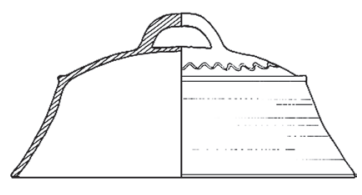

I D

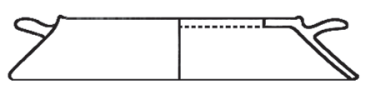

II A1

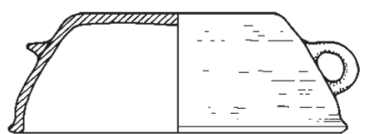

II C1

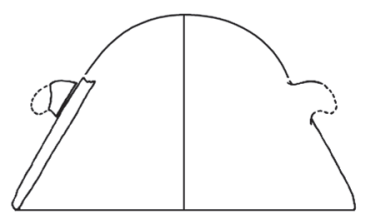

II D

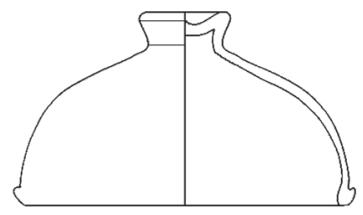

III A

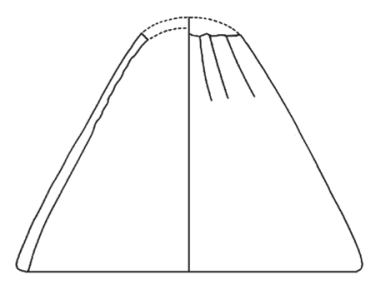

IV A

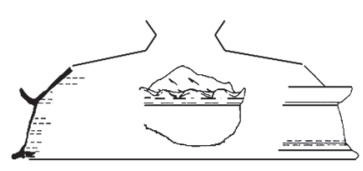

V

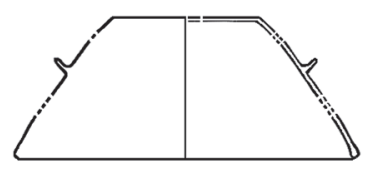

II A2

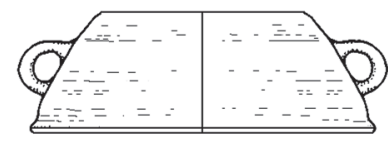

II C2

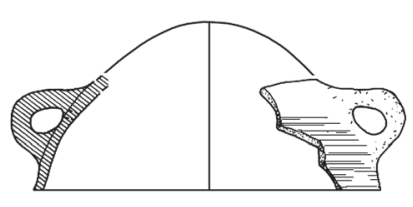

II E

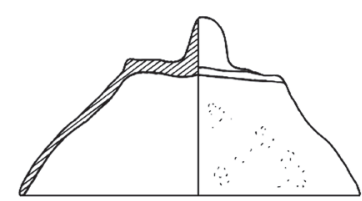

III B

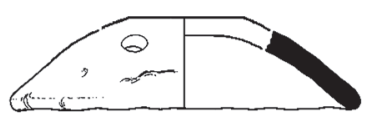

IV B

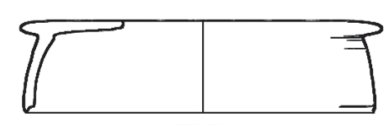

II B 
schen, wirtschaftlichen oder kulturellen Umgebung steht. Letztlich ist mein vorrangiges Ziel, eine archäologische Datenbasis zusammenzustellen, die - beim heutigen Forschungsstand - alle Informationen und Belege aus unterschiedlichen kulturellen und geographischen Regionen erfasst, die das mehrtausendjährige Weiterleben dieser Backtechnik im süd- und mitteleuropäischen Raum bezeugen. ${ }^{11}$

\section{FORSCHUNGSGESCHICHTE}

Obwohl Backglocken in der ethnographischen Fachliteratur des 19.-20. Jahrhunderts bekannt waren, ${ }^{12}$ erkannte man die Funktion entsprechender Funde in archäologischen Ausgrabungen zunächst nur langsam. Der Archäologe W. Radimský bestimmte 1895 das Backglockenfragment aus Ripač in Bosnien noch als Deckel. ${ }^{13}$ Die ersten, wissenschaftlichen Ansprüchen genügenden Beschreibungen von Backglocken und die ersten Darlegungen ihrer archäologischen Zusammenhänge wurden am Anfang des 20. Jahrhunderts von Ć. Truhelka und V. Čurčić verfasst, die versuchten, die Fragmente aus Donja Dolina in Bosnien auf Grund ethnographischer Beispiele funktional zu bestimmen. ${ }^{14}$ Es wurde früher angenommen, dass Backglocken schon im späten Neolithikum in Siedlungen in Bosnien vorgekommen waren, ${ }^{15}$ jedoch hat die neuere Fachliteratur gezeigt, dass diese eher Backschüsseln waren. ${ }^{16}$ In der Forschung bereitet es anscheinend heute noch Schwierigkeiten, die Funktionen als Deckel, Backglocke und Backhaube bei diesen ähnlich geformten Gefäßen auseinanderzuhalten. ${ }^{17}$ Zahlreiche Backglocken verfügen nämlich über ein kleines Lüftungsloch, was öfters als Argument für die Funktion der Backglocke als Backhaube herangezogen worden ist. Der Backdeckel aus Koper/Capodistria wurde eindeutig als für Brotbacken geeignet beschrieben, trotzdem verfügt er über ein kleines Lüftungsloch unter dem einen Seitenlappen. ${ }^{18}$

Bislang konnten sich die zusammenfassenden ethnographischen Studien über Backglocken bei der Behauptung einer ununterbrochenen tausendjährigen Tradition nur lückenhaft auf archäologische Daten berufen und bisher sind sie nicht nur eine genaue Chronologie der einzelnen Funde, sondern - vor allem was die Zeit vor dem Mittelalter betrifft - auch die kulturgeschichtliche Bewertung des Phänomens schuldig geblieben. ${ }^{19}$ Wichtige Ergebnisse zur Erforschung der Backverfahren wurden in erster Linie auf Grund der erhalten gebliebenen Darstellungen und Brotfunde geliefert (M. Währen), aber ein Vergleich der neu gewonnenen Daten mit den archäologischen Funden ist ausgeblieben. ${ }^{20}$

In der archäologischen Forschung ist die Frage nach der kontinuierlichen Verwendung dieses Objekttyps seit der Vorgeschichte, nach den Gründen und Umständen seines Erscheinens in verschiedenen Regionen Europas noch nicht behandelt worden. Es ist kein Zufall, dass man den Gebrauch von Backglocken und Backdeckeln eben in den Gebieten und Epochen erfolgreich untersuchen konnte, von denen schriftliche Quellen über die Verfahren der Zubereitung von Speisen zur Verfügung standen. Die Bearbeitung der Daten über die Zubereitung von Speisen und über die Gefäße durch die Analyse der schriftlichen Quellen einerseits und von der Archäologie andererseits erfolgte zunächst unabhängig voneinander. Bei Ersterer handelte es sich primär um die Klärung der Benennungen und Definitionen, bei Letzterer um die Aufstellung einer Typochronologie.

Mit A. Hilgers' Veröffentlichung eröffnete sich die Möglichkeit, im archäologischen Material nach den Entsprechungen der in den römischen Quellen belegten Gefäßtypen zu suchen. ${ }^{21} 1965$ und 1970 unternahm T. Mannoni, die in den mittelalterlichen Quellen genannten Backdeckel (testi) mit ihren archäologisch-ethnographischen Entsprechungen zu identifizieren. ${ }^{22} 1978$ bewiesen die Studien von J. Frayn und D. B. Whitehouse die Beziehung

\footnotetext{
${ }^{11}$ „What was the modus operandi of these vessels? What was the nature of the food so produced? What are the socio-economic implications in the variations in size at different periods and different areas?" CUBBERLEY 1995, 67.

${ }^{12}$ RÜTIMEYER 1924; NOPCSA 1925, 100.

${ }^{13}$ RADIMSKÝ 1895, 309, 483.

${ }^{14}$ TruhelKa 1904, 34-35; ČUrČIĆ 1912, 45.

15 TruHELKa 1914, 43, 67, 83; FILIPOVIĆ 1951, 73; RỎMER 1966, 391-394.

${ }^{16}$ BENAC 1979, 434.

${ }^{17}$ Bei einigen Gefäßen mit einem Loch kann die Haubenfunktion erwogen werden; es sicherte aber nicht genug Luft, um die
}

Glut glühend zu erhalten (FrEIHERR vON Miske 1907, Taf. LX.11) Über die hoch gewölbten Deckel aus der keltischen Siedlung auf der Heuneburg finden wir eine Hypothese für die - meiner Meinung nach höchstwahrscheinliche - Backglockenfunktion nur in einer Fußnote.

${ }^{18}$ Gustin-Cunja 1989, 29, Kat.-Nr. 25.

${ }^{19}$ GAVAZZI 1965; RỎMER 1966, 390.

${ }^{20}$ WÄHREN 1960a; WÄHREN 1960b.

${ }^{21}$ Hilgers 1969.

${ }^{22}$ Mannoni 1970, 297-319; ManNoni 1965, 49-64; MaNNONI 1970, 297-319. 
zwischen dem römischen sub testu Beckverfahren und dem Backen unter einem Backdeckel im Mittelalter; sie schufen damit die Grundlagen für die weitere Erforschung des Themas. ${ }^{23}$ Mit dem lateinischen Wort testum wurde ein Deckel bezeichnet, unter dem man Fladenbrot backen konnte. ${ }^{24}$ Das rumänische Wort ţest ist mit dem lateinischen nahe verwandt. Im Ungarischen erscheint es in der Form ceszt. Von Ch. Scheffer wurden 1981 Backglocken als wichtige Elemente der mediterranen Küche behandelt. ${ }^{25}$ In ihrem Aufsatz von 1988 haben sich A. L. Cubberley, J. A. Lloyd und P. C. Roberts zum ersten Mal mit den auf dem Gebiet des klassischen Italiens verwendeten Backdeckeln (testa, clibani) auseinandergesetzt. ${ }^{26}$ Es ist vor allem geklärt worden, dass das Backen unter den aus der römischen Republik- und Kaiserzeit bekannten Gefäßen namens clibanus und testum bzw. das Backen sub testu ein und dasselbe Verfahren benannten. In der römischen Keramik konnten die archäologisch früher nicht analysierten ${ }^{27}$ Objekte, auf die sich die in den Quellen reichlich belegten Wörter clibanus und testum bezogen, archäologisch erst vor einem Jahrzehnt identifiziert werden. ${ }^{28}$ Die Ergebnisse von A. L. Cubberley können als solide Basis für die Erkenntnis und Bestimmung ähnlicher Funde aus der späten Antike, der frühbyzantinischen Zeit und dem frühen Mittelalter dienen. ${ }^{29}$ Jedoch hat A. L. Cubberley die prähistorische Geschichte dieses Objekttyps nur kurz beschrieben. Seine Bemerkungen über die mittelalterlichen Backglocken sind skizzenhaft und er kannte die frühmittelalterlichen und byzantinischen Analogien überhaupt nicht.

Die für unser Thema grundlegend wichtige Monographie von Ch. Bakirtzes, in der er eben die mit der Zubereitung, Aufbewahrung und Lieferung von Speisen verbundene, einfache byzantinische Keramik behandelt, erschien im Jahre 1989. Ein großer Vorteil seines Werks liegt darin, dass er die Gefäße nicht nur auf Grund der byzantinischen schriftlichen Quellen beschrieben hat, sondern dass er nach deren archäologischen Entsprechungen suchte und ein genaues Bild von der im alltäglichen Leben verwendeten einfachen Keramik gab. ${ }^{30}$

Die archäologische Forschung im Karpatenbecken ist - trotz der zahlreichen früheren ethnographischen Zusammenfassungen - dank der Forschungen von B. M. Szőke erst in den vergangenen Jahrzehnten auf die frühmittelalterlichen und árpádenzeitlichen Backglocken aufmerksam geworden und hat ihre Funktion vor dem Hintergrund der ethnographischen Fachliteratur richtig erkannt, obwohl zunächst Unsicherheit bezüglich der Datierung der Funde in die Awarenzeit ${ }^{31}$ bzw. die Árpádenzeit herrschte. ${ }^{32}$ B. M. Szőke ist auch die Erkenntnis zu verdanken, dass Backglocken und handgeformte Tonkessel, eingestempelte Gefäße und bestimmte Töpfe im selben archäologischen Horizont erscheinen.

Bei der Bearbeitung der spätawarenzeitlichen Siedlung in Eperjes hat Cs. Bálint auf Grund der Fundzusammenhänge die spätawarenzeitliche Datierung der Backglocken für möglich gehalten und eine Formtypologie vorgenommen. Da Backglocken nach dem heutigen Stand der Forschung auf der eurasischen Steppe völlig unbekannt waren, wurde von Cs. Bálint - weiterhin in erster Linie auf Grund von ethnographischen und einigen vorgeschichtlichen Analogien - die Möglichkeit einer balkanischen Herkunft der awarenzeitlichen Backglocken vorgeschlagen. Er konnte aber damals die an sich korrekte Lösung nicht mit entsprechenden und genügenden archäologischen Analogien untermauern. ${ }^{33}$ Die Möglichkeit der spätawarenzeitlichen Datierung der Backglocken wurde später während der Bearbeitung der Siedlung in Gyoma, FO 133 weiter bestätigt. ${ }^{34}$ Der größte Streit in der ungarischen Forschung wurde von der Frage nach dem Weiterleben der handgeformten Tonkessel und Backglocken im 10. Jahrhundert ausgelöst. ${ }^{35}$

\footnotetext{
${ }^{23}$ FRAYN 1978; WHITEHOUSE 1978.

${ }^{24}$ HiLGERS 1969, 287.

${ }^{25}$ SCHEFFER 1981.

${ }^{26}$ CubBERley et al. 1988; CubBerley 1995, 55-68.

${ }^{27}$ Es ist aber festzuhalten, dass Gefäße, die als Backglocken oder Backdeckel verwendet werden konnten, trotz der guten Quellenlage nicht gesammelt wurden; z. B. BRUKNER 1981, 43; HiLGERS 1969

${ }^{28}$ Nur in Italien wurden Parallele zu Backglocken aus dreiBig Fundorten der Republik- und der Kaiserzeit gesammelt (CUBBERLEY et al. 1988, 112-113, Fig. 3). A. Cubberley weist auf den engen Zusammenhang der indoeuropäischen Wörter im Zusammenhang mit Brot und Backen hin: klibanos (griechisch), clibanos (latein), hlaifs (gotisch), hleib (althochdeutsch), hleb, chleb (slawisch), klepas, klaips (baltisch).

${ }^{29}$ CuBberley 1995, 55-68.
}

\author{
${ }^{30}$ BAKIRTZES 1989. \\ ${ }^{31}$ SZŐKE 1980, 182-188 \\ ${ }^{32}$ TÁtrai 1981, 510. Im Eintrag werden nur die vermute- \\ ten árpádenzeitlichen Backglockenfragmente und die Diskussion über \\ ihre landnahmezeitliche Datierung erwähnt, die awarenzeitlichen Vor- \\ bilder nicht. \\ ${ }^{33}$ Es ist wichtig, dass im nomadischen Fundmaterial der \\ eurasischen Steppe, im Gebiet der Saltovo-Majaki-Kultur, bis Ende \\ der 1980er Jahre keine Backglocken gefunden worden sind. Nach der \\ Meinung von Csanád Bálint kann das nicht bloß als eine Forschungs- \\ lücke betrachtet werden (BÁLINT 1991, 58-61). \\ ${ }^{34}$ VIDA 1996, 323-364. \\ ${ }^{35}$ SZŐKE 1980; letztens zusammenfassend: FIEDLER 1994.
}


U. Fiedler hat die frühmittelalterlichen Backglocken im Karpatenbecken - entsprechend der slawischen Archäologie, unabhängig von ihren mediterranen Zusammenhängen - als Begleiterscheinung der slawischen kulturellen Umgebung interpretiert, ohne zu überlegen, dass sich die Verwendung von Backgefäßen auch unter den Slawen erst später, in den für Weizenanbau geeigneten Gebieten herausbildete, wahrscheinlich unter südlichem oder östlich-pontischem Einfluss. Dafür spricht auch die Tatsache, dass Backgefäße nicht charakteristisch sind z. B. für Polen, wo eher Roggen angebaut wurde. ${ }^{36}$ Dass Dj. Janković die in der Region des Eisernen Tores in frühbyzantinischen Festungen ausgegrabenen Backglocken im Jahre 1981 wiederum mit den Slawen assoziierte, kann als Rückprojektion des mittelalterlich-neuzeitlichen und des heutigen Zustandes bewertet werden. ${ }^{37}$ In den breiter angelegten Zusammenfassungen über die ostslawische materielle Kultur und Töpferei sind aber keine Daten zur Verwendung von Backglocken zu finden. ${ }^{38}$

Dieses Backverfahren ist vor allem für den Balkan, die südlichen Alpen und die italienische Halbinsel charakteristisch, erscheint aber in verschiedenen Epochen auch bei den sich in den benachbarten Gegenden niederlassenden Völkern (Kelten, Romanen, Byzantinern, Slawen, Awaren, Magyaren usw.). ${ }^{39}$

Die heutigen ethnographischen Beobachtungen und die Erfahrungen der experimentellen Archäologie können neue Daten zum Gebrauch von Backglocken liefern. Erfolgreiche Untersuchungen sind auf der adriatischen Insel Iž (Kroatien) durchgeführt worden. ${ }^{40}$ Das Studium dieser Gefäßform bildete den Gegenstand eines ethnographischen Forschungsprojektes der Ephorie von Komotini in Griechenland, das in den Jahren 1987 und 1988 im nordöstlichen Gebiet der bergigen Gegend von Rodope stattgefunden hatte. Es handelt sich um Gebiete, die fast ausschließlich von Pomaken besiedelt sind (Komotini). ${ }^{41}$ Schwerpunkt der ersten Forschungskampagne war die soziale und gesellschaftliche Bedeutung dieser Keramikgattung. Es handelt sich um ein handgemachtes, dickwandiges Hausgerät, in dem man Brot backen kann ( $A b b$. 28.4). Das Gefäß besitzt eine runde Form, hat einen konischen Deckel mit Henkel und ist unterschiedlich groß. Dieses Hausgerät wird nie als Tausch- oder Handelsobjekt, sondern

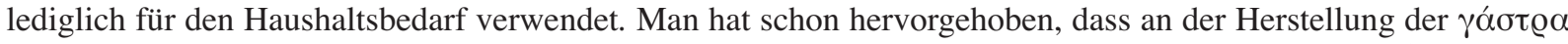

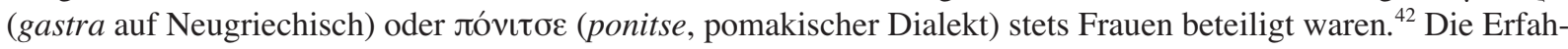
rungen aus der experimentellen Archäologie haben bewiesen, dass man mit dem in den römerzeitlichen Quellen beschriebenen Verfahren sehr gutes Fladenbrot backen kann. ${ }^{43}$

In der archäologischen Fachliteratur wurde bislang nicht erwogen, dass die süd- und mitteleuropäischen scheibengedrehten Backglocken guter Qualität und die handgeformten Backglocken geringerer Qualität in derselben Region die im kulturellen Sinne voneinander nicht unabhängigen Beweise für ein und dasselbe, seit der Bronzezeit bis heute ununterbrochen verwendete Backverfahren waren; ${ }^{44}$ so ist auch kein einheitlicher Katalog dieser Gefäße zusammengestellt worden. Das ist aber kein Zufall, denn die archäologische Forschung ist in bestimmten Regionen erst jetzt auf die nicht scheibengedrehten Backglocken aufmerksam geworden, die im Allgemeinen von minderer Qualität als die Hauskeramik sind.

\section{TECHNOLOGIE, TYPOLOGIE, HERSTELLUNG}

Backglocken verschiedener Größen wurden vor allem aus Ton hergestellt; wir kennen aber auch mittelalterliche Exemplare aus Metall ${ }^{45}$ bzw. solche aus Stein aus Siebenbürgen ${ }^{46}$ und neuerdings auch Backglocken aus Glas. ${ }^{47}$ Im weiteren Sinne konnte die Funktion der Backglocken von irgendeinem weitmündigen Gefäß erfüllt werden, womit auf offenem oder in geschlossenem Herd bzw. im Ofen gebacken werden konnte. „Es kann schließ-

${ }^{36}$ FIEDLER 1994, 338.

${ }^{37}$ JANKOVIĆ 1981, 144.

${ }^{38}$ Sedov 1982; Drevnjaja Rus' 1997.

${ }^{39}$ Die schwach geschlämmte, stark gemagerte, grob gemachte Gefäßform wurde früher in fragmentarischem Zustand schwer identifiziert. Die zusammenfassende Behandlung dieser Funde ist wahrscheinlich deswegen so lange ausgeblieben.

${ }^{40}$ Chapman-BintlifF-Gaffney-Slapsak 1988, 431.

${ }^{41}$ Efstratiou 1987, 479; Efstratiou 1988, 520.
${ }^{42}$ Efstratiou 1987, $480 \mathrm{f}$.

${ }^{43}$ JunKELMANN 1997, 193, Abb. 85.

${ }^{44}$ FILIPOVIĆ 1951. In den Gräbern 5, 9, 25 und 27 des römischen Gräberfeldes in Nave sind Backschüsseln mit Griff ausgegraben worden. Obwohl Back- und Kochgefäße nur selten ins Grab kamen, halten wir es für unbegründet, eine rituelle Funktion anzunehmen. JORIO 1987, 207.

${ }^{45}$ WiegelmanN 1973, 573-576; BAKIRTZES 1989, Taf. 11.5.

${ }^{46}$ LARIONESCU-ARMASESCU 1973, 247.

${ }^{47}$ STOKAR 1951, 141. 
lich jede weitmündige Irdenware, besonders Schalen, die man über die Backteller stülpte, zur Backglocke werden, ohne daß sie für uns heute als solche noch erkennbar wäre.“48

Unter den aus Ton hergestellten Backglocken und Backdeckeln sind sowohl scheibengedrehte wie auch handgeformte Exemplare bekannt. Die ohne eine Töpferscheibe, mit Hand geformten Backglocken - bronzezeitliche, etruskische, archaisch- und klassisch-griechische bzw. die awarischen, ungarischen, türkenzeitlichen Exemplare im Karpatenbecken - weisen über Jahrtausende hinweg eine überraschend einheitliche Form auf und sind in sehr ähnlichen Techniken hergestellt worden. ${ }^{49}$ Von den hoch gewölbten, hohlen Backgefäßen ist die unten breite, glockenartige Form mit oberem Henkel am beliebtesten. Diese Form ist vor allem für die handgeformten Stücke charakteristisch, weil Ton geringer Qualität von der Statik her am ehesten diese einfache Form ermöglichte. Auf einer Drehscheibe wurden Glocken mit oberem Henkel im seltensten Fall getöpfert, da die bessere Materialbearbeitung die Herstellung einer nicht so hohen, jedoch sehr weitmündigen, flachen bzw. tiefen Tellerform ermöglichte, die dann umgedreht, mit seitlichen runden Henkeln oder mit Lappen oder Kragen versehen, nach dem Vorbild von Deckeln verwendet wurden.

Backglocken wurden aus grob geschlämmtem, ungenügend bearbeitetem Ton hergestellt, der mit Schotter, quarzigem Sand, Muscheln oder gemahlenen Steinen, Keramikbruchstücken vermischt wurde, damit das Gefäß wärmehaltend wird. ${ }^{50}$ Die awarenzeitlichen und árpádenzeitlichen bzw. türkenzeitlichen Backglocken im Karpatenbecken sind alle aus schwach geschlämmtem, mit Spreu vermischtem Material; oft wurden noch an die Außenoberfläche Schotter oder kleinere Steine in den Ton gedrückt. ${ }^{51}$ Auf der adriatischen Insel Iž ist beobachtet worden, dass man zu fünf Einheiten Ton zwei Einheiten kalkhaltige Magerung dazugab, um das Material für die Backglocken vorzubereiten. ${ }^{52}$ Im Jahre 1988 hat man im Rodope-Gebirge beobachtet, dass von den Frauen der pomakischen Hirten für ihre Backglocken der Ton zuerst aus verschiedenen Gegenden der Siedlung gesammelt, dann von seinen Steinchen gesäubert, mit einer Holzstange ,geschlagen“ und mit Wasser gemagert wird. Der weicher gewordene Ton wird danach mit den Füßen oder mit den Händen für 4 bis 5 Stunden geknetet, wobei Sand, Tierkot, Stroh und eventuell Ziegenhaar hinzugefügt wird. Der Zweck ist die verstärkte Kohärenz des Tones. Die zügige Formgestaltung wird ausschließlich mit den Händen gemacht. Das fertige Gefäß bleibt anschließend 10 bis 15 Tage im Schatten, um abzutrocken. Die Gefäßoberfläche ist stets undekoriert. ${ }^{53}$

In Italien wurden die meisten römerzeitlichen, spätantiken und einige frühbyzantinische bzw. mittelalterliche Backdeckel und Backglocken - wie die modernsten - auf einer Töpferscheibe hergestellt. Die scheibengedrehten Backgefäße weichen von anderen gedrehten Hauskeramiktypen nur in der größeren, aber einheitlichen Magerung des Materials und in der dickeren Wandung ab. An den scheibengedrehten Backdeckeln sind verschiedenartige Henkel zu finden. Am verbreitetsten war der in der Mitte des Gefäßes herumlaufende, nach unten gebogene kurze Lappen, mit dem man die heißen Gefäße leicht heben konnte. Oft dienten aber bloß zwei symmetrisch angeordnete Lappen oder die glatte oder mit Fingereindrücken verzierte Ausstülpung am oberen Teil als Henkel. Es kam auch vor, dass zwei ringförmige Henkel symmetrisch an beiden Seiten angebracht waren oder dass an der einen Seite ein kurzer Lappen, an der anderen ein ringförmiger Henkel befestigt wurden (Lago di Ledro B). Es gibt Backdeckel mit einem Knopf ganz oben (Korinth, Ephesos, Sip), deren römerzeitliche Vorläufer auch bekannt sind (Sirmium). ${ }^{54}$

Die in verschiedenen Epochen und geographischen Regionen hergestellten Backglocken und Backdeckel haben einen Durchmesser von 20-60 cm und eine Höhe von 10-40 cm. ${ }^{55}$ Der rekonstruierbare Außenranddurchmesser der in der türkenzeitlichen Palisadenburg von Barcs gefundenen Gefäße betrug 30-50 cm, ihre Höhe ca. $32 \mathrm{~cm} .{ }^{56}$ Gebrannt wurden die Backglocken ziemlich einfach, ohne einen Ofen, vermutlich in einer Brenngrube oder im Herd, wo später auch Brot gebacken wurde.

Auf Grund der Form des Gefäßes bzw. der Form und der Position des Henkels können wir grundsätzlich zwei Typen unterscheiden: die glockenförmigen mit oberem Henkel (Typ I) und die schüsselförmigen mit flacherem Deckel (Typ II). Die Backhauben mit Henkelknopf oder Knubben sind in einen neuen Typ zu reihen (Typ III), auch wenn sie die Formelemente der Typen I und II teilweise vereinigen. In eine weitere Gruppe können die glockenoder schüsselförmigen Exemplare ohne Henkel (Typ IV) und die deckelförmigen, in der Mitte mit einem Loch

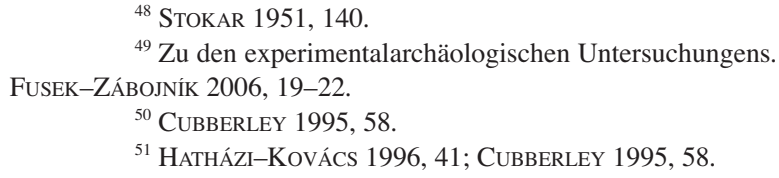

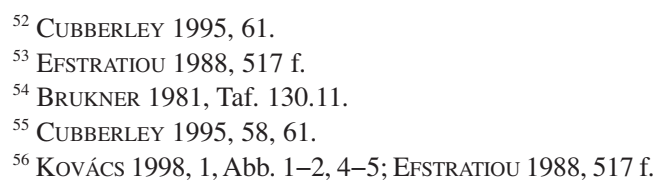


versehenen Exemplare (Typ V) gereiht werden. Beim heutigen Stand der Forschung ist es nicht nötig, eine detailliertere Typologie aufzustellen, da es in erster Linie notwendig ist, die lokalen Formen genau zu klassifizieren und die schon erkannten bzw. die neuen Formen zu bestimmen und typologisch einzuordnen.

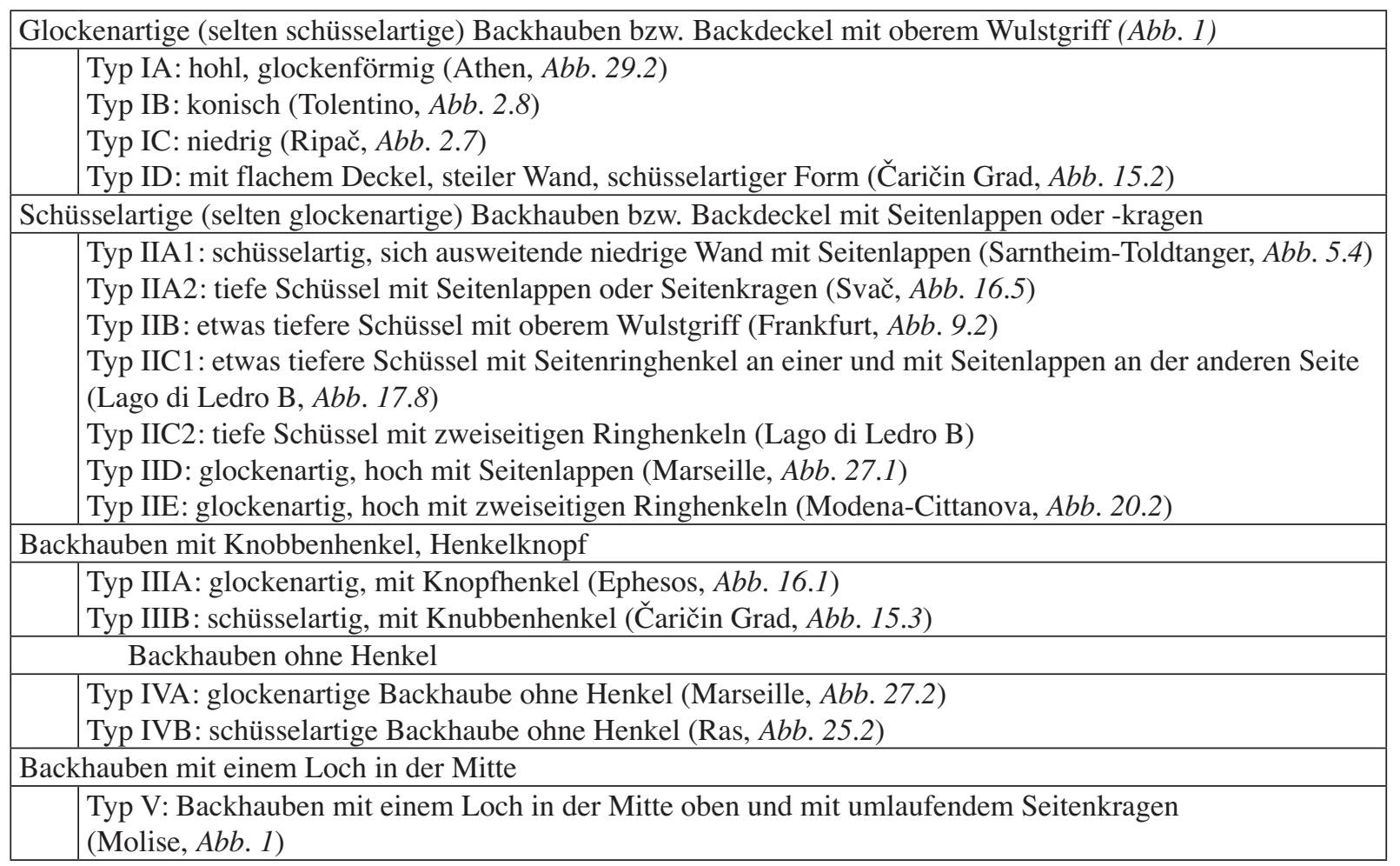

Die uns zur Verfügung stehenden Daten bezeugen, dass Backglocken immer vor Ort, wo man sie gebrauchte, hergestellt wurden, vor allem wegen ihrer Zerbrechlichkeit. Sie wurden also nie im regionalen oder im Fernhandel erworben. ${ }^{57}$ Ethnographische Daten beweisen, dass Backglocken nicht von spezialisierten Töpfermeistern, sondern von den Bauern hergestellt wurden. ${ }^{58}$ An einigen Orten war es sogar die Aufgabe der Frauen, die handgeformten Backglocken herzustellen. ${ }^{59}$ In der serbischen Gemeinsprache haben sich jedoch die Begriffe crepuljarstvo, pokljukari herausgebildet, was zum Teil eine spezialisierte Herstellung von Backgefäßen und Backglocken im Balkangebiet impliziert.

\section{FUNKTION}

Da in bestimmten Gebieten des Balkans Backglocken noch in jüngster Vergangenheit in Gebrauch waren, ${ }^{60}$ konnten die wichtigsten ethnographischen Daten über die Verwendung von Backglocken aus einer noch lebendigen Tradition gewonnen werden ${ }^{61}$ Einige Autoren, vor allem in der serbischen Forschung, berufen sich jedoch im Zusammenhang mit diesem Keramiktyp oft auf Werke aus dem 19. Jahrhundert, vor allem auf das linguistische Werk von V. Karadžič, ${ }^{62}$ in dem er die Verwendung der Backglocken nach der Tradition seiner Zeit beschrieb. Die antiken und mittelalterlichen schriftlichen Quellen bzw. die ethnographische und auf dem Balkan heute noch lebendige

\footnotetext{
${ }^{57}$ Williams-Evans 1991, 51-55.

${ }^{58}$ TOMIĆ 1958, 209; LECHNER 1962, 257-258.

${ }^{59}$ RÖMER 1966, 397-410; FILIPOVIĆ 1951, 1-3, 107-118;
} Gunda 1966, 17, Fig. 1-2; Tомić 1970; ToMIĆ 1983, 18-23; VAKARELSKI 1977, 359-360, obr. 335-336; ONUZI 1980, Fig. 5-9, 11. Über

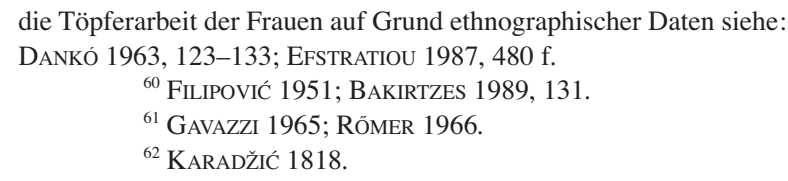


Tradition beweisen eindeutig, dass diese Gefäße geeignet und dementsprechend auch zum Backen gebraucht worden waren, widerlegen aber die Annahmen von der Funktion der Backglocken bloß als Glutdeckel. ${ }^{63}$ Auf Grund ihrer Form waren nämlich Backglocken und Backdeckel geeignet, auch die Funktion einer Gluthaube zu erfüllen. Diese Funktion wird nahe gelegt, wenn eine Backhaube mit einem oder mehreren Löchern versehen wurde, da man dadurch die für das Feuer benötigte Luft sichern konnte. Die glockenförmigen Gefäße könnten natürlich auch andere Funktionen erfüllen. Sie können zum Beispiel die Speisen vor dem Kaltwerden oder vor anderen Einflüssen schützen. ${ }^{64}$ Meines Erachtens dienten Backglocken und Backdeckel doch primär zum Backen und haben ihre Form in dieser Funktion jahrtausendelang bewahrt.

Das Backen unter glocken- oder deckelförmigen Gefäßen ist eine Art, Speisen bei offenem Feuer zuzubereiten und bildet eine bedeutende Entwicklung gegenüber dem Backen zwischen Steinplatten oder in Glut bzw. auf einem mit Glut bedecktem Rost. ${ }^{65}$ Unter diesen nach unten offenen, oben oder seitlich mit einem Henkel oder einem Griff versehenen Gefäßen, die die Form etwa eines Halbkreises bzw. eines umgekehrten Kegelstumpfes oder einer Schüssel bzw. eines Tellers hatten, wurden Brot, Fladen, Teig und in einigen Gegenden auch Fleisch gebacken. ${ }^{66}$ Die Verwendung dieses Gefäßtyps zum Backen von Brot war so allgemein bekannt, dass dieser Typ von Ć. Truhelka schlicht und einfach Brotdeckel ${ }^{67}$ genannt wurde.

Ć. Truhelka beschrieb den Gebrauch von Backglocken schon 1904: „Wir brauchen gar nicht weit zu gehen, um zu sehen, wie diese Deckel funktionieren. In Bosnien werden wir sie auf dem Lande fast in jedem Hause in der ganz gleichen Form in Verwendung finden. Der Vorgang beim Backen mit diesem Deckel - in Bosnien sać oder crjepulja genannt - ist Folgender: Auf dem flachen Herde wird der Boden durch Feuer erhitzt und wenn er die gewünschte Hitze erreicht, wird die Asche sauber abgekehrt, das zu backende Brot darauf gelegt und mit dem vorher gehörig erhitzten Brotdeckel zugedeckt. Um ein zu rasches Abkühlen des Deckels zu verhindern, wird er mit glühender Asche und Glut zugedeckt. So bäckt sich das Brot unter dem Deckel in kürzester Zeit gar. Daß auch die aus dem Pfahlbau stammenden Tondeckel größerer Dimensionen zum Brotbacken in ähnlicher Weise verwendet wurden, bestätigt uns nicht bloß die gleiche Form, sondern auch der Umstand, daß ausnahmlos alle auf der Oberfläche von einer Aschenkruste überzogen waren, welche nur durch längeres Liegen in Asche entstehen konnte. Diese Vorrichtung veranschaulicht uns den vorgeschichtlichen Ofen in seiner primitivsten Gestalt." ${ }^{\text {68 }}$

Während des Backens wird nicht nur das zu backende Brot, sondern in gleicher Weise der Teig oder auch das Fleisch auf die erhitzte Backoberfläche, auf den Backteller oder die Backschüssel gelegt und mit der/dem zuvor erhitzten Backglocke/Backdeckel zugedeckt, die/der dazu noch mit glühender Asche bedeckt wird. ${ }^{69}$ Unter der Backglocke wurde anfangs, in der vorgeschichtlichen Zeit, vor allem Fladenbrot ohne Sauerteig gebacken. ${ }^{70}$ Dieses Verfahren war günstiger als das Backen im Ofen, indem der Teig allmählich gebacken wurde, zunächst unten, dann die Seiten und das obere Teil. Ein großer Vorteil der Backglocke bestand darin, dass der Teig nicht austrocknen konnte, da die Feuchtigkeit unter der Backglocke behalten wurde und als Dampf im Backraum den frischen Fladen weich werden ließ. Das war ein bedeutender Fortschritt im Vergleich zum Backteller, wo der Teig die Feuchtigkeit verlor, trocken und hart wurde. Damit das Brot auch länger weich blieb, musste man es mit Sauerteig backen, der den Teig auflockerte. Um aus diesem Teig Brot zu backen, war aber eine gleich hohe Temperatur notwendig, die nur ein Backofen mit gleichmäßiger Hitze von unten, von den Seiten und von oben sichern konnte. ${ }^{71}$ Nur bei großer Hitze konnte sich nämlich schnell eine dünne Kruste bilden, so dass der durch den Sauerteig weich gewordene Teig nicht zergeht. Bei dem eher dichten Teig eines Fladenbrotes ohne Sauerteig wäre aber eine zu hohe Temperatur eher

${ }^{63}$ Salier 16, Vitrine 1. Koch- und Vorratsgefäße in der Salierzeit. Laut bestimmter Quelleninterpretationen gab es am clibanus kleine Löcher, damit die Hitze der Glut besser in den Backraum eindrängen kann. S. K. E. Georges: Ausführliches Lateinisch-Deutsches Handwörterbuch. Aus den Quellen zusammengetragen und mit besonderer Bezugnahme auf Synonymik und Antiquitäten unter Berücksichtigung der besten Hilfsmittel. Basel-Stuttgart [1913, 8. Auflage] 1967, 1207. Diese Hypothese wird aber von den archäologischen Daten nicht bestätigt. An römerzeitlichen und mittelalterlichen Funden gibt es höchstens ein Loch (z. B. Molise, Ras).

${ }^{64}$ WAHL 1982,191
${ }^{65}$ Backglocken können als Vorläufer von Öfen betrachtet werden, denn sie haben sich durch den Zusammenbau von Backplatten und Backglocken herausgebildet. RAPAICs 1934, 158-159.

${ }^{66}$ LECHNER 1962, 255-272.

${ }^{67}$ TruhelKa 1912, 35.

${ }^{68}$ TRUHELKa 1912, 35

${ }^{69}$ Die Oberfläche von einigen Backdeckeln war flach, damit man mehr Glut darauf legen konnte; STOKAR 1951, 141; POPOVIĆ 1956, 95-122; RŐMER 1966, 390.

${ }^{70}$ Laut Mitteilung von Al. Zaharia wurde unter dem rumänischen zest in erster Linie nicht gesäuertes Brot (acima) gebacken. MAURIZIO 1927, 310.

${ }^{71}$ StOKAR 1951, 142. 
nachteilig gewesen. ${ }^{72}$ Zur Herausbildung von stärker gewölbten Backglocken trug auch die bessere Qualität der Getreidesorten bei, denn dadurch stieg der Teig während des Backens höher an. ${ }^{73}$ Ein Nachteil der Backglocken war aber, dass sie nur für kleinere Portionen, für einige Personen, ausreichten. ${ }^{74}$ Größere Familien oder Gemeinschaften konnten nur versorgt werden, wenn man Öfen zum Backen baute.

An einigen Fundorten wurden Backglocken sogar in einer auf ihre Verwendung hinweisenden Position ausgegraben. Am slowenischen spätbronzezeitlichen Stična wurde die Backglocke in situ am Feuerplatz gefunden. ${ }^{75}$ In Békés-Ditér, einem ungarischen mittelalterlichen Fundort, wurde eine Backglocke auf zwei Ziegeln gefunden, vielleicht eben wie sie für das Backen vorerhitzt worden war. ${ }^{76}$ Besonders interessant sind die Fundumstände der Backglocke aus Doboz: Sie wurde auf dem zentralen offenen Feuerplatz gefunden und zwar in einem Haus, in dem es in der Ecke auch einen gebauten Ofen gab. ${ }^{77}$ Das weist eben darauf hin, dass Backglocken für die Herstellung einer speziellen Speise verwendet wurden, die man im gebauten Ofen nicht backen konnte, so dass die zwei Backeinrichtungen parallel in Gebrauch waren. Im Ofen konnten die Temperatur und die Feuchtigkeit, die für das Backen von wohlschmeckendem Fladenbrot notwendig waren, wahrscheinlich nicht gesichert werden. Bei der Ausgrabung der türkenzeitlichen Palisadenburg in Szekszárd-Újpalánk konnte ein lange gebrauchter Feuerplatz im Freien beobachtet werden, an dem zahlreiche Backglocken und andere Backgefäße ans Tageslicht kamen. An diesem Platz hatte man früher Ton gewonnen und die Grube dann mit Abfall gefüllt. ${ }^{78}$ Am selben Ort wurde der jüngste Feuerplatz aus dem Ende des 17. Jahrhunderts schon mit Ziegeln bedeckt, auf die man, nachdem sie erhitzt wurden, die Backglocke stellte. ${ }^{79}$

Mit Fragmenten von Backglocken wurden oft Backschüsseln oder flache, ausgebrannte Tonplatten mit einem Durchmesser von paar Zentimetern gefunden. Früher war der Zusammenhang dieser Gefäßtypen, ihre Verwendung im selben Backverfahren nicht eindeutig, zumal Backglocken und Backdeckel formal lange nicht genau definiert wurden und das ähnliche Material schlechter Qualität sehr oft zur Verwechslung der beiden Typen führte. Der enge Zusammenhang von Backdeckeln und Backschüsseln bzw. -tellern wird von zahlreichen Daten aus dem Mittelalter und der Neuzeit nahe gelegt. ${ }^{80}$ Im mittelalterlichen, türkenzeitlichen Fundmaterial sind sowohl im Karpatenbecken wie auch auf dem Balkan ${ }^{81}$ Backglocken zusammen mit Backschüsseln von verschiedenem Durchmes$\operatorname{ser}^{82}$ ausgegraben worden, was ihre gemeinsame Verwendung beweist.

\section{VERBREITUNG, CHRONOLOGIE}

\section{Bronzezeit (Spätbronzezeit: Hallstatt B)}

In dieser Analyse kann die genaue Bearbeitung der vorzeitlichen Verwendung von Backglocken und ähnlich verwendeten Gefäßen nicht vorgenommen werden (Karte 1); es soll jedoch mit Hilfe von einigen Funden und der Beschreibung des Forschungsstandes auf die uralten Verfahren des Backens von Fladenbrot oder des Fleischbratens bzw. auf die dabei gebrauchten Backglocken- und Backdeckelformen aufmerksam gemacht werden. Die Behandlung dieser vorgeschichtlichen Gefäße erscheint umso notwendiger, als sie in Form und Material überraschende Ähnlichkeiten mit einigen in naher Vergangenheit noch verwendeten Gefäßen aufweisen.

Unter günstigen Umständen sind uns zahlreiche Fladenbrotfunde aus dem Neolithikum, der Kupferzeit und der Bronzezeit erhalten geblieben, ${ }^{83}$ aber wie sie genau gebacken wurden - bzw. in was für Gefäßen -, ist kaum erforscht worden. Als ein primitives Verfahren wird das Backen in Glut, in einer Backgrube oder zwischen Blättern angesehen, wobei der Teig oft auf eine Tonplatte oder auf einen Rost gelegt wurde. ${ }^{84}$ Sauberer war das Backen

72 STOKAR 1951, 142.

${ }^{73}$ MAURIZIO 1927, 309-310.

${ }^{74}$ BAKIRTZES 1989, 53-54.

${ }^{75}$ GABROVEC et al. 1970, 22, 37.

${ }^{76}$ In ähnlicher Position wurde eine Steinbackglocke aus Siebenbürgen von A. Maurizio veröffentlicht: MAURIZIO 1926, 313, Abb. 75a.

${ }^{77}$ KovalovszKi 1975.

${ }^{78}$ Die Schichten von Asche, die vielen Gefäßfragmente und Tierknochen in der Grube deuten darauf hin, dass hier ständig gekocht und gebacken, sogar Gewehrkugeln gegossen wurden; GAÁL 1981, 146.

${ }^{79}$ GAÁL 1981, 147.

${ }^{80}$ ManNoni 1970, Pl. III; Whitehouse 1978, 146-147.

${ }^{81}$ Bajalović-HadŽI-PEsIĆ 1981, 51, T. XII.9, sl. 43.

${ }^{82}$ Jüngst über mittelalterliche Backschüsseln (Babócsa,

Barcs, Buda, Eger, Segesd, Szekszárd-Újpalánk, Szolnok, Török-

koppány, Visegrád): HATHÁzI-KovÁcs 1996, 41.

${ }^{83}$ WÄHREN 1989, 9-28.

${ }^{84}$ RAPAICS 1934, 158. 


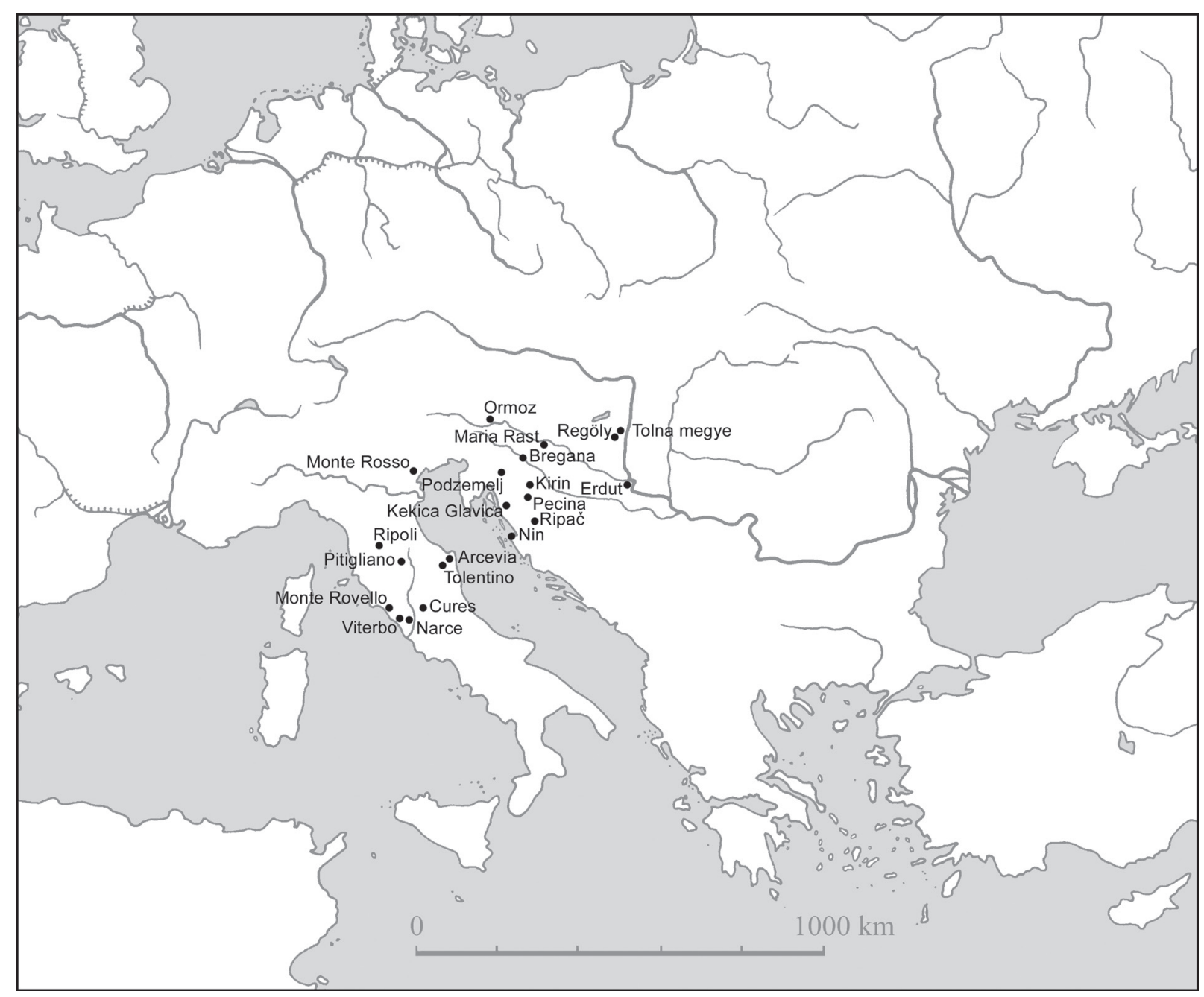

Karte 1. Bronzezeitliche Backglocken und Backdeckel

zwischen erhitzten Stein- oder Tonplatten, die als „primitive Gefäße“ aufgefasst werden können. Die sporadischen Brotfunde aus dem Neolithikum beweisen, dass das Backverfahren schon früh bekannt war; die dabei verwendeten Gefäßtypen sind aber bisher nicht identifiziert worden. ${ }^{85}$ Die Wölbung der einen Tonplatte war ein großer Fortschritt: Es entwickelte sich der Backdeckel oder die Backglocke, mit denen man bei bleibender Feuchtigkeit, durch Dünsten, bessere Speisen bzw. Speisen höherer Qualität backen konnte. ${ }^{86}$

Die frühesten, handgeformten Backglockenfunde aus spätbronzezeitlicher Umgebung kennen wir aus dem heutigen Bosnien, Kroatien, ${ }^{87}$ Slowenien ${ }^{88}$ und Italien. ${ }^{89}$ Einige rechnen mit dem Gebrauch von Backglocken erst ab der italienischen Eisenzeit, ${ }^{90}$ aber die Daten sprechen dafür, dass das Verfahren älter ist und in der Bronzezeit schon bekannt war. Backglocken erscheinen auch in Mittelitalien: in Umbrien, Latium und Etrurien um das 9.-10. Jahrhundert v. Chr., auch in den spätbronzezeitlichen Protovillanova-Siedlungen (Poggio Civitate bei Siena, Potesina, Le Sparne di Poggio Buco) und in der späten Hallstattzeit (s. Fundliste). Sie fehlen aber im Gebiet des Veneto. ${ }^{91}$ Ähnliche handgeformte, kleinere Deckel mit oberem Henkel sind auch in der damaligen Grabkeramik als Urnen-

${ }^{85}$ WiEGELMANN 1973, 575.

${ }^{86}$ Dieses Backverfahren war auch in Afrika und Amerika bekannt. Eigentlich führte diese Entwicklung zur Herausbildung von Öfen, gewonnen durch den Zusammenbau der flachen und der gewölbten Backoberflächen. RAPAICS 1934, 159-160.

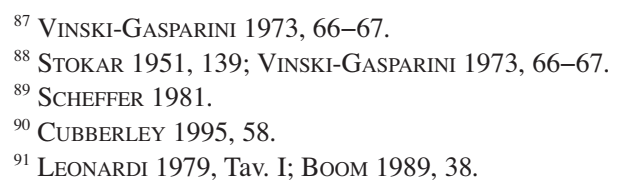


deckel zu finden. ${ }^{92}$ Mit einer Funktion als Backglocke ist jedoch für größere Gefäße in Siedlungen zu rechnen. Durch eine genaue Betrachtung der Siedlungskeramik werden wahrscheinlich weitere Gefäße ermittelt, die zum Backen dienen konnten. ${ }^{93}$ (Abb. 2-4)

Am Beginn von Hallstatt B (Ha B1) sind Backglocken überall dort in Italien und auf dem Balkan zu finden, wo sie schon früher, in der Bronzezeit, vorhanden waren. Die Backglockenfunde aus dem Wohnhaus in Regöly, Ungarn, sowie weitere Funde aus dem Komitat Tolna (Fundort unbekannt) sind auch in die Zeit der Urnenfelderkultur (Spätbronzezeit), Hallstatt B, zu datieren. ${ }^{94}$

\section{Eisenzeit (Hallstatt C - La Tène, 8.-1. Jahrhundert v. Chr.)}

Nach der Bronzezeit wurden Backglocken im Mediterraneum kontinuierlich verwendet, sowohl in den zentralen wie peripheren Gebieten. Schöne Exemplare der späten archaischen (520-490 v. Chr.) und der klassischen (420-400 v. Chr.) Zeit wurden bei der Ausgrabung der Agora in Athen gefunden. ${ }^{95}$ (Abb.29, 1-2) Die Funktion dieses Kochgefäßes wurde bereits von B. A. Sparkes in einem Aufsatz angesprochen. ${ }^{96} \mathrm{Im}$ Mediterraneum kann eine ähnliche Rolle bei zahlreichen gewölbten Deckeln unterschiedlicher Formen, mit oberem oder seitlichem Henkel angenommen werden (Kaman-Kalehöyük ${ }^{97}$ ). (Karte 2)

Lappenschüsseln/Lappenbecken gibt es im Raum der südlichen Alpen, auf dem Gebiet von Tirol-Ostschweiz-Kärnten ab der späten Hallstattzeit. Sie erscheinen zuerst in der Laugen-Melaun-C-Keramik und ihre Anzahl nimmt später zu. ${ }^{98}$ (Abb. 5) Auf dem Gebiet der Fritzes-Sanzeno-Kultur, ${ }^{99}$ im Tal und in der Umgebung des Flusses Etsch bzw. in den benachbarten Gebieten bilden die mit einem oder mit zwei Griffen bzw. Henkeln versehenen Gefäße (Lappenbecken, Lappenschüsseln), die umgekehrt höchstwahrscheinlich als Backdeckel verwendet worden waren, eine eng zusammenhängende Gruppe in der Eisenzeit. Obwohl die Gefäße ständig um $180 \mathrm{Grad}$ gedreht dargestellt und veröffentlicht werden, ${ }^{100}$ weisen die Richtung und die Position der Tragelappen an den Seiten darauf hin, dass sie nur mit dem Boden nach oben verwendet werden konnten, was aber eben der Backdeckelfunktion entspricht. Diese Form war sehr lange in Gebrauch. ${ }^{101}$ Der älteste Fund in Pfatten ist vor das 7. Jahrhundert v. Chr. zu datieren ${ }^{102}$ und in Sottosenga gibt es Funde noch aus dem 1. Jahrhundert v. Chr. ${ }^{103}$

Während der Ausgrabung der Festung Stična in Slowenien sind im Schnitt IV Backdeckel ans Tageslicht gekommen, die in die Stufen Hallstatt C-D datiert werden können. ${ }^{104}$ (Abb. 6) Es ist besonders zu betonen, dass diese Backglocken zusammen mit Backtellern gefunden wurden, was den engen Zusammenhang der beiden Objekttypen bereits in ältester Zeiten beweist. Fragmente von einer Backhaube wurden im Schnitt IV noch in situ auf einer Herdstelle der ältesten Hallstattzeit angetroffen. ${ }^{105}$

Weitere Backhauben aus der späthallstattzeitlichen Siedlung auf der Heuneburg wurden als Deckel publiziert, obwohl H. van den Boom in einer Fußnote selber die Möglichkeit der Deutung als Backhaube erwähnt und sogar auf mehrere Parallelen hinweist. ${ }^{106}$ Sie hielt es für möglich, dass die „Deckel“ die in der Urnenfelderkultur und in der Hallstattzeit bekannten Backhauben waren, zugleich hielt sie aber diese Interpretation wegen ihrer geringen Höhe für eher unwahrscheinlich. Das von uns gesammelte Vergleichsmaterial - vor allem die Lappenschüsseln oder Lappenteller - zeigen aber, dass Gefäße zum Backen von Fladenbrot nicht sehr gewölbt zu sein brauchten (Abb. 7). So ist das Argument von H. van den Boom gegen die Interpretation als Backhaube nicht hinreichend. Viel wichtiger erscheint es, dass das Material dieser Deckel grober ist als das anderer handgeformter

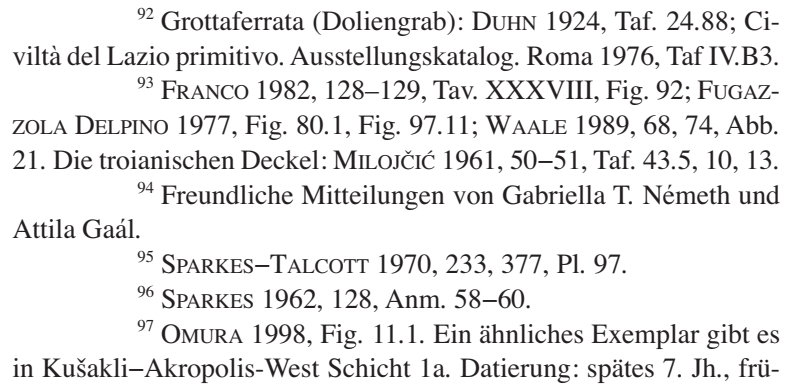

${ }^{92}$ Grottaferrata (Doliengrab): DuHn 1924, Taf. 24.88; Civiltà del Lazio primitivo. Ausstellungskatalog. Roma 1976, Taf IV.B3.

${ }^{93}$ FranCO 1982, 128-129, Tav. XXXVIII, Fig. 92; FugaZZOLA Delpino 1977, Fig. 80.1, Fig. 97.11; WaAle 1989, 68, 74, Abb. 21. Die troianischen Deckel: MiLoJČIĆ 1961, 50-51, Taf. 43.5, 10, 13. Attila Gaál.

${ }^{94}$ Freundliche Mitteilungen von Gabriella T. Németh und

${ }^{95}$ Sparkes-Talcott 1970, 233, 377, Pl. 97.

${ }^{96}$ SPARKES 1962, 128, Anm. 58-60.

${ }^{97}$ Omura 1998, Fig. 11.1. Ein ähnliches Exemplar gibt es in Kušakli-Akropolis-West Schicht 1a. Datierung: spätes 7. Jh., frü-

hes 6. Jh. v. Chr. Für die Angaben bedanke ich mich bei Herren Andreas Müller-Karpe und Andreas Schachner (beide Marburg).

${ }^{98}$ Rodriguez 1986, 313.

${ }^{99}$ MarZATICO 1992, 213-246.

100 Ähnlich umgekehrt werden auch die spätantiken Exemplare veröffentlicht.

${ }^{101}$ RodrigueZ 1986, 312 f.; GLeIRSCHER 1987, 221, Anm. 207.

${ }^{102}$ GLEIRSCHER 1987, 221.

${ }^{103}$ SALZANi 1981, 101-102.

${ }^{104}$ Gabrovec et al. 1970, 32.

${ }^{105}$ GABRovec et al. $1970,32$.

${ }^{106}$ Boom 1989, 36, Anm. 123. 


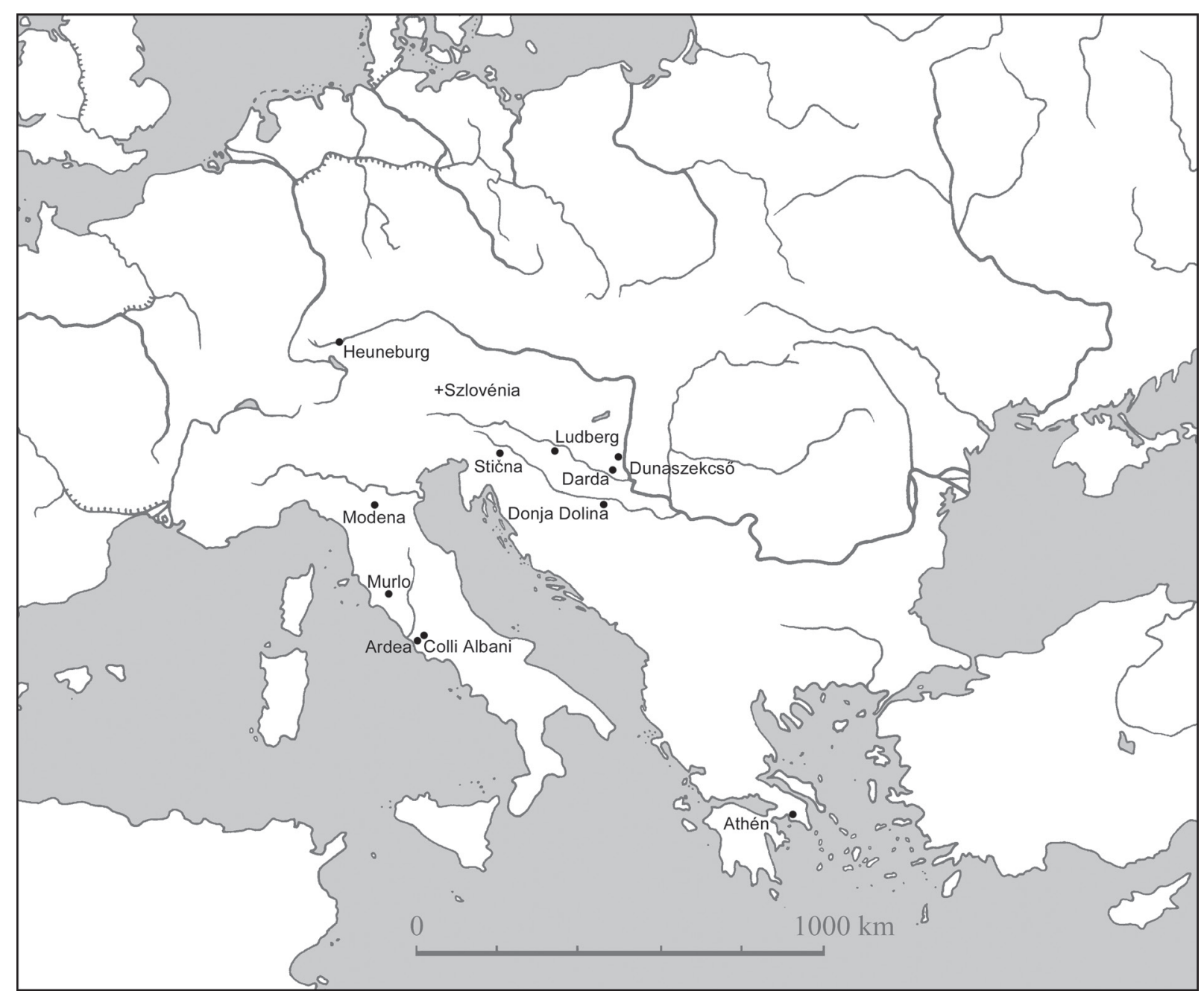

Karte 2. Eisenzeitliche Backglocken und Backdeckel

Keramikstücke, ${ }^{107}$ so dass sie meines Erachtens nicht als zusammengehörig betrachtet werden können. ${ }^{108}$ Die Dicke der Wandung dieser Deckel (4-18 mm), ihr Durchmesser von 20-30 cm, ihr stark gemagertes Material und ihre schwarz gebrannte Innenoberfläche entsprechen eindeutig den Kriterien von Backhauben. Leider ist auf der Heuneburg nur eine einzige Haube in situ gefunden worden; es kamen keine im Fundmaterial aus Häusern und Türmen vor. ${ }^{109}$ Das ist aber nicht weiter überraschend, denn sie wurden wahrscheinlich bei offenem Feuer verwendet. Dass die Verfasserin die eigentliche Funktion der Hauben nicht erkannte, spiegelt sich darin wieder, dass sie die Gefäße, die mit den Hauben zugedeckt waren, schwer identifizieren kann. Ihre Annahme, dass sie Großgefäße (große Töpfe, große Schüsseln, große Schalen) zudeckten, scheint kaum akzeptabel. Es ist unwahrscheinlich, dass man labile Schüsseln und Schalen mit so rohen, dicken Hauben zugedeckt hätte. Man vermisst dann auch mit Recht die kleineren Deckel. Es scheint alles eher dafür zu sprechen, dass die glockenförmigen Hauben mit oberem Henkel vielmehr zu den genauso groben, stark gemagerten Backtellern oder niedrigen Backschüsseln gehörten, deren Durchmesser dem der „Deckel“ entspricht. Diese Deutung erklärt und beseitigt die formulierten Widersprüche: Dasselbe Material weist nicht nur darauf hin, dass sie zusammen hergestellt wurden, sondern auch darauf, dass sie in derselben Funktion, nämlich als Backschüsseln bzw. Backhauben, verwendet wurden. Der mögliche Zusam-

${ }^{107}$ Boom 1989, 36.

${ }^{108}$ Dagegen: ForT-LinKSFEILER 1989, 163.
${ }^{109}$ Bоом 1989, 37. 


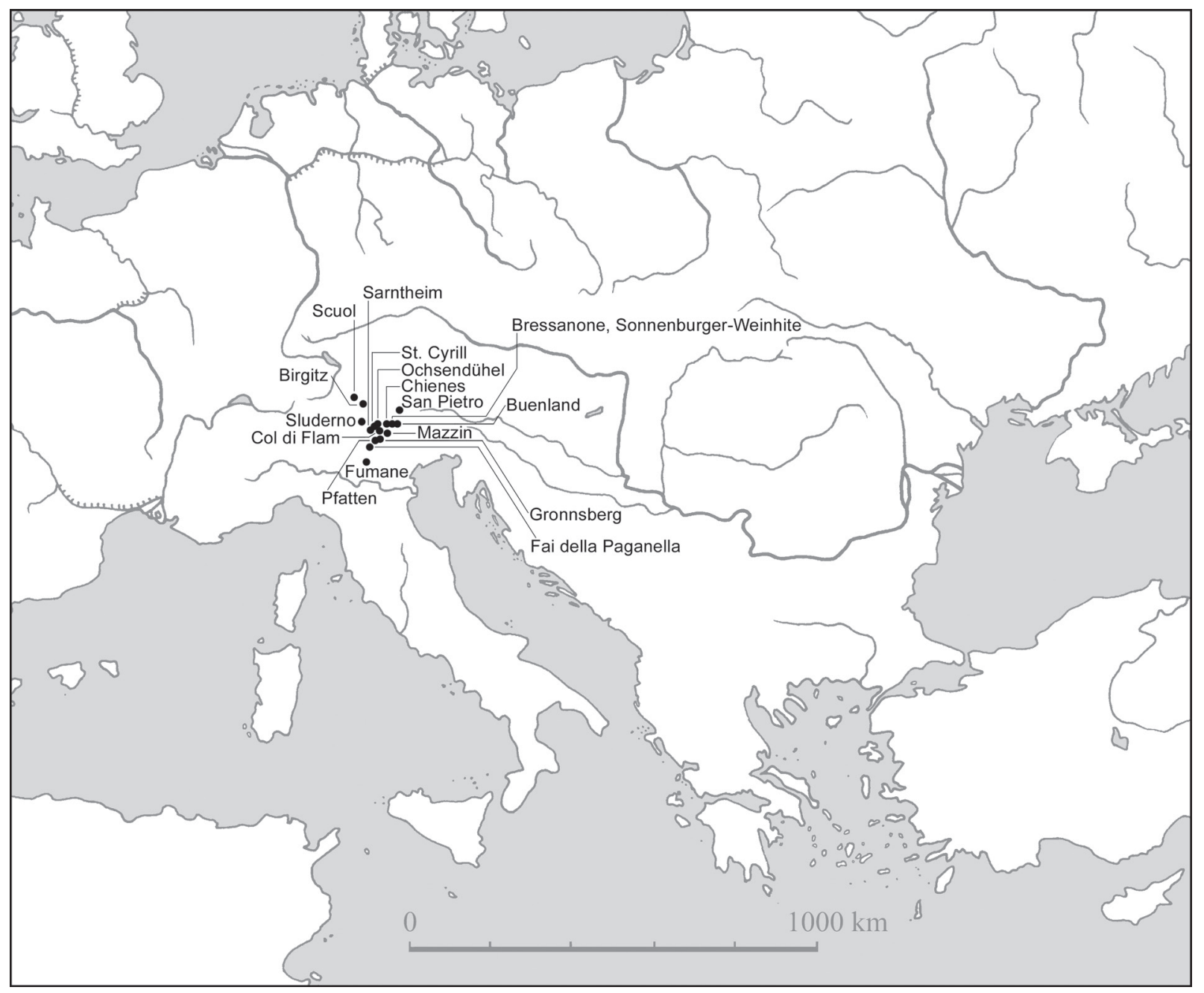

Karte 3. Die Verbreitung der Backglocken und Backdeckel im Südost-Alpenraum

menhang dieser Gefäße wurde in der ursprünglichen Veröffentlichung nicht erwähnt, obwohl Parallelen aus Stična schon bekannt waren. Diese Interpretation erscheint auch auf Grund der breit angelegten Materialsammlung der vorliegenden Analyse plausibel. Der Durchmesser der flachen Backschüsseln beträgt 20-30 cm. Ihre Wände sind ein paar Zentimeter hoch, wie bei anderen frühmittelalterlichen Exemplaren (Horgoš/Horgos, Ras, Székesfehérvár). Die als Deckel/Haube veröffentlichten Backglocken wurden allem Anschein nach auf diese Backschüsseln oder Teller gelegt, wobei man nicht ausschließen kann, dass die Backschüsseln auch ohne Haube zum Backen verwendet worden waren. Die hohe Anzahl der Funde legt nahe, dass dieses Backverfahren unter den Bewohnern der Heuneburg äußerst beliebt war. Bei Laboruntersuchungen wurden Reste tierischen Fetts gefunden - ein Hinweis dafür, dass nicht nur Fladenbrot, sondern auch Fleisch unter Backhauben gebacken wurde. ${ }^{110}$ (Abb. 30-31)

Die gehenkelten Hauben von der Heuneburg sind für die Keramik des Westhallstattkreises nicht charakteristisch, sondern eigenartig in ihrer Umgebung. H. van den Boom betrachtet sie als eine lokale Entwicklung oder als Ergebnis von fremdem, vielleicht italienischem Einfluss. ${ }^{111}$ In Hinblick auf die engen Beziehungen der Siedlung Heuneburg zu Italien nehmen wir an, dass der Brauch, unter einer Haube zu backen/braten, von den Bewohnern der

${ }^{110}$ Воом 1989, 40.

${ }^{111}$ Boom 1989, 1989, 38, Anm. 136. Die backglockenförmigen, mit Graphit gemagerten, verzierten Deckel mit oberem Griff in den Gräbern des Osthallstattkreises waren, auf Grund des gut bearbeiteten
Materials, Deckel von den genauso gut bearbeiteten Urnen und keine Backgefäße; z. B. Sopron: EIBNER-PERSEY 1980, Taf. 86.1, Taf. 88.1. 
Siedlung - zusammen mit anderen Kulturgütern - aus Italien übernommen worden ist. ${ }^{112}$ In der Kalenderberger Kultur und in Slowenien erscheinen Deckel in der Stufe Hallstatt C meistens in Gräbern. Sie hatten aber mit den in den Siedlungen gefundenen Backdeckeln, gehenkelten Backhauben wenig zu tun. ${ }^{113}$ Die in der Siedlung angetroffenen tragbaren Öfen funktionierten nach dem gleichen Prinzip wie Backglocken und standen diesen sowohl in ihrer Struktur wie auch in ihrer Form nahe. ${ }^{114}$ Der Unterschied bestand lediglich darin, dass sie mit dem unteren Teil der Backschüssel zusammengebaut wurden und der obere Teil gerade (abgeschnitten) war. ${ }^{115}$

Wir können im südlichen Alpenraum mit dem Fortleben der so genannten Lappenbecken in der mittleren und späten La Tène-Periode rechnen (Sottosenga) ${ }^{116}$ - auch wenn es bisher nicht gelungen ist, sie in einer eindeutig in die Stufe La Tène D zu datierenden Umgebung zu dokumentieren. ${ }^{117}$ Das Weiterleben dieses Objekttyps in der Römerzeit kann aber erst erklärt werden, wenn man eine Kontinuität von der früheren Epoche her annimmt.

Im Zusammenhang mit dem Gebrauch der rohen handgeformten, so genannten „,dakischen Schalen“ wird von K. Horedt eine geistreiche Erklärung formuliert. ${ }^{18}$ Diese Schalen kamen in der späten La Tène-Zeit (1. Jahrhundert v. Chr.-1. Jahrhundert n. Chr.) in Kulturen unter dakischem Einfluss vor, ${ }^{119}$ in der heutigen Slowakei, in der Umgebung des Neusiedlersees (Fertő See) und im östlichen Teil der Großen Ungarischen Tiefebene. Da diese gehenkelten Schalen auch in Gräbern gefunden wurden, brachte man sie fälschlicherweise mit dem Totenkult in Zusammenhang. ${ }^{20}$ Beispiele aus Mesopotamien und Ägypten führten K. Horedt zur Schlussfolgerung, dass sie wie Backglocken zum Backen von Fladenbrot ohne Sauerteig dienten. Das kann von der rußigen Außenoberfläche der Gefäße sowie von der Position der Henkel, die das Hochheben der glühenden Backform ermöglichten, nahe gelegt werden. Bei den Dakern kann das Backen unter einem umgekehrten Gefäß als mediterraner Einfluss angesehen werden, das auch im 2.-4. Jahrhundert n. Chr. noch zu beobachten ist. Ähnliche Gefäße, die wahrscheinlich demselben Zweck dienten, sind in römischen Siedlungen im kaiserzeitlichen Pannonien auch oft anzutreffen. ${ }^{121}$

Unter den Funden aus Ripač gibt es zwei kleinere Gefäße, die man im Licht der neueren Forschungen für kleine Backglocken halten kann, obwohl sie von W. Radimský als Deckel/Hauben publiziert worden sind ${ }^{122}$ Ihre Form stimmt mit der Form der „dakischen Schalen“ aus der La Tène-Zeit vollkommen überein und da der runde, schleifenhafte Henkel des einen Exemplars den unteren, offenen Riemen mit dem oberen, geschlossenen Teil verbindet, besteht kein Zweifel darüber, dass dieses Gefäß umgekehrt verwendet worden war. Diese Tatsache ist zugleich ein mittelbarer Beweis für die Backhaubenfunktion der ,dakischen Schalen“, die die Form eines umgekehrten Kegelstumpfes hatten. ${ }^{123}$

\section{Römisch-republikanische und Kaiserzeit}

Eine Gruppe von Broten wurde in der römischen und der byzantinischen Zeit artos klibanites genannt, (Karte 4) was darauf hinweist, dass sie in einem kleinen Backgefäß namens clibanos hergestellt wurden (clibanitius, in testa coctus). ${ }^{124}$ Unter den einfacheren Verfahren des Brotbackens ${ }^{125}$ war das Backen unter Hauben oder umgekehrten Töpfen, Schüsseln in der römisch-republikanischer und Kaiserzeit bekannt. ${ }^{126}$ Durch den Vergleich von literarischen und linguistischen Daten über die in der antiken Literatur genannten zwei, vor allem zum Brotbacken verwendeten Gefäße (clibanus, testum) ist erst vor einem Jahrzehnt bewiesen worden, dass sie dieselbe Funktion hatten und in den Küchen aller sozialen Schichten im Mediterraneum vorzufinden waren. ${ }^{127}$ Ein grundlegender

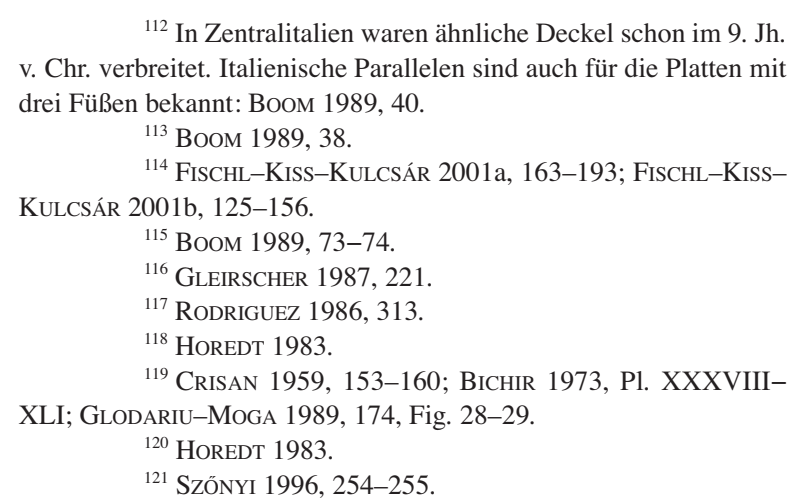

${ }^{122}$ RÖMER 1966, 392-393, Abb. 4. Die kegelstumpfartige Form der kleinen Gefäße aus Ripač ist der Form der so genannten „dakischen Schalen“ sehr ähnlich. Auch für Letztere wurde in letzter Zeit Backglockenfunktion vorgeschlagen: HOREDT 1983, 233-234.

${ }^{123}$ HOREDT 1983, 234-235.

${ }^{124}$ Isodorus, Etymologiarum libri viginti, or. XX 2, 15.

${ }^{125}$ Zum Beispiel in Asche oder zwischen erhitzten Tonplatten gebackenes Brot.

${ }^{126}$ Gal. VI 489; FrAYN 1978, 28-33; Whitehouse 1978, $146-147$.

${ }^{127}$ Neben das lateinische Wort testum kam die Benennung clibanus für dasselbe Verfahren im 2. Jh. v. Chr. nach hellenistischem Einfluss. Sie lebte auch im archaisierenden Latein des Mittelalters weiter. Cubberley et al. 1988, 98; CubBerley 1995, 55-56, 68, Anm. 6. 


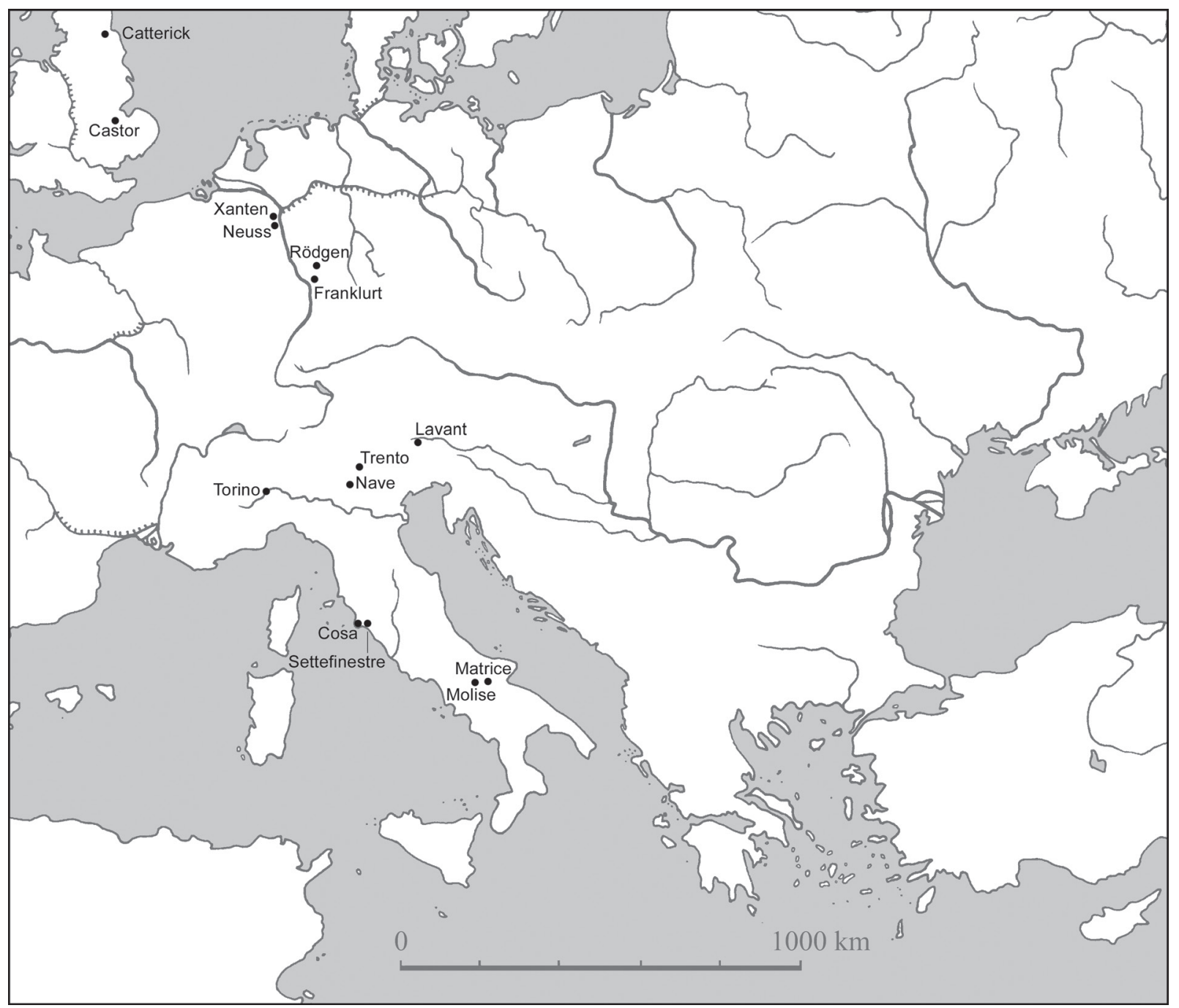

Karte 4. Verbreitung einiger Backglocken und Backdeckel in der römischen Republik- und Kaiserzeit

Unterschied war nur, dass die Reichen das warme, frische Fladenbrot als Delikatesse verzehrten, während es das tagtägliche Essen der Armen war.

Der runde, unten etwas breitere clibanus war auf Grund der zur Verfügung stehenden Daten wahrscheinlich ein Übergang zwischen Gefäße und Ofen und stimmte in Form und Funktion mit den Backglocken überein. ${ }^{128} \mathrm{Er}$ war aus Ton oder Metall hergestellt. ${ }^{129}$ Unter den unter einem clibanus gebackenen Brotsarten gab es feinere, bessere und einfachere, die gegebenenfalls im clibanus serviert wurden. Mit clibanitus in testa coctus verwies Isidor auf ein unter einer Backhaube gebackenes Brot. ${ }^{130}$

Das andere Gefäß, das testum, ähnelte eher einer Pfanne, unter der gebacken wurde. ${ }^{131} \mathrm{M}$. P. Cato hat das Backverfahren bei der Behandlung von Rezepten genau beschrieben. Es war dasselbe mit einem testum und einem clibanus: focum, ubi cocas, calfacito bene et testum (erhitze die Herdstelle, auf der du bäckst, und die Tonhaube), ${ }^{132}$ dann focum duerrito temperatoque, tunc lacentam imponito: testo cldo operito, pruna insuper et circum operito

\footnotetext{
${ }^{128}$ MAU 1896, 2738; HiLGERS 1969, 148-149.

${ }^{129}$ Hilgers 1969, 148, Anm. 580.

${ }^{130}$ Isodorus, Etymologiarum libri viginti, or. XX 2, 15.
}

${ }^{131}$ HILGERs 1969, 287.
${ }^{132}$ M. P. Cato, De agricultura 76, 10. 
(fege die Herdstelle, erhitze sie ein wenig, lege den Fladen darauf, decke ihn mit einer warmen Tonhaube zu, lege Glut auf die Haube und um sie herum). ${ }^{133}$

Unter Backhauben wurde vor allem Brot für die Ernährung einer Familie gebacken. Diese einfache Brotsorte war das libum, das die Römer später, als sie zahlreiche andere Brotsorten kannten, immer noch backten. ${ }^{134}$ Das als Opfergabe gebackene Brot (placentam ${ }^{135}$ ) wurde mit demselben einfachen, uralten Verfahren hergestellt: ${ }^{136}$ sacrificium coctum in clibano, ${ }^{137}$ omne sacrificium, quod fiat in clibano. ${ }^{138}$ Dieses Brot kam während der Kaiserzeit nur als Delikatesse bei den Reichen vor, das Fladenbrot war aber im Allgemeinen billig und geeignet, die Armen zu ernähren. ${ }^{139}$

Obwohl die Wendung sub testu coquito in der römerzeitlichen Literatur allgemein bekannt ist, kennen wir in der provinziellen römischen Keramik aus dem ganzen Reich kaum hoch gewölbte Hauben, unter denen das handgemachte Brot gebacken wurde. ${ }^{140}$ Man muss diese von denjenigen hoch gewölbten Backhauben unterscheiden, die mit tiefen Schüsseln zusammen verwendet wurden; diese dienten nämlich eher zum Dünsten als zum Backen (z. B. Neapel, ${ }^{141}$ Olympia ${ }^{142}$ ). Auf Grund der schriftlichen Quellen müssen wir mit Backhauben nicht nur bei den armen bzw. ländlichen Haushalten rechnen, sondern auch bei den reicheren städtischen; sie waren also ein wichtiges Zubehör in allen Haushalten des Mediterraneums.

In archäologischen Fundkomplexen erscheinen Backhauben seit römisch-republikanischer Zeit und werden während der Kaiserzeit allgemein verbreitet. Es ist uns im vorliegenden Beitrag gelungen, die von A. Cubberley et al. zusammengestellte Fundliste mit etwa 30 Fundorten um weitere Exemplare zu ergänzen. ${ }^{143}$ An der Seite des Haubenfragments aus Molise läuft ein Lappen mit eingedrückter Zierde rund herum, der die Glut für die Oberhitze hielt $(A b b .8)$. Die Funde aus Matrice aus der mittleren und späten Kaiserzeit weisen nicht die gewöhnliche Glockenform auf, sondern sind in ihrer Form komplexer: Vom Riemen aus erhebt sich die Wand des Gefäßes mit einem konkaven Bogen schräg nach oben, dann streckt sie nach einem Bruch nach außen gewölbt weiter und formt oben ein Loch. ${ }^{144}$ Bei der Schulter der Haube läuft ein gedreht gezierter Lappen herum.

Hauptsächlich am Anfang der Kaiserzeit entwickelten sich charakteristische Formen der Backhauben in den frühen Lagern und Siedlungen der ständig umherziehenden Soldaten, wo es manchmal, wenn auch vorübergehend, notwendig war, das eigene Brot selber zu backen, weil es keine Öfen gab (Neuss/Novaesium, Frankfurt, Rödgen) (Abb. 9-10). ${ }^{145}$ Ihre Anzahl ist immer noch überraschend. Man muss jedoch damit rechnen, dass viele Fragmente schlechter Qualität noch nicht typologisiert wurden bzw. dass sie solche, bereits bekannten Gefäßtypen als Backhaube verwendeten, bei denen diese Funktion noch nicht erwogen wurde. In einigen augusteischen Lagern am Niederrhein kommen manchmal Stücke ans Tageslicht, die Backhauben sein könnten. Es handelt sich hier um eine zwar selten belegte, aber doch typische Form. Bei diesen Gefäßen springt die Bodenplatte weit über den Wandsatz vor, die Wandung läuft verkehrt konisch (Frankfurt-Domhügel). A. Bruckner hat eine typologische Verwandtschaft zwischen den Backdeckeln und den Formen von Kragengefäßen in Hofheim $96 \mathrm{~A}^{146}$ und in Vindonissa Nr. $133,134^{147}$ wohl erkannt. ${ }^{148}$

Der Backdeckel aus Frankfurt ist stark gemagert, hat eine rohe Oberfläche und weist außen - ähnlich wie das Gefäß aus Hofheim - Feuerspuren auf. ${ }^{149}$ Die Backdeckel von Frankfurt, Neuss und Xanten konnten mit ihrer konischen Wandung Backplatten übergreifen und an der vorspringenden Deckplatte ließ sich der Deckel hochheben.

${ }^{133}$ M. P. Cato, De agricultura 76, 10.

${ }^{134}$ BOMMER-Bommer 1943, 46.

${ }^{135}$ M. P. Cato, De agricultura 75.

${ }^{136}$ MAu 1896, 2735; Hilgers 1969, 148.

${ }^{137}$ Hilgers 1969, 148 (Vulg., lev. 2, 4).

${ }^{138}$ Hilgers 1969, 148 (Mala, lev. 7, 9).

${ }^{139}$ Bommer-Bommer 1943, 91; RATTi 1966, 194.

${ }^{140}$ TENGSTRÖM 1974.

${ }^{141}$ ZAJCEV-PUZDROVSKIJ 1994, 217-237.

${ }^{142}$ EILMAnN 1944, 102, Abb. 86.1-3. Der am oberen Teil der Backdeckel aus Olympia vorhandene Kragen war geeignet, die heiße Glut aufzufangen, damit beim Kochen auch eine Oberhitze erreicht wird.

${ }^{143}$ Cubberley et al. $1988,112-113$, Fig. 3.

${ }^{144}$ Die Exemplare mit einem Loch oben beweisen, dass man auch unter solchen Deckeln backen konnte. Einige meinen näm- lich, dass Löcher nur bei den als Gluthaube verwendeten Backglocken wichtig waren, um die Lüftung zu sichern.

${ }^{145}$ JUNKELMANN 1997, 129-130, 193, Abb. 85.

${ }^{146}$ RITTERLING 1913, 325-326, Taf. 35.96. A-B.

${ }^{147}$ EtTlinger-SimonetT 1952, Taf. 8, Nr. 133-134.

${ }^{148}$ Bei diesem primitiven Backgerät handelt es sich um Küchengeschirr: ,,in denen wie in den gewöhnlichen Backtellern ohne Kragen, auf dem offenen Herd Fladen oder dergl. gebacken wurden. [...] Wenn man aber ein Gericht mit dierkter Oberhitze backen wollte und keinen Backofen hatte, so konnte man sich damit helfen, dass man einen Backdeckel aus Metall oder Ton über die Backplatte stülpte und ihn mit glühender Kohle bedeckte, wodurch eine ordentliche Oberhitze erzeugt werden konnte. Dafür ist dann ein solcher Kragen nützlich, da der Raum zwischen Deckel und Backplatte gut abgeschlossen wird und die Hitze beisammen bleibt" (BRUCKNER 1975, 93).

${ }^{149}$ WAHL 1982, 191. 
Auf der ebenen Oberfläche konnte man glühende Kohlen aufhäufen. Obwohl all dies von A. Bruckner als eine nicht beweisbare Hypothese bezeichnet wurde, erscheint eine Funktion der zitierten Funde als Backdeckel doch wohl wahrscheinlich. Auf Grund der Erzeugnisse der Werkstatt in Neuss/Novaesium sind die Backdeckel von FrankfurtDomhügel in das 1. Jahrhundert v. Chr. zu datieren. Im Maingebiet ist die spätere Verwendung dieses Gefäßtyps nicht bekannt. ${ }^{150}$ Neulich ist es gelungen, verschiedene haubenartige Gefäße mit ähnlicher Funktion im britischen Gebiet zu identifizieren (Castor bei Peterborough). ${ }^{151}$

In Österreich kamen am Lavanter Kirchbichl Fragmente eines Deckels mit Lappengriff, mit wellenartiger Kammstrichverzierung und mit in Reihen eingedrückten Vierecken zum Vorschein. Diese Verzierung kennzeichnet die west- bzw. nordwestnorische, provinzialrömisch-kaiserzeitliche Gebrauchskeramik und sie lebt in spätrömischer Zeit weiter. Auch in Aguntum wurde ein aus grobem Tonmaterial gefertigter und ganz dunkel durchgebrannter Backdeckel mit seitlichen Grifflappen gefunden. Die umschwingende Kammstrichverzierung des Gefäßes ist wiederum für die west- und nordwestnorische kaiserzeitliche, lokal gefertigte Gebrauchskeramik typisch. ${ }^{152}$

In Italien kommen Backdeckel in der römischen Kaiserzeit sogar in Gräbern vor. Im Grab 40 der römerzeitlichen Nekropole in Tires/Tiers in Südtirol war eine Backschüssel mit gegenständigen Grifflappen beigegeben. ${ }^{153}$ In den Gräbern 5, 9, 25 und 27 von Nave wurden ebenfalls Deckel mit Lappenhenkel gefunden. ${ }^{154}$ Die provinzialrömischen Exemplare gehen im Gebiet Tirol-Ostschweiz-Kärnten auf lokale vorgeschichtliche Vorbilder zurück. ${ }^{155}$

Die schriftlichen Quellen legen nahe, dass das einfache Fladenbrot, das libum, unter irgendeinem umgekehrten Gefäß gebacken werden konnte. Dementsprechend sollten für das Fladenbrotbacken geeignete Gefäße in großer Anzahl in den Haushalten der Armen, in dörflichen Siedlungen oder in kleineren militärischen Lagern vorhanden sein. An einigen Fundorten sind zahlreiche grobe Gefäße aus gemagertem Material zu finden, bei denen eine Backschüsselfunktion angenommen werden könnte. Bisher erfolgte aber keine typologische Klassifizierung dieser Funde. ${ }^{156}$ Die einfachen Tellerfunde aus militärischen Lagern mit einem Deckel oder umgekehrt waren eigentlich auch geeignet, Brot zu backen. ${ }^{157}$

Bei bestimmten stark gewölbten Deckeln aus stark gemagertem Material kann eine Backdeckel- oder Backglockenfunktion angenommen werden. Solche Deckel kamen zum Beispiel im Fundmaterial Niederpannoniens (Sirmium, ${ }^{158}$ Viminacium ${ }^{159}$ ) in großer Anzahl vor. Die kegelstumpfförmigen Deckel waren wegen ihres größeren Volumens sehr gut zum Brotbacken geeignet. ${ }^{160}$

Im römerzeitlichen sarmatischen Barbaricum waren die kegelstumpfförmigen, so genannten „,dakischen Schalen“ auch im 2.-4. Jahrhundert verbreitet, die oft mit schlingenartigem Henkel oder mit symmetrisch angelegten Griffen versehen und mit Fingereindrücken verziert wurden. Diese groben Schalen waren nach der wahrscheinlich richtigen Hypothese von K. Horedt zum Brotbacken geeignet. Im gegebenen Verbreitungsraum hatte dieser einem bestimmten Zweck dienende Keramiktyp vor allem eine kulturelle Bedeutung und keine, wie der verbreitete Name nahe legen würde, spezifisch ethnische Rolle. ${ }^{161}$

In osteuropäischen Siedlungen des römerzeitlichen Barbaricums, zum Beispiel im Gebiet der ZarubincyKultur, kommen sporadisch Backglockenfragmente vor, die als Deckel interpretiert wurden (Berezovka-2). ${ }^{162}$ (Abb. 11, 1-4). In den Siedlungen zwischen den Flüssen Sula und Vorskla kamen große Backplatten ans Tageslicht, zu denen vielleicht auch Backdeckel gehörten. ${ }^{163}$ Im römerzeitlichen Barbaricum ist die Anzahl von Backdeckeln

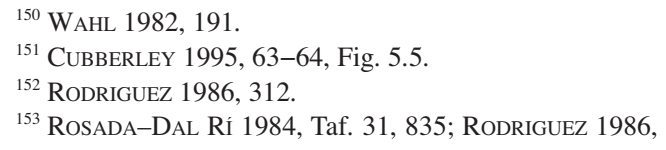
Abb. 38.2 .

${ }^{154}$ JORIO 1987, 206, Abb. 37.1-4

${ }^{155}$ RodRIGUEZ 1986, 313.

${ }^{156}$ Roth-Rubi 1986, 32-37, 129-133; FABER 1994, Taf. 17.

${ }^{157}$ PEACOCK 1977, 147-162; ChIRILA-GudeA-LuCACELPoP 1972, Taf. XIX-XXIV.

${ }^{158}$ BRUKNER 1981, Taf. 129.8, Taf. 130.11.

${ }^{159}$ Golubović 1999, 17, Fig. 1.1. Über die Verwendung ähnlicher Gefäße: JunKELMANN 1997, 193, Abb. 85.

${ }^{160}$ Sirmium, Čortanovci, Beška: Brukner 1981, Taf.
${ }^{161}$ VADAY 1989, 176-177, 344, Abb. 52; VADAY 1996, 284, Fig. 167.4, Fig. 168.

162 OBLOMSKiJ 1994, 44. G. Vékony hat mich auf dieses Fundstück aufmerksam gemacht; ich bedanke mich für seine Hilfe. Es kann nicht ausgeschlossen werden, dass bei Siedlungsgrabungen im Barbaricum die eigentliche Funktion von zahlreichen stark gemagerten Tonfragmenten geringerer Qualität (die einst vielleicht Backglocken waren) nicht erkannt wurde, sondern sie einfach als Lehmbewurf bestimmt wurden. Die gründliche Überprüfung des Fundmaterials aus dem Barbaricum kann zur Identifizierung neuerer Backglocken und Backdeckel führen.

163 Slavjane 1993, 232, Taf. XIII.6, 21; Backteller: ebd. 232, Taf. XIII.14, 29.

$131.31-34$ 
überraschend gering, obwohl dieses einfache Backverfahren vermutlich bekannt war. So bleibt es eine Aufgabe der künftigen Forschung, zu zeigen, ob dieses Fehlen eine Forschungslücke bildet.

Als Backdeckel waren auch aus Lavezstein gefertigte Gefäße, vor allem Schüsseln, geeignet. ${ }^{164} \mathrm{Im}$ Gebiet von Cambodunum kommen sogar Lavezsteingefäße mit kleinen Griffen an beiden Seiten vor. ${ }^{165}$ Es bleibt eine künftige Aufgabe der römerzeitlichen Keramikforschung, diejenigen Gefäßtypen in der Hauskeramik aufzuzeigen, die einst wie Backdeckel verwendet worden waren.

\section{Spätantike, frühbyzantinische Zeit (5.-7. Jahrhundert)}

Die Zunahme der Backglocken- und Backdeckelfunde in Italien, Istrien, in der Alpenregion (Karte 5), auf dem Balkan und wahrscheinlich auch im Nahen Osten in der Spätantike spiegelt die Entwicklung wider, das eigene Brot zu backen. In diesen Regionen wurden unterschiedliche Gefäße zum Backen verwendet, was uns aber daran nicht hindert, die gemeinsame Funktion zu erkennen.

In Norditalien, im südlichen Alpengebiet (Tirol, Schweiz, Kärnten) und in Istrien sind Backdeckel in groBer Zahl ausgegraben worden, die in der Fachliteratur aus der Eisenzeit als Lappenschüsseln/Lappenbecken bekannt sind (Duel, Teurnia, Hemmaberg) (Abb. 14) (Abb. 18, 3-5). Ich nehme an, dass diese Gefäße als Backdeckel verwendet worden waren und schlage demzufolge die Benennung „Lappendeckel“ vor. Diese Gefäße wurden nicht in der Position veröffentlicht, die ihrem Gebrauch entspricht, sondern umgekehrt, mit schräg nach oben steckendem Henkel und breitem Riemen nach oben. ${ }^{166}$

Lappendeckel sind in Kärnten in großer Anzahl ans Tageslicht gekommen. Aus dem Bereich der westlichen Doppelkirchenanlage auf dem Hemmaberg ist eine von außen mit Wellenlinien, innen mit Kammstrich verzierte Schüssel mit zwei Lappen bekannt, die wohl als Backdeckel zu interpretieren ist. ${ }^{167}$ In der befestigten Siedlung Duel an der Drau waren flachbodige Lappenbecken, genauer gesagt Backdeckel mit zwei Griffen, häufig ${ }^{168}$ mit einem Durchmesser von 30-50 cm, außen mit Kammstrichwellenlinien und mit schrägen oder geraden Wellenlinienbändern verziert. ${ }^{169}$ Die Backdeckel sind mit ihren charakteristischen Verzierungen bereits ins 5.-6. Jahrhundert zu datieren. Auch in Teurnia wurden im Areal der Bischofskirche und ihrer Nebengebäude ${ }^{170}$ Backdeckel mit Griffleisten gefunden. Die Gefäße mit Lappengriff in Teurnia sind - wie die übrige Gebrauchskeramik - mit Linien und Wellenlinien bzw. mit Linienbändern und Wellenlinienbändern verziert. An der inneren Seite der Backdeckel befinden sich Kammstrichverzierungen.

In Norditalien wurde oberhalb von Riva del Garda, am nordöstlichen Ufer des Ledro-Seehus, wenige hundert (Abb. 17). Meter vom bronzezeitlichen Pfahlbau entfernt eine Siedlung des 7. Jahrhunderts n. Chr. ausgegraben. ${ }^{171}$ In dem für frühmittelalterliche Verhältnisse außerordentlich reichen Fundmaterial kamen unterschiedliche scheibengedrehte Keramiktypen guter Qualität vor. Unter ihnen sind die gewölbten Deckel mit gegenständigen Seitenlappen charakteristisch, die höchstwahrscheinlich die gedrehten Varianten der im südostalpinen Gebiet verbreiteten ähnlichen Lappendeckel (Lappenschüsseln/Lappenbecken) sein können. Besonders interessant erscheint, dass manche Deckel mit gegenseitig gesetzten Lappen und Ringhenkeln versehen sind. ${ }^{172}$ Ringhenkel sind für die frühmittelalterlichen Backdeckel aus Italien charakteristisch, obwohl sie sporadisch bereits im Fundmaterial der La Tène-Zeit vorkommen (Telfes), sich aber erst im 9.-10. Jahrhundert verbreiten (Mantova, Cremona ${ }^{173}$ ). In Italien verbreiteten sich vor allem die zum Brotbacken geeigneten Lappenschüsseln und Kragendeckel, was typologisch mit den Vorläufern aus der Hallstatt-, der La Tène- und der Römerzeit (Lappengriff, Kragenrand) erklärt werden kann. ${ }^{174}$ Die Varianten mit oberem oder seitlichem Griff sind eher für den Balkan charakteristisch. Im frühmittelalterlichen Italien kommen Backdeckel mit Lappen- oder Kragengriff sowohl in städtischer als auch in ländlicher Umgebung vor (Milan (Abb. 12-13), Ravenna-Classe, Bellaria-Sesto Calende, Brescia). ${ }^{175}$ Die Verzierung der Backdeckel ist abwechslungsreich: eingeritzte, Kammstrich- oder eine plastische Dekoration.

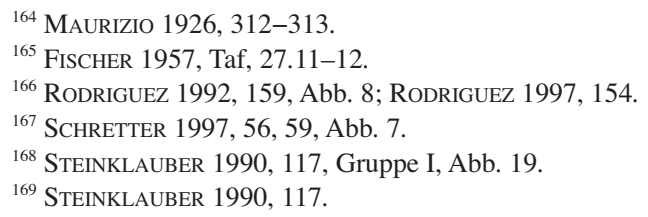

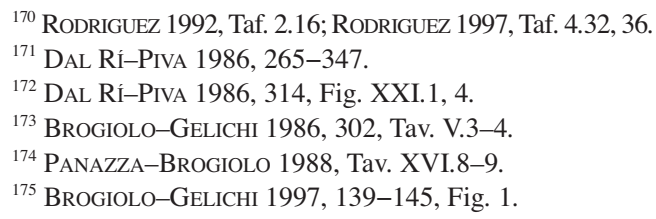




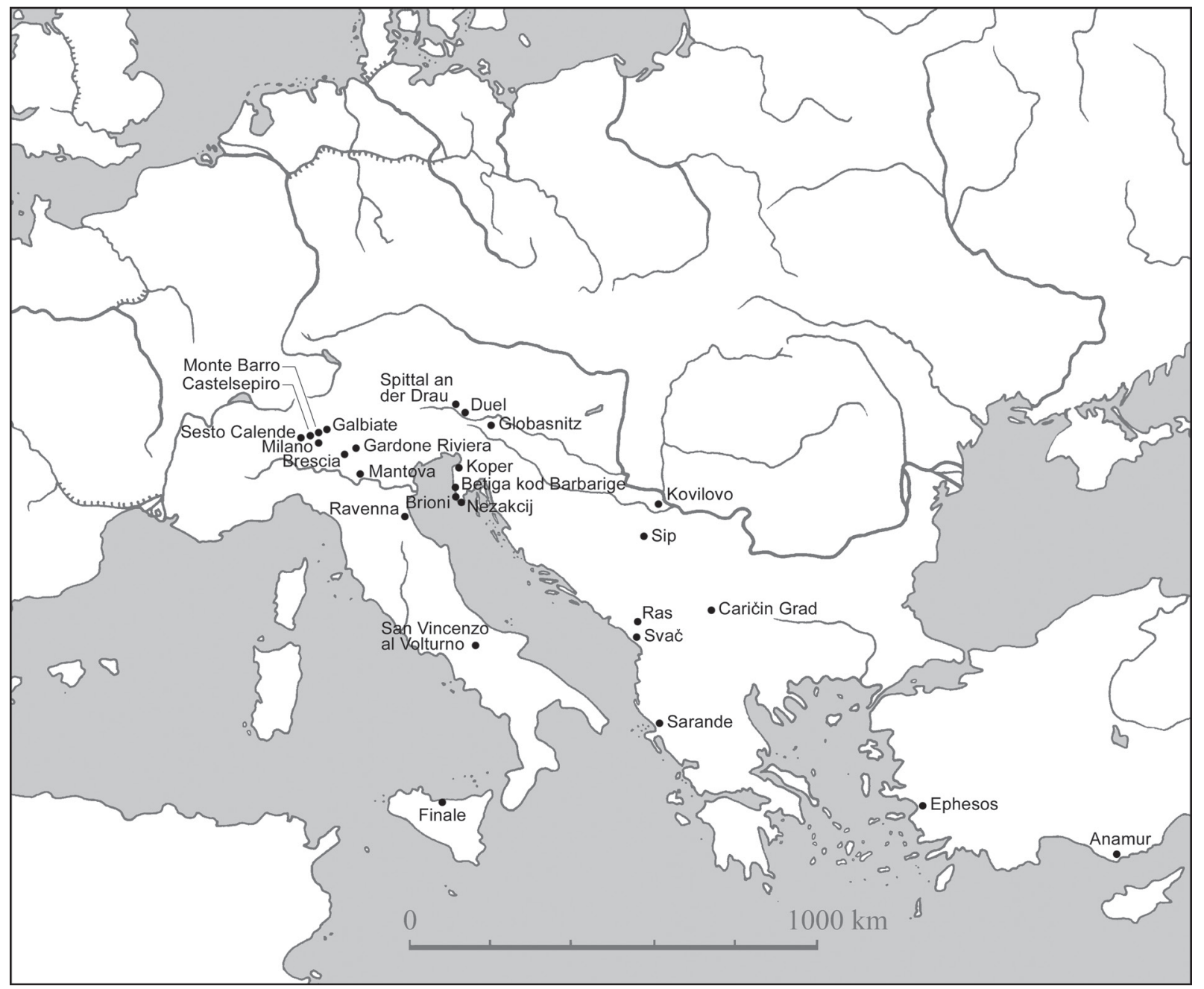

Karte 5. Verbreitung der spätantiken und frühbyzantinischen Backglocken und Backdeckel

Während systematischer Ausgrabungen sind auch im Gebiet Istriens zahlreiche Backdeckel aus der Spätantike ans Tageslicht gekommen. Diese sind - den norditalienischen Exemplaren ähnlich - mit Lappengriff versehen (Koper, Brioni, (Abb. 32,2). Betiga kod Barbarige) und zweifelsohne Erzeugnisse lokaler Werkstätten. Sie wurden eindeutig als zum Brotbacken geeignete Objekte beschrieben. Am Fundort Brioni-Castrum wurde auch eine Backschüssel gefunden, die mit ihrem Deckel zum Brotbacken dienen konnte - das Fundmaterial kann in das 7.-8. Jahrhundert datiert werden. ${ }^{176}$ Die am Fundort Betiga kod Barbarige in spätantiker/frühbyzantinischer Umgebung entdeckten gleichförmigen Backdeckel wurden zum Brotbacken verwendet (,coperchio per la cottura del pane“). Es ist F. Juroš-Monfardin gelungen, einen kleineren und einen größeren Typ zu identifizieren, was eine Variation in der Größe der Brote nahe legt. ${ }^{177}$

In letzter Zeit steigt in überraschendem Maße die Anzahl der Backglocken und Backdeckel aus den frühen Festungen in den balkanischen Gebieten des byzantinischen Reiches an, die an die Wende des 6. zum 7. Jahrhundert zu datieren sind (Onhesmit/Onhesmos, Čaričin Grad/Iustiniana Prima, Svač, Sip, Kovilovo) (Abb. 15-16). Unter ihnen sind sowohl scheibengedrehte als auch handgeformte Exemplare geringerer Qualität anzutreffen. Typologisch gesehen sind die frühbyzantinischen balkanischen Backglocken sehr variationsreich: Es sind fast alle, aus anderen Regionen schon bekannten Formelemente vorhanden. Vorherrschend sind im Allgemeinen die stark gewölbten,

${ }^{176}$ MARUŠIĆ 1986, 81-105.

177 JUROŠ-MONFARDIN 1986, 209-233. 
glockenförmigen Exemplare mit oberem Griff (Onhezmit/Onhesmos, Čaričin Grad/Iustiniana Prima) (Abb. 32, 1, 3 ), es gibt aber auch die für Norditalien charakteristischen Lappendeckel(schüssel)-Formen (Svač (Abb. 16,5) sowie Backdeckel mit Knubbengriff (Sip). Der Knubbengriff führt offenbar römische Formtraditionen weiter; eine Interpretation als Backdeckel wird durch ähnliche Funde aus Ephesos und Korinth bestätigt. ${ }^{178}$ (Abb. 16, 1-2). Es fällt auf, dass eine Backglocke aus Čaričin Grad/Iustiniana Prima keinen oberen Griff, sondern nur einen einfachen Knopf hat. ${ }^{179}$ Der Henkel der in der Festung Kovilovo-Grad ausgegrabenen Backglocken ist nicht bekannt; sie könnten solche mit oberem Griff gewesen sein. Der wohl zum Auffangen der Asche dienende Kragen rund herum ist aber eindeutig vorhanden. Dieser Kragen ist ein Beweis für das Weiterleben der römerzeitlichen italienischen Traditionen. Interessanterweise ist der Kragen, auf den heiße Glut gelegt wurde, um Oberhitze zu erreichen, am oberen Drittel der beiden Exemplare zu finden. Obwohl die awarenzeitlichen Exemplare im benachbarten Karpatenbecken nicht über einen Kragen verfügten, sind solche Exemplare als ihre Vorbilder anzusehen. Die unmittelbare Übernahme der Backglockenform kann durch das Vorkommen der Backglocken aus grobem Material bzw. mit oberem Griff in dem an das Awarenreich grenzenden Balkanraum bewiesen werden, wo die Awaren ein halbes Jahrhundert hindurch oft verkehrten.

Die an frühbyzantinischen Fundorten ausgegrabenen Backglocken sind problemlos ins 6. Jahrhundert zu datieren. Die befestigte Stadt Svač in Montenegro, nahe der albanischen Grenze, wurde zur Zeit der Kaiser Anastasius (492-518) und Iustinianus (527-567) gebaut. ${ }^{180}$ Unter der Siedlungskeramik der Unterstadt wurden die Backglocken gefunden, die auf Grund eines Kruges mit Kleeschnabel ${ }^{181}$ bzw. des Grabmaterials aus der mit der Siedlung gleichaltrigen Oberstadt ${ }^{182}$ ins 6. Jahrhundert zu datieren sind. Die byzantinischen Festungen von Sip, Kovilovo verödeten nach den awarischen Angriffen im Jahre 585. Eine der zur Ernährung der Soldaten im byzantinischen Heer verwendeten Brotsarten wurde in einem speziellen Ofen gebacken (klibanos, kribanos), ${ }^{183}$ der in seinem Gebrauch am ehesten den Backglocken entsprach. Das unter einer Backglocke oder einem Backdeckel gebackene Brot ${ }^{184}$ ist - wie durch die Übersetzung angedeutet - nicht mit dem heute bekannten „Zwieback“ zu identifizieren. ${ }^{185}$ Es war im Fall des flachen, schmalen „trockenen Brotes“ wahrscheinlich ein nicht gesäuertes Brot, das die unter dem Backdeckel bewahrte Feuchtigkeit nach dem Backen schnell verlor, trocken, hart und dadurch länger haltbar wurde. Das so gebackene haltbare, schmale, flache Brot, das die Soldaten bei Gefahr mit ihrer Feldflasche bei sich behalten konnten, ermöglichte vor allem die schnelle Versorgung von kleineren, beweglichen militärischen Einheiten, Wachen. ${ }^{186}$

In den spätrömischen und byzantinischen Schichten einiger Ausgrabungen im Nahen Osten kommen zahlreiche gewölbte, glockenförmige Gefäße, Deckel, vor, die einst zum Brotbacken geeignet waren (Ephesos). ${ }^{187}$ Die ephesischen Backhauben (?) sind alle formgleich. Sie stammen aus der byzantinischen Überbauung der Hanghäuser und datieren in das erste Viertel des 7. Jahrhunderts. ${ }^{188}$ Einige ähnliche Fragmente aus Korinth können eine direkte Kontinuität zwischen den spätrömischen und frühbyzantinischen glockenartigen Deckeln beweisen, jedoch ist eine Funktion als Backdeckel, Backhaube noch nicht überzeugend belegt. ${ }^{189}$ Bis heute ist die Identifizierung und die Untersuchung der Verbreitung der in den Quellen klibanos genannten Gefäße in der frühbyzantinischen Keramik in ländlichen und städtischen Siedlungen auf dem Balkan, in Kleinasien oder im Nahen Osten nicht unternommen worden. ${ }^{190}$ In diesen Gebieten ist mit einer Vielzahl von Formen der als Backhaube verwendeten Backschüsseln zu rechnen - zum Beispiel in Pella in Jordan, ${ }^{191}$ Anemurium - weil die Backglockenfunktion auch auf bisher in diesem

\footnotetext{
${ }^{178}$ SANDERS 1999, 470, Fig. 20; 472, Fig. 21; bzw. freundliche Mitteilung von Sabine Ladstätter (Wien).

${ }^{179}$ BJelajaC 1990, 182, Fig. 139.

${ }^{180}$ ZEČEVIĆ 1989, 112.

${ }^{181}$ ZEČEVIĆ 1989, 115, Taf. II.1-4.

182 ZEČEVIĆ 1989, 115, Taf. II.5-13.

${ }^{183}$ Kolias 1984, 198.

${ }^{184}$ Suda II, 254 (IV 25, 13 Adler); VÁRI 1917, 1922, 57, 2

${ }^{185}$ Die Übersetzung als ,Zwieback“ ist wahrscheinlich falsch. Es scheint nicht plausibel, dass Brot durch zweimaliges Backen oder durch bewusstes Austrocknen haltbar gemacht worden wäre; KoliAs 1984, 198.
}

\footnotetext{
${ }^{186}$ Im Nahen Osten waren Fladensorten bekannt, die getrocknet gehalten und mit Wasser geweicht verzehrt wurden. RAPAICS 1934, 166.

${ }^{187}$ Die Bearbeitung der lokalspezifischen Backglocken und Backdeckel aus dem Nahen Osten kann nur im Rahmen einer selbstständigen Studie vorgenommen werden. Hier möchten wir nur auf das Thema aufmerksam machen und Fragen stellen.

${ }^{188}$ Freundliche Mitteilung von Sabine Ladstätter (Wien).

${ }^{189}$ SANDERS 1999, 470, Fig. 20; 472, Fig. 21.

${ }^{190}$ Nach freundlicher Mitteilung von Sabine Ladstätter (Wien). Ähnliche Gefäße kommen in sehr großer Zahl bei Ausgrabungen im Nahen Osten vor.

${ }^{191}$ WeInBERg 1988, 220, P1. 7.55-56; 351, Pl. 7.7; MCNICOLL et al. 1992, Pl. 114.8.
} 
Sinne nicht definierte, nicht verzierte Gefäße geringer Qualität übertragen werden konnte. ${ }^{192}$ Die an der Peripherie des Byzantinischen Reiches, in den balkanischen byzantinischen Festungen beobachteten Backglocken aus schlechterem Material stehen sowohl in der Bearbeitung des Materials als auch in der Form den awarenzeitlichen und landnahmezeitlichen Backglocken im Karpatenbecken nahe.

\section{Frühmittelalter (7.-9. Jahrhundert)}

\section{Awarenzeit und 9. Jahrhundert im Karpatenbecken}

(Ende 6. Jahrhundert - 9. Jahrhundert)

Backglocken aus grobem Material, mit oberem Griff erschienen in der Awarenzeit - nach dem Stand unserer derzeitigen Kenntnisse - ohne Vorläufer. Ihre Verbreitung im awarischen Siedlungsgebiet ist als eine neue kulturelle Wirkung in der Ernährungskultur, in der Lebensweise zu interpretieren. Die ungarische Forschung datierte die Backglocken zunächst in das 9.-10. Jahrhundert, ${ }^{193}$ in letzter Zeit in das 8. Jahrhundert. ${ }^{194}$ Meiner Meinung nach kann auf Grund der vorliegenden Datenbasis ihre Datierung in das 7. Jahrhundert begründet werden (Karte 6).

Die Backglocken aus den awarenzeitlichen Siedlungen sind zumeist fragmentarisch erhalten und können im Allgemeinen nur auf Grund des charakteristischen Randes oder des glockenartigen Körpers bzw. des wulstartigen Henkels identifiziert werden. Im Material, in der Gestaltung und dem Brand sind die awarenzeitlichen Backglocken einander sehr ähnlich. Ihre Schlämmung ist schlecht, sie wurden mit Sand, grobkörnigen Kies-, Stein- und Keramikstücken oder mit zerkleinerten Gras- und Getreidearten gemagert. Die Qualität der Bearbeitung des Materials und der Gestaltung der Backglocken war im Allgemeinen geringer als die Durchschnittsqualität der handgeformten Keramik. In einigen Fällen sind die Backglocken mit geraden oder Wellenlinien bzw. mit Kammstrich oder mit Stempelmuster (Veresegyház) in schwacher Qualität verziert.

Die typologische Analyse von Backglocken und Backdeckeln ist dadurch beeinträchtigt, dass wir wegen des schlechten Materials und des schwachen Brandes kaum intakte Exemplare kennen und die Fragmente keine gut fundierten Schlüsse auf die Form ermöglichen. ${ }^{195}$ Die von Cs. Bálint vorgeschlagene Formenklassifikation auf Grund der Technologie, der Form des Henkels und der Seitenfragmente braucht im Licht des neueren Fundmaterials nicht modifiziert zu werden, sondern soll nur mit den vielfachen Backdeckeln aus anderen Regionen ergänzt werden. Sein Klassifikationsprinzip - niedrige, flache (Typ A), hohe, konische (Typ B1) und hohe, innen gewölbte (Typ B2) Backglocken - lässt sich im Grunde auch auf die Backglocken aus anderen Regionen übertragen. ${ }^{196}$ Das reiche Fundmaterial der letzten Jahrzehnte hat bewiesen, dass Backglocken im ganzen Raum des spätawarischen Siedlungsgebiets zu finden sind, auch wenn ihre Anzahl in einigen Gebieten noch gering ist (z. B. in den mittleren und südlichen Regionen Transdanubiens). Das von U. Fiedler 1994 gezeichnete Verbreitungsgebiet der Backglocken kann mit neuen Funden westlich und östlich bedeutend erweitert werden, denn sie kommen auch im westlichsten Teil des awarischen Siedlungsgebietes (Kajárpéc, Lébény-Kaszás, Mosonmagyaróvár, Zillingtal) vor, sind aber in Südwesttransdanubien nicht vorhanden.

Die Frage nach der Datierung von Backglocken wurde in der ungarischen Archäologie in den letzten Jahrzehnten dank der Siedlungsforschungen von B. M. Szőke in der Großen Tiefebene ständig diskutiert. 1980 wurde vorgeschlagen, dass die Backglocken und die handgeformten Tonkessel zum selben archäologischen Horizont gehören (Szőke-Gruppe A) ${ }^{197}$ und in die Spätawarenzeit, in das 8. Jahrhundert, zu datieren sind, was in den Veröffentlichungen der Siedlung in Eperjes ${ }^{198}$ und in Gyoma ${ }^{199}$ bewiesen wurde. Auf Grund einiger neuerer Siedlungsausgrabungen stellte sich aber die Frage, ob die Backglocken eher in die frühe oder mittlere Awarenzeit datiert werden könnten. In der Vorpublikation wird die Siedlung Tatabánya-Alsógalla vom Leiter der Ausgrabung in die frühe und mittlere Awarenzeit datiert. ${ }^{200}$ Backglocken

\footnotetext{
${ }^{192}$ WeinBerg 1988, 351, Pl. 7.56, Pl. 7.7, Nr. 848, 851.

${ }^{193}$ SZŐKE 1980, 182-188; FIEDLER 1994.

${ }^{194}$ BÁLINT 1991, 58-61.

${ }^{195}$ Die Fragmente von dickwandigen, handgeformten Gefäßen anderen Typs (z. B. Backschüsseln, Deckel, tiefe Schüsseln) sind den Backglocken nur in ihrem Material, in der Magerung mit grobkörnigem oder organischem Material ähnlich. BÁLINT 1991, 47-51, 53, 62; FIEDLER 1994, 338.
}

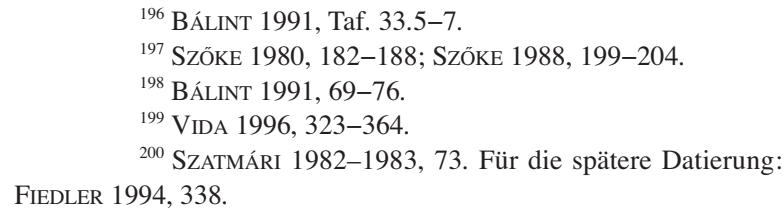




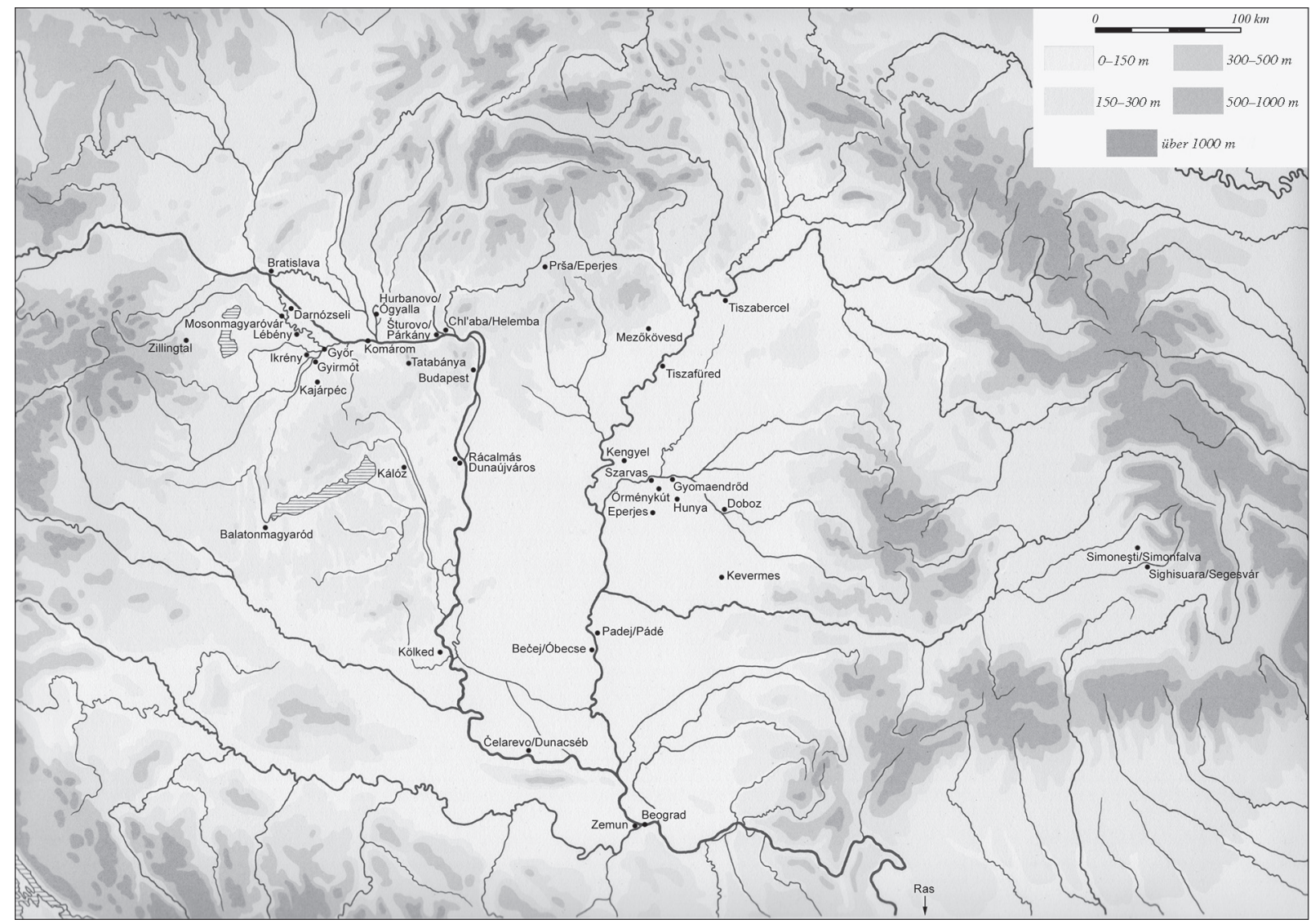

Karte 6. Awarenzeitliche Backglocken im Karpatenbecken

kommen auch in der zum Teil in die Frühawarenzeit datierten Siedlung Kölked-Feketekapu in großer Zahl vor. ${ }^{201}$ Das Gefäß mit dem Trichterrand und andere Funde lassen auch im Fall der Siedlung in Doboz eine Datierung in das 7. oder auch frühes 8 . Jahrhundert zu. ${ }^{202}$

Zahlreiche unlängst publizierte Siedlungsfundkomplexe aus den südlichst gelegenen, an Byzanz grenzenden Regionen des Karpatenbeckens beweisen, dass die Tradition, Fladenbrot unter einer Backglocke zu backen, schon am Anfang der Awarenzeit bekannt war. Backglocken- und Backdeckelfragmente wurden zusammen mit charakteristischen frühawarischen handgeformten Gefäßen mit Trichterrand ${ }^{203}$ in der Siedlung in Padé/Padej (6.-7. Jahrhundert) ausgegraben. ${ }^{204}$ Die Siedlungskomplexe aus Küllöd/Kolut-Bačan und Horgos ${ }^{205}$ (Abb. 19) können in dieselbe Periode datiert werden, obwohl S. Trifunović für eine Datierung ins 5.-6. Jahrhundert argumentiert, ${ }^{206}$ wofür ich aber keine ausreichenden Beweise kenne. ${ }^{207}$ Die meisten Backglocken wurden in der Großen Ungarischen Tiefebene ausgegraben, von wo uns interessanterweise kaum Siedlungen aus dem 7. Jahrhundert bekannt sind, denn hier fehlen die in Transdanubien verbreiteten, mit Sicherheit in das 7. Jahrhundert zu datierenden Keramiktypen. ${ }^{208}$

${ }^{201}$ Freundliche Mitteilung von Attila Kiss (Budapest), 1999.
${ }^{202}$ KovalovszKi $1975,209$.
${ }^{203}$ Vida $1999,111-129$.
${ }^{204}$ TrifunOvić 2000,104, Tab. XX.1, 32.
${ }^{205}$ TrifunOVIĆ $2000,95,99$.
${ }^{206}$ TrifunOvić $2000,94,99$.
${ }^{207}$ Die Keramik aus Padej/Padé, Kolut/Küllőd-Bačan und Horgoš/Horgos stimmt nach unseren Kenntnissen mit der frühawarischen handgeformten Keramik vollkommen überein. VIDA 1999, 137-147, Abb. 58-59.
${ }^{208}$ VIDA 1999, 137-147. Es fällt auf, dass wir bisher nur aus Transdanubien eindeutig in das 7. Jahrhundert datierbare Siedlungen kennen. Darauf ist schon Uwe Fiedler aufmerksam geworden. Meiner Meinung nach ist dies durch die gegenwärtige Forschungslage bedingt, in der wir die Siedlungskeramik aus dem 7. Jahrhundert in der Großen Tiefebene noch nicht betimmen können. Zur Lösung dieses Problems werden wahrscheinlich künftige Siedlungsausgrabungen beitragen. 
Die Verwendung von Backglocken in der Awarenzeit kann also als Arbeitshypothese im Licht der vorläufigen Ergebnisse neuerer Ausgrabungen von der Mitte des 7. Jahrhunderts angenommen werden.

In der Fachliteratur gibt es keinen Hinweis darauf, dass Backglocken und Backdeckel in den angenommenen Herkunftsgebieten der ins Karpatenbecken siedelnden awarenzeitlichen Nomaden, in Innen- und Zentralasien, in der zentralasiatischen und osteuropäischen Steppe und deren Randgebiet bekannt waren oder verwendet worden wären. Nach unseren bisherigen Kenntnissen fehlen solche Gefäße im Fundmaterial der eurasischen Nomaden. ${ }^{209}$ Obwohl in bestimmten Regionen Backglocken mit der nomadischen Lebensweise verbunden sind (Nord-Afrika, Irak), ${ }^{210}$ kann ihre Verwendung bei den Awaren mangels vergleichbaren eurasischen Fundmaterials nicht für eine Tradition östlicher Herkunft gehalten werden.

Vielmehr sind die Exemplare aus schlecht bearbeitetem Material und mit oberem Griff aus frühbyzantinischen Fundorten (Onhezmit/Onhesmos und Čaričin Grad/Iustiniana Prima) den awarenzeitlichen Backglocken am ähnlichsten. Die große Anzahl von spätantiken und frühbyzantinischen Backglocken und Backdeckeln stammt aus dem südlichen Teil Europas, aus Italien, Istrien, der Alpenregion und dem Balkan und deutet den möglichen Ursprung des kulturellen Einflusses an. Nach der Ansiedlung im Karpatenbecken kamen die awarenzeitlichen Völker 568-626 für ein halbes Jahrhundert in eine sehr enge Beziehung zu den balkanischen Gebieten. Die Backglocken kamen in der Mitte der Awarenzeit wahrscheinlich dank des balkanischen Einflusses auf. Die Übernahme der nicht transportierbaren, im Hausgewerbe hergestellten Backglocken bei den Awaren kann als ein anschaulicher Beweis für die sesshafte neue Lebensweise gelten. Es ist natürlich kein Zufall, dass diese großen, sehr zerbrechlichen Gefäße in Quartieren in der Steppe nicht vorkommen; sie sind eindeutig für die Haushalte sesshafter Völker charakteristisch.

2. Süd- bzw. Südosteuropa (Italien, Serbien, Kroatien, Bulgarien, Rumänien, 7.-10. Jahrhundert)

Nach der spätantiken Zeit wurden Backglocken in Italien ohne Unterbrechung verwendet. Die Formen der frühmittelalterlichen Exemplare bewahren die Eigenheiten der spätantiken Backdeckel mit Seitenhenkel, wie man das an den Fundorten Ravenna-Classe, Brescia-S. Giulia und Via Alberto Mario beobachten kann (Abb. 20-21). So können in den oft schwer datierbaren italienischen Siedlungen die spätantiken und die frühmittelalterlichen Exemplare nicht präzise auseinandergehalten werden. ${ }^{211}$ Backglocken mit oberem Griff sind nicht früher als im 9. Jahrhundert erschienen und vertreten einen charakteristischen Typ des späten Mittelalters.

Es fällt auf, dass Backglocken zwischen der Wende des 7./8. und des 9./10. Jahrhunderts, als sie in der Awarenzeit im Karpatenbecken sehr verbreitet waren, auf dem von den Slawen besetzten Balkan nicht zu finden sind. ${ }^{212}$ Zwar versuchte M. Janković, einige in der Festung am Eisernen Tor gefundene Exemplare mit den Slawen zu verbinden, wie auch von U. Fiedler dargestellt wurde, ${ }^{213}$ handelt es sich aber nach Fundanalogien eher um die lokalen balkanisch-byzantinischen Traditionen. Auf dem von Slawen besiedelten Balkan sind Backglocken nach den spätantiken/frühbyzantinischen Vorbildern des 7. Jahrhunderts in dörflichen und städtischen Siedlungen erst seit der Wende des 9./10. Jahrhunderts und später seit dem 14./15. Jahrhundert in großer Anzahl belegt. ${ }^{214}$ Backglocken fehlen im frühen Fundmaterial überhaupt im ganzen slawischen Siedlungsgebiet. ${ }^{215}$ Die uns zur Verfügung stehenden Daten weisen eher auf byzantinische Beziehungen hin. ${ }^{216}$

Bei den Slawen wurde die Rolle der Backglocken, Backdeckel zunächst wahrscheinlich von den in ihrem osteuropäischen Siedlungsgebiet schon wohlbekannten einfachen Backschüsseln mit einem Durchmesser von

209 BÁLINT 1989.

${ }^{210}$ Das Backen unter einer Glocke ist bei den irakischen Nomaden sehr verbreitet: OCHSENSCHLAGER 1974, 162-174.

${ }^{211}$ Brogiolo-Gelichi 1986, 293; CuBBERLEY 1988, 133. Deswegen sind im Katalog die frühmittelalterlichen Backdeckel bei der spätantiken/frühbyzantinischen Gruppe aufgelistet; BROGIOLOGELICHI 1997, 139-145, Fig. 1.

${ }^{212}$ Keine Backglocken aus bulgarischen Ausgrabungen erscheinen in DONČEVA-PETKOVA 1977. Die Zusammenfassungen über die mittelalterliche Keramik in Jugoslawien enthalten auch keine solchen Gefäße: Bajalović-Hadži-Pešıć 1981. Der die Funde aus der byzantinischen Festung am Eisernen Tor bearbeitende Archäologe,
Đorđe Janković, hat Backglocken mit den Slawen verbunden, was kaum glaubwürdig ist (JANKOVIĆ 1981).

${ }^{213}$ FIEDLER 1994.

${ }^{214}$ BiKIĆ 1994, 24, Abb. 13.30, Abb. 15-16.

${ }^{215}$ Herrmann 1981; Hensel 1987.

${ }^{216}$ Popović 1999, 154-155. Theoretisch ist es möglich, dass die wegen der slawischen Expansion zurückgedrängte balkanische romanisierte Urbevölkerung die Tradition des Backens unter einer Backglocke weitergegeben hat. Das ist aber bis heute nicht erforscht worden, denn die Bestimmung des Fundmaterials der romanisierten spätantiken Bevölkerung ist im ganzen Mediterraneum mit erheblichen Schwierigkeiten verbunden. 
10-30 cm erfüllt, die zum Backen von nicht gesäuertem Fladenbrot dienten. ${ }^{217}$ In den Backschüsseln konnte Brot auf zweierlei Weise gebacken werden. Im einfachen Verfahren wurde die Backschüssel einfach in heiße Glut gelegt, später, um das Verfahren effektiver zu machen, wahrscheinlich mit einem einfachen flachen Deckel zugedeckt vielleicht von den Archäologen bisher nicht beachtet -, wie die ethnographischen Daten aus Albanien beweisen. ${ }^{218}$ Ethnographische Beispiele aus der nahen Vergangenheit haben gezeigt, dass die Serben in einigen Gebieten neben den flachen Backschüsseln auch gewölbte herstellten, welche sie auch crepulja nannten und mit denen sie die untere Backschüssel mit dem Teig zudeckten.

Zusammenfassend wurden die Backschüsseln zuerst von B. Babić ${ }^{219}$ behandelt. Er stellte fest, dass sie in den von Slawen bewohnten Siedlungen des Ost- und Südbalkans sehr verbreitet waren. Er fand zudem heraus, dass diese seit Urzeiten bekannte Backtradition in der Region des heutigen Rumäniens, Mazedoniens und Bulgariens bis in die Gegenwart vorhanden war. ${ }^{220}$ In diesen Back- oder Tontellern ${ }^{221}$ wurden Weizen-, Gersten- oder Hirsefladen gebacken - solche Funde sind aber leider nicht erhalten worden. Ähnliche Gefäße kommen in den ostslawischen Gebieten zwischen dem Unterlauf der Donau und dem Dnjestr in großer Anzahl vor. ${ }^{222}$ In den von Westslawen bewohnten Gebieten haben sie eine viel geringere Bedeutung. In größerer Anzahl erscheinen sie nur bei den sich im Elba-Saal-Gebiet angesiedelten Sorben, ${ }^{223}$ zu finden sind sie auch im heutigen Gebiet Tschechiens und der Slowakei. Es ist anzunehmen, dass sich das Backen von Fladenbrot in Backtellern auch nach einem südlichen, pontischen, mediterran-antiken Einfluss unter den südlichen und südöstlichen Slawen verbreitet hat, was zugleich erklären könnte, warum sie im heutigen Polen und im nordöstlichen slawischen Siedlungsgebiet fehlen. Die im Norden wohnenden slawischen Völker stellten nämlich Roggenbrot her, was ein anderes Backverfahren mit geschlossenem Ofen erforderte. ${ }^{224}$

\section{Mittelalter und Neuzeit (10.-17. Jahrhundert)}

1. Ungarische Landnahmezeit und Árpádenzeit im Karpatenbecken (10.-13./14. Jahrhundert)

Die Siedlungsforschung hat in den letzten Jahrzehnten gezeigt, dass Backglocken eine feste Gruppe in der Keramik der landnahmezeitlichen und árpádenzeitlichen Siedlungen sind. Das technologische Niveau der landnahmezeitlichen und árpádenzeitlich ungarischen Töpferei war nur etwas niedriger als im 9. Jahrhundert. Obwohl man die fortlebenden lokalen Traditionen qualitativ und quantitativ nicht bestimmen kann - zum Beispiel das Überwiegen der Technik der langsamen Drehscheibe, das Fehlen der Gefäße mit eingezogenem Rand, der handgeformten Keramik -, haben sich die verwendeten Gefäßtypen, die Techniken und die gewerbliche Organisation der Herstellung von Tongefäßen im Grunde genommen nicht verändert. Die Herstellung weiterhin im Rahmen des Hausgewerbes bzw. das weitere Vorhandensein spezieller Gefäßtypen, wie der Tonkessel zum Kochen und der Backglocken und Backdeckel zum Backen, implizieren die Kontinuität der Lebensweise und des Wirtschaftens (Karte 7).

Backglocken sind von Siebenbürgen bis zur Kleinen Tiefebene im ganzen frühen ungarischen Siedlungsgebiet zu finden. In der Kleinen Tiefebene wurden handgeformte Backglocken an zwei Fundorten (Mosonszentmiklós, Lébény) entdeckt, die in das 10.-11. Jahrhundert zu datieren sind. ${ }^{225}$ Backglockenfragmente sind auch im mittleren Landesteil in Visegrád ausgegraben worden. Die in Békés-Ditér in situ auf zwei Ziegeln gefundene Backglocke datiert auf Grund eines Münzfundes in das 12. Jahrhundert. ${ }^{226}$ Weitere Funde in der Großen Tiefebene sind aus Tiszavalk, Tiszalök, Kardoskút und Endrőd bekannt. Backglocken kommen auch in den rumänischen Gebieten

${ }^{217}$ HeRRMANN 1986, 267-272. In der früheren Fachliteratur wurden Backteller und eckige, $1 / 4$ oder $1 / 2 \mathrm{~m}^{2}$ große, wahrscheinlich nur zum Trocknen verwendeten Lehmwannen nicht immer auseinandergehalten.

${ }^{218}$ ONUZI 1980, 145, Fig. 5-8; 146, Fig. 9-11.

219 BABIĆ 1972, 108.

${ }^{220}$ BABIĆ 1986, 300-301, Abb. 82.

${ }^{221}$ BABIĆ 1972, 101-123.

${ }^{222}$ Herrmann 1986, 271, Abb. 1.
${ }^{223}$ Mit einer bedeutenden westslawischen Verbreitung können wir im Elba-Saale-Gebiet rechnen. Bei der slawischen Bevölkerung dieser Region sind eindeutige südliche Kontakte vorhanden. HERRMANN 1986, 268-270.

${ }^{224}$ Die Verbreitungskarte von Kurt Horedt entspricht den archäologischen Funden von Backglocken nicht: HoREDT 1984, 42-43, Abb. 24. Die Verbreitung von Backglocken wird präzisiert von HERRMANN 1986, 270.

225 TAKÁCS 1996, 170.

${ }^{226}$ PARÁDI 1966, 50. 


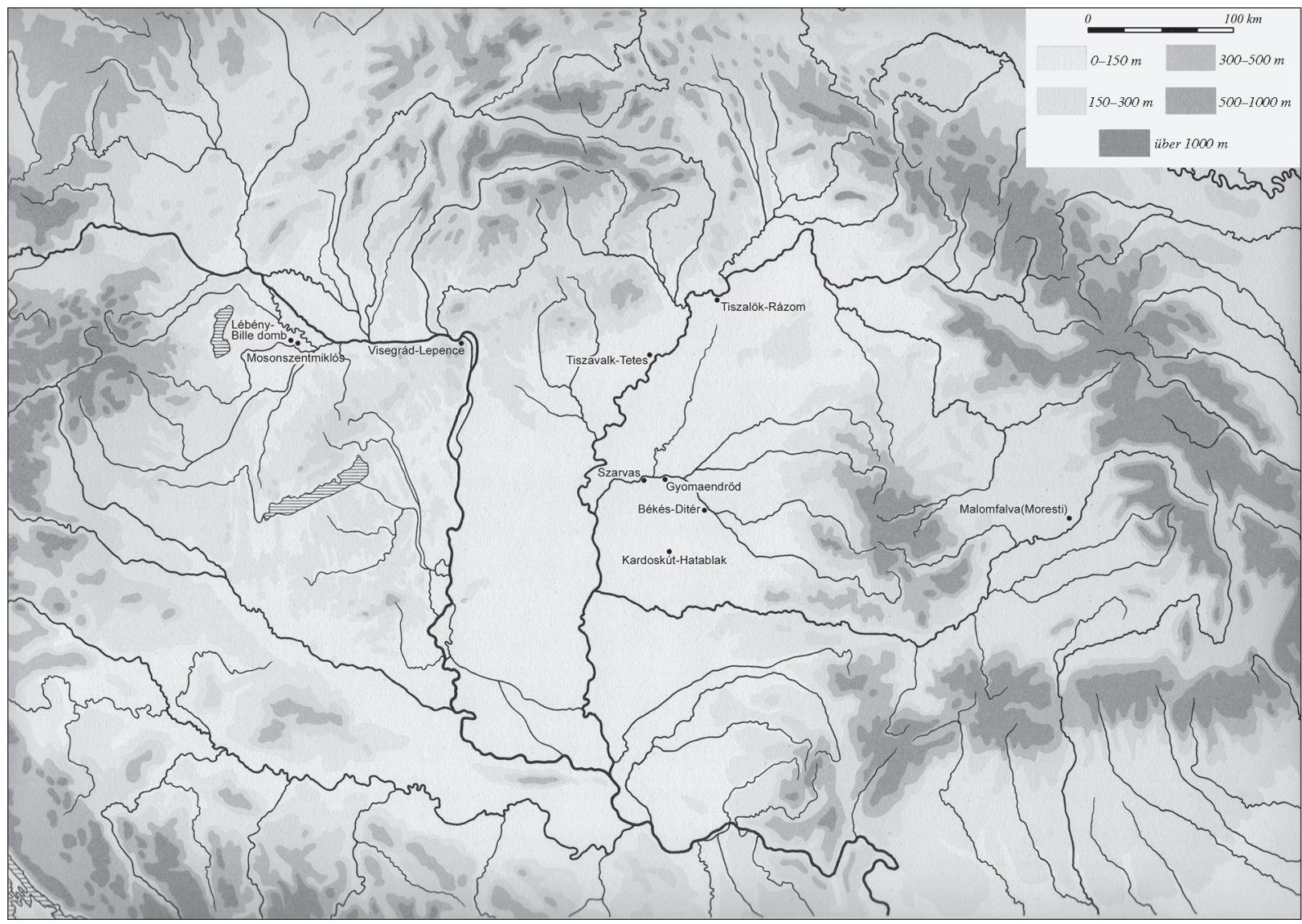

Karte 7. Backglocken und Backdeckel im 10.-11. Jahrhundert im Karpatenbecken

des Karpatenbeckens vor, in der Siedlung von Aszó/Sarasău-Zapodie aus dem 9.-11. Jahrhundert ${ }^{227}$ oder Lapusel, Popeni-Cuceu, Taga Lazuri ${ }^{228}$ aus der ersten Hälfte des 8. Jahrhunderts in der oberen Theißregion und in Moreşti/ Malomfalva im Maros-Tal. ${ }^{229}$

Wir haben die Möglichkeit, in den mittelalterlichen schriftlichen Quellen Hinweise auf die im Spiegel des archäologischen Materials bestimmt auch im Alltagsleben verwendeten Backglocken zu finden. Das Wort clibanus erscheint auch in mittelalterlichen ungarischen Quellen. Während clibanus in der Árpádenzeit wahrscheinlich eher eine Backglocke als einen Ofen bezeichnete (Equites monasterio ministrent: ... calefaciunt stubam et clibanum: s. 1086, 1135-71), hat sich die Bedeutung - in Einklang mit dem damaligen europäischen sprachlichen Zustand - seit dem 14. Jahrhundert verändert: Das Wort bezeichnete nunmehr einen Ofen. Zu dieser Zeit tritt auch die Verwendung des Wortes clibanus im übertragenen Sinne auf: Ecce venit Sponsa de Libano, fugit Virgo de mundi clibano. ${ }^{230}$

\section{Türkenzeit in Ungarn (15.-17. Jahrhundert)}

Unserer Kenntnis nach wurden Backglocken im 13.-15. Jahrhundert in Ungarn nicht mehr verwendet, weil es die Funde in dieser Periode fehlen. Im türkenzeitlichen ungarischen Fundmaterial des späten Mittelalters und der frühen Neuzeit kommen aber Backglocken in großer Anzahl vor, die von den aus dem Balkan stammenden, vorwiegend südslawischen Söldnern benutzt und verbreitet wurden. Ähnliche Funde gibt es auch in ihrer Umgebung. ${ }^{231}$

\footnotetext{
${ }^{227}$ POPA-HARHOIU 1989, 266

${ }^{228}$ Freundliche mündliche Mitteilung von Ion Stanciu (Cluj).

${ }^{229}$ HoREDT 1984.
}

${ }^{230}$ Lexicon Latinitatis Medii Aevi Hungariae II.1. Budapest 1991, 152; Mittellateinisches Wörterbuch III.5. Berlin 1973 720-721; DANKÓ 1893, 372. 1998, 155-156.

${ }^{231}$ Hatházi-KovÁcs 1996, 41 und Anm. 263; KovÁcs 
Da im Mittelalter Backglocken für die kleinasiatischen Türken nicht charakteristisch waren, müssen wir auf jeden Fall mit dem Erscheinen einer lokalen balkanischen Tradition im Karpatenbecken rechnen.

Die türkenzeitlichen Backglocken waren glockenartig geformt, mit oberem Griff und mit Spreu oder Kies stark gemagert. Backglocken sind ein häufiger Fundtyp in kleinen Palisadenburgen. So wurden zum Beispiel in Barcs 256 St. Backglockenfragmente gefunden, was 4,4 Prozent des ganzen Keramikfundmaterials ausmacht. ${ }^{232}$ Es fällt auf, dass Backglocken in der Siedlung Sarasău-Zapodie aus dem 9.-11. Jahrhundert auch 4-5 Prozent der Keramik ausmachten, was auf eine ähnlich bedeutende Rolle der Backglocken hinweist. ${ }^{233}$ Eine große Zahl von Backglocken wird von Archäologen für die türkische Palisadenburg bei Szekszárd-Újpalánk erwähnt (Abb. 24). Ein intaktes Exemplar wurde an der einstigen Feuerstelle ausgegraben. ${ }^{234}$ Neben den Backglocken gab es auch in der Türkenzeit niedrige Backschüsseln aus schlecht bearbeitetem Material; ${ }^{235}$ eine mit Ton verstrichene oder verziegelte Backoberfläche ist aber leider selten zu beobachten (Abb. 25). ${ }^{236}$

Die bisher bekannten Daten weisen darauf hin, dass Backglocken im 16.-17. Jahrhundert in den von den Türken nicht eroberten Gebieten Ungarns nicht verbreitet waren ${ }^{237}$ und mit einem Fortleben dieses Backgefäßes ist auch nur in den einst von den Türken besetzten Regionen zu rechnen. In den südlichen Gebieten Ungarns waren Backglocken auch im 18.-20. Jahrhundert zu finden. ${ }^{238}$ Zur selben Zeit verbreiteten sie sich auch in Siebenbürgen und in der Olt-Region. ${ }^{239}$ Das klassische Verbreitungsgebiet war aber der Balkan, wo das reiche Fundmaterial von den Ethnographen bereits bearbeitet worden ist. ${ }^{240}$

3. Süd- bzw. Südosteuropa

(Italien, Serbien, Griechenland, Rumänien)

Aus dem 9.-12. Jahrhundert sind Backglocken aus zahlreichen italienischen Fundorten, vor allem im Fundmaterial von Siedlungen, städtischen Ausgrabungen und Kirchen, bekannt. Die Daten besagen, dass die Verwendung von Backdeckeln im mittelalterlichen Italien kontinuierlich und weit verbreitet war (Cremona, Brescia, Ravenna, Forlì, Santa Cornelia, Roma-Crypta Balbi) (Abb. 20-21). ${ }^{241}$ Am Fundort Mola di Monte Gelato in Südetrurien machten Backdeckel 50 Prozent der alltäglichen Küchenkeramik aus, was an und für sich ihre bedeutende Rolle in der Zubereitung von Speisen beweist (Abb. 22). ${ }^{242}$ Die Backdeckel waren aber schlechter gearbeitet als die übrige Küchenkeramik. Ihrer Größe nach können zwei Gruppen aufgestellt werden: Die Größeren waren 30-35 cm, die Kleineren 19-25 cm breit. Die dickere Wandung und der dickere Rand, das schlechter bearbeitete Material und ihre Form lassen bei den Backdeckeln aus Roma-Crypta Balbi, Santa Cornelia und Mola di Monte Gelato eine Datierung ins 9.-10. Jahrhundert zu, während die Exemplare mit dünnerer Wandung, aus besserem Material und mit einer schöneren Form ihrerseits an das Ende des 10. Jahrhunderts und ins 11. Jahrhundert zu datieren sind. ${ }^{243}$ Die Backdeckel aus dem 12. Jahrhundert können von den älteren Formen durch ihren vorspringenden Rand unterschieden werden. ${ }^{244}$ Die Backdeckel wurden auch in den schriftlichen Quellen erwähnt: So hielt Pietro di Crescenzi, ein Autor im 13. Jahrhundert, das in einem Ofen gebackene Brot für besser als das unter einem Deckel hergestellte. ${ }^{245}$

Während früher Backdeckel und Backglocken in den serbischen Gebieten erst ab dem 14./15. Jahrhundert bekannt waren, kamen neulich in der Festung von Ras zahlreiche Backschüsseln und Backdeckel aus den ins 9.-11. Jahrhundert datierten Schichten zum Vorschein (Abb. 26). Die einstige spätantike Festung, in der schon Backdeckel vorgekommen waren, wurde in der zweiten Hälfte des 9. Jahrhunderts, zur Zeit der bulgarischen Expansion, neu befestigt. ${ }^{246}$ Diese Funde zeigen, dass die Tradition, Speisen unter einem Backdeckel zuzubereiten, bekannt war. Die Anzahl an Backschüsseln und Backdeckeln wird nach einer genauen Überprüfung der Fundmaterialien anderer Ausgrabungen wohl weiter steigen. Obwohl in den Schichten der Festung des 12.-14. Jahrhunderts keine Backglo-

${ }^{232}$ Kovács 1998, 1, Abb. 1-2, 4-5.

${ }^{233}$ POPA-HARHOIU 1989, 266.

${ }^{234}$ S. Kapitel IV.

${ }^{235}$ KovÁcs 1991, Taf. VIII.7.

${ }^{236}$ GAÁL 1981, 145-147.

${ }^{237}$ KovÁcs 1998, 155-156

${ }^{238}$ ВÁTKY 1935, 16-17; ВÁTKY 1936, 113-117; RŐMER 1966, 411-412.

${ }^{239}$ Chelcea 1968, 172; LARIOnEscu-ARMASESCU 1973,
${ }^{240}$ RÕMER 1966, 400-410; FILIPOVIĆ 1951, 73-78; PoPOVIĆ 1956, 1957; TOMIĆ 1970; VAKARELSKI 1977, 359-360; ONUZI 1980, 145-146, Fig. 5-11.

${ }^{241}$ RicCi 1986, 537; CubBerley et al. 1988; PATTERSON 1997, 372.

${ }^{242}$ PATterson 1997, 372.

${ }^{243}$ RiCCI 1986, Taf. XI-XIII; PATTERSON 1997, 372.

${ }^{244}$ PATTERSON 1997, 372.

${ }^{245}$ CubBerley 1995, 60.

${ }^{246}$ PoPOVIĆ 1999, 139-161. 247. 


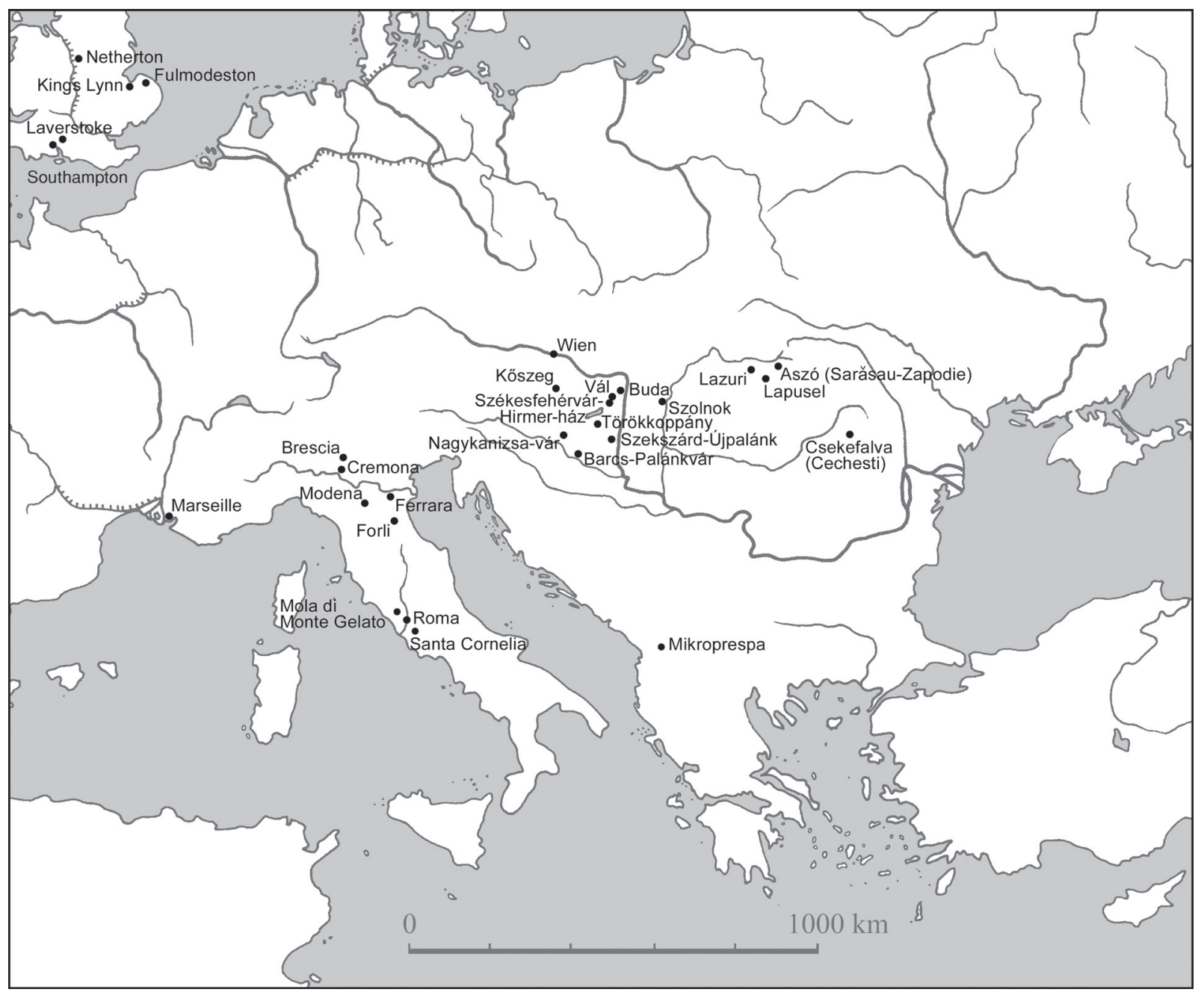

Karte 8. Mittelalterliche und frühneuzeitliche Backglocken und Backdeckel

cken- oder Backdeckelfragmente vorkamen, gab es weiterhin Backschüsseln in großer Zahl. ${ }^{247}$ So ist die Annahme vielleicht nicht unbegründet, dass bestimmte tiefe Schüsseln mit herausgebogenem Rand als Backdeckel verwendet werden konnten. ${ }^{248}$ Es fällt auf, dass es bis heute keine Backglocken und Backdeckel des 9.-10. Jahrhunderts in den rumänischen und bulgarischen Ausgrabungen in der Region der unteren Donau gefunden wurden. Es kann aber sein, dass wir es mit einer Forschungslücke zu tun haben. Die Backglocken und Backschüsseln aus der Siedlung SarasăuZapodie (9.-11. Jahrhundert) und aus dem Maros-Tal in Rumänien lassen sich kulturell und geschichtlich mit dem damaligen Fundmaterial des Karpatenbeckens verbinden (Karte 8).249

Im Fall von Griechenland haben wir aus dem 10.-14. Jahrhundert auch nur sporadische archäologische Daten für die Existenz der Tradition, unter einem Deckel zu backen. Das Fehlen der Funde ist umso überraschender, weil die schriftlichen Quellen eindeutig beweisen, dass dieses Backverfahren in den byzantinischen Gebieten auch im Mittelalter üblich war. Manuel Moschopoulos (1265-1335) schreibt, dass unter dem Metall- oder Tondeckel (klibanos) nicht nur Brot (klibanikios, klibanites), sondern in kleineren Portionen auch andere Speisen zubereitet oder aufgewärmt wurden $(A b b .28,1-3) .{ }^{250}$ In den Quellen wird neben der Verwendung der klibanos auch ein an-

\footnotetext{
${ }^{247}$ Popović 1999, 231, Abb. 189.

${ }^{248}$ PoPOVIĆ 1999, 221, Abb. 176.13.

${ }^{249}$ PoPA-HARHOIU 1989, 266.
}

${ }^{250}$ BAKIRTZES 1989, 53-54, Pl. 11.3-6. 
derer Gefäßtyp, die gastra ( $\gamma \alpha \dot{\sigma} \sigma \varrho \alpha, \gamma \alpha \tau \varrho i ́ \alpha)$, erwähnt, die von Ch. Bakirtzes mit den bei Ausgrabungen in großer Menge gefundenen Backschüsseln identifiziert wurde. Somit ist im mittelalterlichen Byzanz nicht nur die Verwendung von Backglocken und Backdeckeln, sondern - wie bei anderen balkanischen Fundorten - auch der enge Zusammenhang mit den Backschüsseln zu beweisen.

\section{West- bzw. Zentraleuropa (Deutschland, England, Frankreich)}

Im Mittelalter waren eiserne Backglocken in Süddeutschland bekannt, was die Verbreitung der mediterranen Tradition der Speisezubereitung anzeigt. ${ }^{251}$ In Marseille wurden in der in das 13. Jahrhundert datierten Schicht unten offene Backformen mit Bleiglasur gefunden, die auf Grund ihrer Form und der Position des Griffes an einem Exemplar sicherlich als Backglocken verwendet wurden (Abb. 27).

Im mittelalterlichen England waren Backdeckel ohne Henkel oder mit oberem Griff (curfew/cover-fue) auch überall verbreitet; unter ihnen kommen glocken- oder haubenartige und deckelartige Exemplare (King's Lynn) vor. ${ }^{252}$ In der Forschung sind verschiedene Funktionen für diese Backglocken angenommen worden: Backen, Warmhalten von Speisen und manchmal vielleicht auch das Räuchern von Fisch (Abb. 23). ${ }^{253}$

Im Mittelalter blieb dieses Backverfahren wegen der verzweigten Handelsbeziehungen nicht auf ein Gebiet oder eine bestimmte Lebensweise beschränkt, sondern verbreitete sich in einem weiteren Kreis wie eine Mode. Diese ursprünglich südeuropäische Tradition hing nicht mehr von der Lebensweise ab, sondern konnte überall als wanderndes Kulturelement auftauchen. Zugleich ist die Interpretation der mittelalterlichen lateinischen Quellen etwas widersprüchlich. Während nämlich bei den Wörtern clibanicus, clibanitivus die Deutung ,in der Brotform gebacken" sich eindeutig auf die Backglocken beziehen kann, wird das Wort clibanus als sartago 'Pfanne' oder als 'Ofen' interpretiert. ${ }^{254}$

\section{KULTURGESCHICHTLICHE BEOBACHTUNGEN}

\section{Eine mediterrane-südeuropäische Backtradition}

Es ist festzustellen, dass das Auftreten von Backglocken und Backdeckeln mit der Entwicklung der Backtechnik zusammenhängt. Backglocken bedeuten einen Übergang vom Backen zwischen Steinplatten oder in Asche zum Backen im Ofen. ${ }^{255}$ Sie sind in der Zeit erschienen, als man mit dem Rösten oder Backen verschiedener Arten von Brei allmählich anfing, Fladenbrot zu backen. Es ist schwer, den absoluten Zeitpunkt und Ort des Erscheinens von Fladenbroten zu bestimmen, jedoch ist anzunehmen, dass sie zuerst dort erschienen, wo sich der Getreideanbau am frühesten herausgebildet hatte. Backglocken waren bestens geeignet, frisch zu verzehrendes, nicht gesäuertes Brot zu backen, wie es auch dann gerne gegessen wurde, als man in Öfen aus gesäuertem Teig bessere, schmackhaftere Brotsarten backen konnte. Backglocken und Backdeckel sind eigentlich primitive Öfen, Zwischenstationen in der Entwicklung von Backplatten zu Öfen. Die hoch gewölbten Tonglocken und Tondeckel sind Beweisstücke für die Verwendung eines eigenartigen Backverfahrens, das im Lichte unserer Daten in den südeuropäischen Gebieten von der Bronzezeit an bis heute ununterbrochen üblich war.

Der soziale und wirtschaftliche Hintergrund der Verwendung von Backglocken könnte in einer gesonderten Analyse untersucht werden, um zu erklären, wie dieses Backverfahren fortbestand, sich verbreitete oder verdrängt wurde ( $A b b$. 34). Bei den verschiedenen Völkern und in den einzelnen Gebieten hing das Bestehen oder die Übernahme von Backglocken und Backdeckeln mit der Lebensweise, mit geographischen, wirtschaftlichen und gesellschaftlichen Ursachen zusammen. Backglocken wurden in erster Linie in dörflichen Siedlungen und in Quartieren verwendet, ihr Erscheinen war durch die Herausbildung des Brotbackens (Weizenbrot) bedingt. Unter Backglocken wurde zunächst nicht gesäuertes, später gesäuertes Brot gebacken. Ihre Verwendung auf dem Balkan hing mit der jahrhundertelang unveränderten Lebensweise der Bewohner, mit der unveränderten Wirtschaftung und

\footnotetext{
${ }^{251}$ STOKAR 1951, 141; WiegelmanN 1973, 573-576.

${ }^{252}$ MCCARTHY-BROOKS 1988, 118, 188, 264, 339, 407, 720-721.

414, 418; CubBerley 1995, 65-66, Fig. 5.6-7.

${ }^{254}$ Mittellateinisches Wörterbuch III.5. Berlin 1973,

${ }^{253}$ CubBerley 1995, 66.

${ }^{255}$ WÄHREN 1960; WÄHREN 2000, 377, Abb 1.
} 
mittelbar mit der isolierten geographischen Lage zusammen. Das Fortbestehen der Lappendeckel in der südlichen Alpenregion kann auch zum Teil auf die isolierte geographische Lage, auf die Lebensweise der Hirten im Gebirge, auf die jahrhundertelang unveränderte Lebensführung zurückgeführt werden. Wegen der einfachen Herstellung und Verwendung waren sie in vorübergehenden Hirten- und Soldatenquartieren beliebt.

Es war eine Epoche an sich in der Geschichte der Backglocken und Backdeckel, als diese in der mittleren Region Südeuropas einheimische Tradition von den Völkern übernommen wurde, die sich in der Peripherie des Mediterraneums, im Tal der oberen, mittleren und unteren Donau niederließen (die Kelten, Daker, Awaren, Slawen, Ungarn). Die Übernahme dieser mediterranen Backtradition kann als Anzeichen der kulturellen Anpassung dieser barbarischen Völker bewertet werden. Die große Anzahl von Backglocken in der keltischen Siedlung auf der Heuneburg beweist, dass ihren Bewohnern das südeuropäische Backverfahren bekannt war. ${ }^{256}$ Ähnlich ist das Erscheinen der dakischen Schalen zu betrachten. Es besteht kaum Zweifel an den engen südeuropäischen Beziehungen der slawischen Backschüsseln und auf Grund der balkanischen frühbyzantinischen Exemplare ist der mediterran-balkanische Ursprung der awarenzeitlichen Backglocken eindeutig. In der ungarischen Landnahmezeit und in der Árpádenzeit sind im Karpatenbecken Backglocken wahrscheinlich wegen der seit dem 7. Jahrhundert grundsätzlich unveränderten Lebensweise der Bevölkerung erhalten geblieben ( $A b b$. 33).

Das jahrtausendealte Backverfahren war einst wohl überall bekannt, ist aber später in bestimmten Gebieten aus verschiedenen Gründen verdrängt worden, vor allem wegen der wirtschaftlichen Entwicklung, der allgemeinen Verbreitung der aus gesäuertem Teig gebackenen Brote, der Entwicklung von Ofentypen, der Urbanisierung und des Bedarfs an Massenproduktion. Die ununterbrochene Verwendung ist in erster Linie an der Peripherie (auf dem Balkan, in der südlichen Alpenregion) belegt. Dieses einfache Backverfahren ist jedoch von der städtischen Entwicklung und der Produktion in städtischen Bäckereien nicht gänzlich verdrängt worden und kann im Römischen Reich sowohl in städtischen als auch in dörflichen Haushalten dokumentiert werden. Unter dem Backdeckel gebackene Brote waren allgemein beliebt.

Es ist kein Zufall, dass die Anzahl von Backglocken in der spätantiken Periode ansteigt, was die wiederholte Verbreitung dieser Art des Backens beweist und wohl mit der Auflösung der städtischen Bäckereien und der städtischen Handwerksorganisation zusammenhängt. Diese zum alltäglichen Brotbacken verwendeten Backglocken wurden natürlich mit jeweils unterschiedlicher Technik in den bäuerlichen Haushalten, in provisorischen römerzeitlichen oder byzantinischen miltitärischen Quartieren hergestellt, die zum Backen von Kuchen oder anderen Delikatessen verwendeten Backformen aber in den Küchen der römischen und mittelalterlichen französischen Vornehmen.

Das Backen unter dem Deckel ist also in Südeuropa nie verschwunden, es wurde bloß in einigen Gebieten in den Hintergrund gedrängt. In den Peripherien der wirtschaftlichen und gesellschaftlichen Entwicklung kann das unveränderte Fortbestehen von Backglocken von der Vorzeit bis zur spätantiken Periode problemlos archäologisch dokumentiert werden. Besonders interessant ist das formtreue Weiterleben der Lappenschüsseln von der späten Hallstattzeit bis in die späte Antike in den südlichen Alpen, in der Südtiroler Region. Die Grundform des Gefäßes änderte sich nicht, nur ihre Verzierung. Die Lappenschüsseln waren in prähistorischer Zeit meist unverziert und übernahmen dann zum Beispiel in der römischen Kaiserzeit und in der spätantiken Periode die Dekoration der lokalen römischen Gebrauchskeramik. ${ }^{257}$ Im Mittelalter wurden Backglocken in den meisten Gebieten Europas sogar in England - verwendet, so dass ihr Neuerscheinen in verschiedenen Teilen Europas in der Neuzeit und der Moderne auf unterschiedliche Quellen zurückgeführt werden könnte. Auf jeden Fall waren sie dann in diesen Gebieten als fremdes Element und nicht als Bestandteil der lokalen Tradition vorhanden.

Zusammenfassend lässt sich also feststellen, dass die für eine Entwicklungsphase des Brotbackens charakteristischen Backglocken und Backdeckel von den neuen Backverfahren nicht verdrängt wurden, sondern sie wurden in den einzelnen Gebieten und Kulturen aus unterschiedlichen Gründen für längere oder kürzere Zeit noch gebraucht. Die Verwendung von Backglocken in bestimmten Regionen muss aber differenziert bewertet werden, weil man zwar annehmen kann, dass ihr Fortbestehen ein Anzeichen für unveränderte, stagnierende Lebensumstände und Lebensweise sei (Balkan) oder ihre plötzlich zunehmende Anzahl ein Beweis für den wirtschaftlichen Rückgang, den Verfall in der gegebenen Epoche (Spätantike) sei, zugleich ist bei einigen, an der Peripherie des 
Mediterraneums siedelnden barbarischen Völkern (Awaren, Ungarn) die Übernahme der Backglocken - d. h. einer neuen Backmethode - eindeutig als Entwicklung, Neuerung zu betrachten.

Dieses einfache und zweckmäßige Backverfahren wurde von vorübergehend oder langfristig bestehenden Lebensumständen konserviert. Sein Gebrauch weist in der Geschichte oft von der Zeit unabhängige Parallelen auf, denn die römischen Soldaten verwendeten Backdeckel in den augusteischen Lagern genauso wie die aus dem Balkan in den türkenzeitlichen Palisadenburgen angesiedelten Soldaten im 15.-16. Jahrhundert in Ungarn. Die dauerhaft unveränderten Lebensumstände erhielten den Gebrauch der Backglocken bei der Bevölkerung von Bergregionen aufrecht, so in den südlichen Alpen, auf dem Balkan und bei den Berghirten (den Pomaken in Griechenland). Diese einfache und einmalige Erfindung ist heute grundsätzlich nur in der Peripherie vorhanden, konserviert durch den Bedarf und die traditionelle Lebensweise.

\section{Backglocken und Backteller bzw. Backplatten}

Bei präzise beobachteten und dokumentierten modernen Ausgrabungen wurden neben Backglockenfragmenten in zahlreichen Fällen auch Backteller oder Backplatten gefunden. Der enge Zusammenhang von Backdeckeln und Backglocken wurde von T. Mannoni schon 1970 auf Grund von zentralitalienischen liturgischen Exemplaren aus dem 12.-15. Jahrhundert beobachtet. ${ }^{258}$ Wo es keine mit Ton ausgekleideten oder später mit Ziegeln gestalteten Feuerstellen gab, dort wurde der/das zum Backen/Braten vorbereitete Teig/Fleisch auf einen Backteller oder eine Backplatte gelegt und mit einer Backglocke oder einem Backdeckel zugedeckt. Diese ein paar Zentimeter hohen Backteller gehörten also wahrscheinlich zu den Backglocken; in den meisten Fällen stimmen auch ihre Durchmesser überein.

Den Backglocken ähnlich wurden Backteller aus schlecht geschlämmtem Ton ohne eine Töpferscheibe gemacht, mit Sand, Stein- oder Tonsplittern und zermahlenen organischen Resten stark gemagert und bei sehr niedriger Temperatur gebrannt. Die Backteller haben einen Durchmesser von 15-30 cm, ihre Seiten sind ein wenig nach außen gebogen, vertikal oder ein bisschen gewölbt, ihr Rand ist dünn und abgerundet. Diese einfach hergestellten Backteller wurden - wie Backglocken - nicht transportiert. Sie waren keine Handelswaren, sondern müssen als Hausindustrieprodukte betrachtet werden.

Backteller haben in der frühmittelalterlichen Archäologie Ost- und Mitteleuropas und des Balkans eine besondere Rolle und Bedeutung, da sie neben den so genannten Töpfen Prager Typs als das wichtigste Kennzeichen früher slawischer Siedlungen betrachtet werden. ${ }^{259}$ Die Herausbildung und Verbreitung von Backtellern wird im Allgemeinen mit dem Backen von Weizenbrot in Verbindung gesetzt. In den mit Slawen assoziierten Fundkomplexen weisen sie darauf hin, dass sie alleine zum Brotbacken gebraucht werden konnten. Ethnographische Beispiele zeigen aber, dass der eine Teller auf den anderen gelegt auch als Deckel fungieren konnte.

Die ungarische Archäologie hat sich mit dem Vorkommen von Backtellern im Karpatenbecken, mit ihren Formen und ihrer Funktion zusammenfassend nicht auseinandergesetzt. Die neuere Forschung beweist, dass Backteller - im Gegensatz zu früheren Annahmen ${ }^{260}$ - nicht nur in den bergigen, auch von den Slawen besiedelten Gebieten des Karpatenbeckens ${ }^{261}$ (z. B. Mátraszőlős ${ }^{262}$ ), sondern auch in zentralen und peripheren Teilen des awarischen Siedlungsgebiets vorkamen (Dévényújfalu/Bratislava-Devínska Nová Ves, ${ }^{263}$ Dunacséb/Čelarevo, ${ }^{264}$ Eperjes, ${ }^{265}$ (Abb. 29, 3-40) Hunya, Gyoma, Kompolt, ${ }^{266}$ Padé $^{267}$ Veresegyház $^{268}$ ). Die im Siedlungsgebiet der Awaren gefundenen Backteller sind also nicht als Kennzeichen des slawischen Kulturmilieus zu betrachten, sondern als Untersätze zu Backglocken. Jedoch konnten Backteller nicht nur mit Backglocken, sondern auch alleine zum Backen gebraucht werden und hatten wahrscheinlich auch andere Funktionen. Unsere Daten weisen also eher darauf hin,

\footnotetext{
${ }^{258}$ MANNONi 1970, Pl. III.

${ }^{259}$ Zur Fachliteratur über die Keramik und Schüsseln der ostslawischen Siedlungen s. HOREDT 1978, 67, Anm. 22; RuSANOvA 1973, 10, Taf. 17, 19; 11, Taf. 3, 4, 24 usw.; Herrmann 1986, 267-272, Anm. 5.

${ }^{260}$ BÓNA 1985, 228-229; BÁLINT 1991, 60-61, Anm. 178.

${ }^{261}$ FuseK 1994, Taf. V.6, Taf. XX.12, Taf. XXIII.9, Taf. XXXIX.12, 14; HOREDT 1978, 59-68.
}

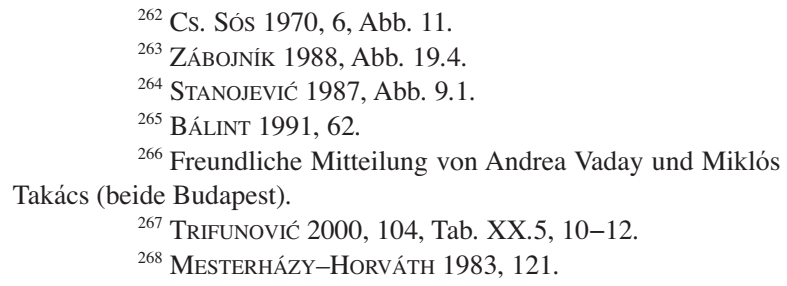




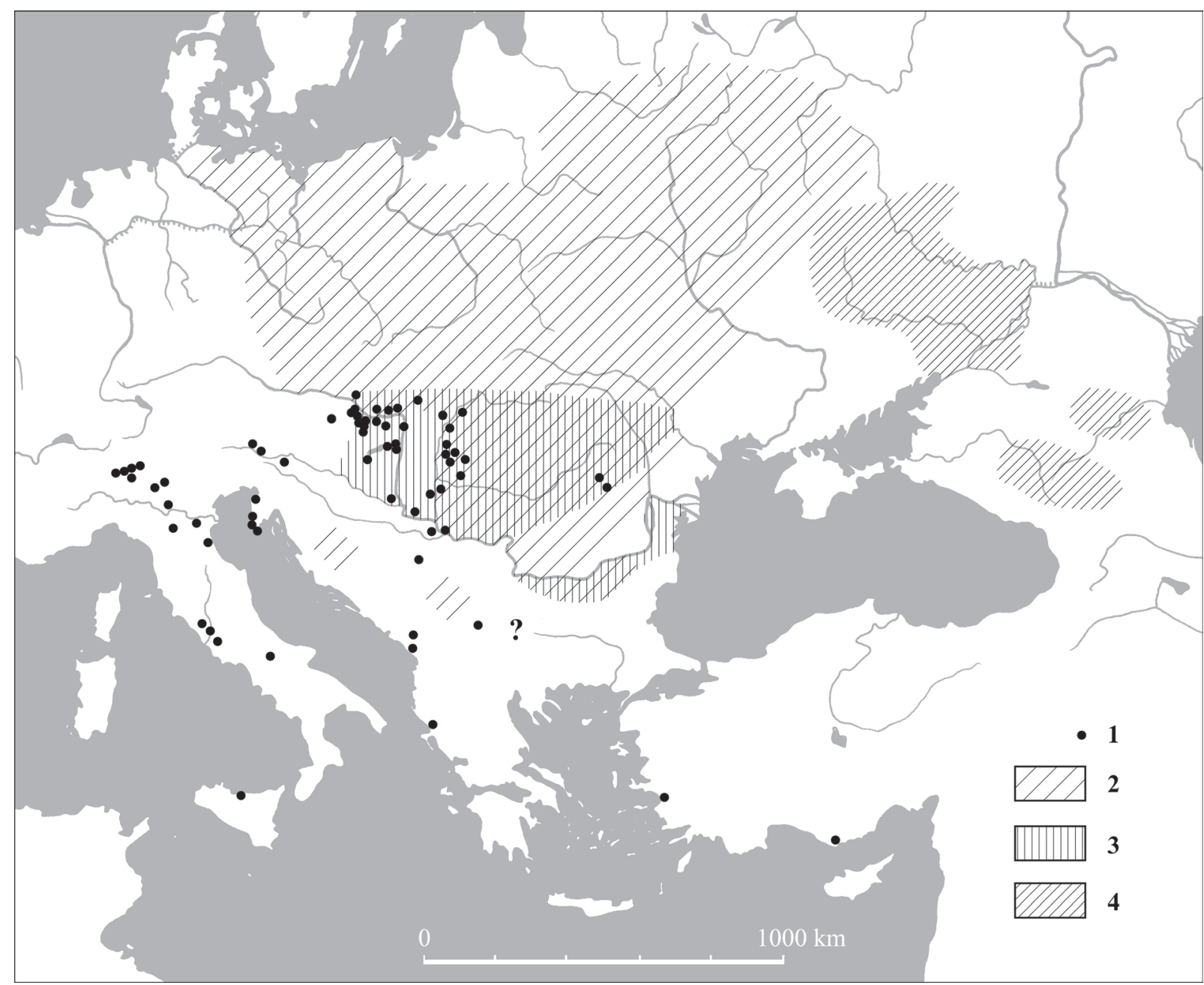

Karte 9.

Verbreitung der Backglocken, Backdeckel (1), Backschüssel, Backteller (2), und der Tonkessel (3) aus dem Karpatenbecken und aus Ost-Europa (4) (nach Horedt 1984 und Takács 1986 mit den Ergänzungen des Authors)

Kochen über offenem Feuer verwendet. ${ }^{277}$ In größerer Anzahl finden wir im Karpatenbecken Tonkessel zuerst bei den Sarmaten im 3.-4. Jahrhundert ${ }^{278}$ und dann einige Jahrhunderte später, am Ende des 7. Jahrhunderts, erscheinen sie im awarenzeitlichen Fundmaterial. ${ }^{279}$ Der Gebrauch von Tonkesseln ist im 8.-9. Jahrhundert kontinuierlich, im 10. Jahrhundert traten aber scheibengedrehte Kessel auf und verdrängten die handgeformten. ${ }^{280} \mathrm{Im}$ Verbreitungsgebiet von Backglocken erschienen die über eine Feuerstelle gehängten Töpfe erst im 10.-11. Jahrhundert, vor allen Hängetöpfe mit Öselappen, die eindeutig Metalltöpfen ähnelten und keine Verbindung zu den in der eurasischen Steppe und im Karpatenbecken verbreiteten Tonkesseln der Nomaden hatten. ${ }^{281}$

Es kann also im 7.-8. Jahrhundert im Karpatenbecken die parallele Verwendung von drei Gefäßtypen, die kulturelle Traditionen unterschiedlichen Ursprungs in der Zubereitung von Speisen in der zweiten Hälfte des ersten

${ }^{277}$ TAKÁCS 1986; TAKÁCS 1991, 135-195.

${ }^{278}$ Die sarmatischen Kessel ahmten wahrscheinlich die Form von Metallkesseln nach; VADAY 1980-1981, 23-34.

${ }^{279}$ Zur Datierung s. BÁLINT 1990, 9-21.

${ }^{280}$ SZŐKE 1980; FIEDLER 1994.
${ }^{281}$ Das bedeutet natürlich nicht, dass Hängetöpfe zum Kochen in den europäischen Gebieten unbekannt waren. In der Töpferei der untersuchten Region kann aber keine jahrhundertlange Tradition erfasst werden. Die Hängegefäße mit Ösenlappen kamen aus den mittelalterlichen Fundorten Cremona, Mantova und Brescia oder EsteBurg, Betiki kod Barbarige vor. BRogiolo-Gelichi 1984, 302, Tav. V.5-6; 303, Tav. VI.2; 307, Tav. VIII.2-6; Este: SiviERO 1975, 61. 
Jahrtausends verkörperten, d. h. von den Tonkesseln aus der Steppe, von den unter den Slawen verbreiteten Backtellern und den mediterranen Backdeckeln, beobachtet werden. Während die Backglocken, Backdeckel und Backteller europäischer Herkunft zum Fundmaterial der sesshaften, Ackerbau treibenden Völker gehören, wurden handgeformte Tonkessel von den Völkern der eurasischen Steppe verwendet. So beweisen die obigen Funde im Frühmittelalter die gleichzeitige Präsenz der westlichen Tradition in der Zubereitung von Speisen vor allem durch Backen und der östlichen Tradition des Kochens im Karpatenbecken. Die einfache, anspruchslose Bearbeitung dieser Gefäße steht nicht in Einklang mit ihrer unentbehrlichen Funktion im Alltagsleben und ihrer kulturellen Bedeutung. In diesen einfachen, zweckmäßigen, traditionellen, handgeformten Gefäßen wurde nämlich das tägliche Essen zubereitet, so dass sie trotz ihres bescheidenen Äußeren eindeutige Hinweise auf die unterschiedlichen kulturellen Einflüsse der gegebenen Periode liefern.

Die Übernahme der Verwendung von Backglocken zeigt die Akkulturation der awarenzeitlichen Bevölkerung und ihre engen Kontakte mit den mediterran-balkanischen Gebieten an. Es ist merkwürdig, dass wir aus den gepidischen Siedlungen der Tiefebene und aus langobardischer Umgebung in Pannonien keine vergleichbaren Backglocken- bzw. Backdeckelfunde kennen. Auf jeden Fall trafen die kulturellen Einflüsse unterschiedlicher Herkunft im Karpatenbecken der Awarenzeit aufeinander. Diese mosaikartige kulturelle Vielfalt ist schon in zahlreichen Aspekten der materiellen und geistigen Kultur aufgezeigt worden ${ }^{282}$ und hiermit haben wir weitere Beweise aus der Ernährungskultur dafür liefern können.

Ziel der vorliegenden Arbeit war, die Aufmerksamkeit auf eine bescheiden erscheinende Keramikgruppe zu lenken, die jedoch auf Grund ihrer engen Beziehung zur Lebensweise kulturgeschichtlich höchstrelevant ist. Die typologische Klassifizierung und die Bestimmung der Funktion dieser Gefäße sind lange ausgeblieben. Es ist eine allgemeine Tendenz, dass neben den Koch- und Backgefäßen gerade die Tischkeramik am meisten vernachlässigt wird. In der letzten Zeit ist aber die Anzahl dieser Funde so stark angestiegen, dass ähnliche Funde aus verschiedenen geographischen und kulturellen Regionen einer vergleichenden Analyse unterzogen werden konnten. Im Rahmen der vorliegenden Studie konnte nur angestrebt werden, eine aussagekräftige, statistisch repräsentative Probe zu untersuchen, da die vollständige Erfassung des Materials von Spezialisten des Fachgebiets ausgeführt werden muss. Bei einer präziseren Überprüfung des Fundmaterials können wahrscheinlich noch weitere, ähnlich gebrauchte Gefäßtypen identifiziert werden. Die vorliegende Arbeit hat auch gezeigt, dass noch genauere typologische und chronologische Untersuchungen zur Erfassung der komplexen Aspekte der Herkunft, Verbreitung, Tradierung und Verwendung von Backglocken und Backdeckeln vonnöten sind. Letzten Endes bedeutet dies, dass Backglocken und Backdeckel noch lange ein interessantes Forschungsthema bleiben werden.

\footnotetext{
${ }^{282}$ BÁLINT 1993, 195-273. Das Manuskript wurde im J. 2002 abgeschlossen.
} 


\section{FUNDLISTE}

\section{Bronzezeit}

B o s n i e n

Kekica Glavica (Abb. 2.4)

Intakte Backglocke mit verziertem Henkel und plastischer Verzierung rund herum in der Mitte. D: $36,5 \mathrm{~cm}$.

Lit.: Čović 1962, 51-52, Abb. 7.

Ripač bei Bihać (Abb. 2.7)

Handgeformte, konische, intakte Backglocke. D: $28 \mathrm{~cm}$.

Lit.: RAdIMSKÝ 1897, Taf. XXVIII.171; TRUhelKa 1914, 82-83, Taf. $\mathrm{V}$, in der Mitte.

Kroatien

Bregana-Kosovac

Backglockenhenkel

Lit.: VINSKI-GASPARINI 1954, 120, Abb. 4; VINSKI-GASPARINI 1973, 66-67, Taf. 22.8.

Erdut brijeg Veliki Varad / Erdőd

Backglockenhenkel

Lit.: VINSKI-GASPARINI 1954, 120-121, Abb. 5-7; VINSKI-GASPARINI 1973, 66-67, Taf. 22.10-12.

\section{Kiringrad}

Backglockenhenkel

Lit.: VinSKI-GASPARINI 1954, 120, Abb. 3; VINSKI-GASPARINI 1973 , 66-67, Taf. 22.13.

Nin (Abb. 2.6)

Lit.: Rittatore-Vonwiller 1984, 131, Fig. 1; Batović 1987, 372, Taf. XXXV.14.

\section{Pećina kod Lešća Ličkog}

Backglockenhenkelfragment

Lit.: VINSKI-GASPARINI 1954, 119-120, Abb. 2.

S low en i e n

Maria Rast, Grab 144 (Abb. 4.3)

Backglockenhenkel, aus einem Grab, Hallstatt B (8. Jh. v. Chr.) Lit.: MÜLLER-KARPE 1959, Taf. 113.

\section{Ormož}

Aus der urnenfelderzeitlichen Ansiedlung stammt eine große Anzahl von Backhauben.

Lit.: GABRovec et al. 1970, 37, Anm. 61; PERC 1962-1963, 375-381.
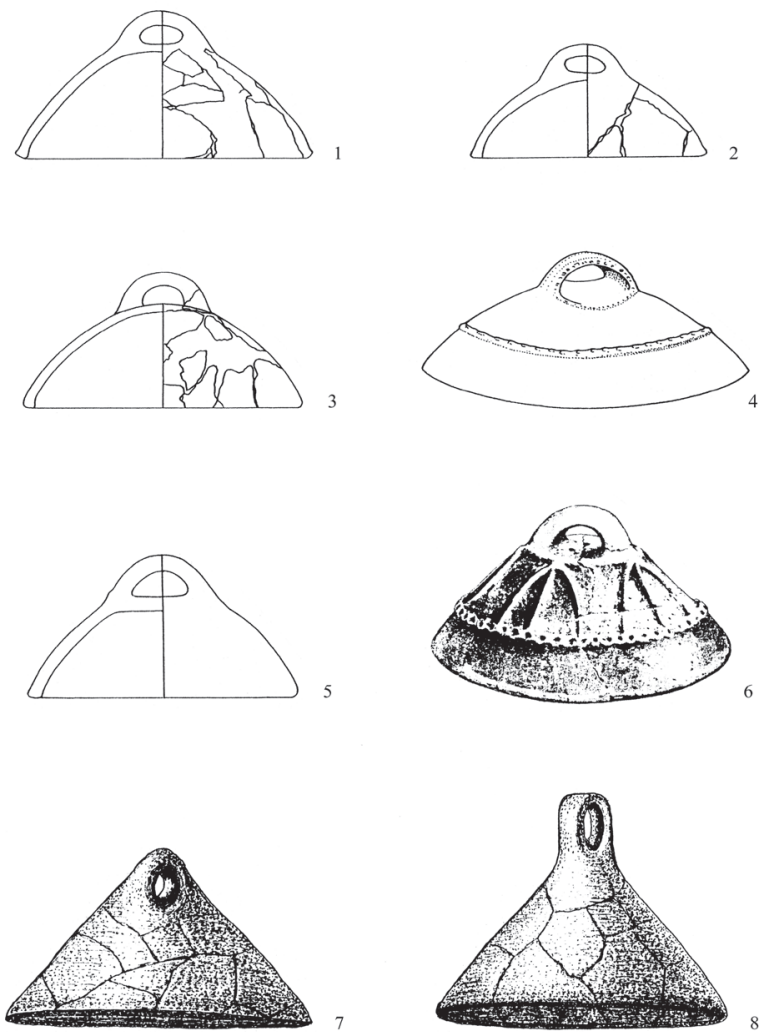

Abb. 2. Bronze- und Eisenzeit. 1-3, 5: Murlo, Poggio Civitate (nach Bouloumié 1978); 4: Kekica Glavica (nach Čović 1962); 6: Nin (nach BATOVIĆ 1987); 7: Ripač (nach TRUHELKA 1904); 8: Tolentino (nach MonTELIUS 1904)
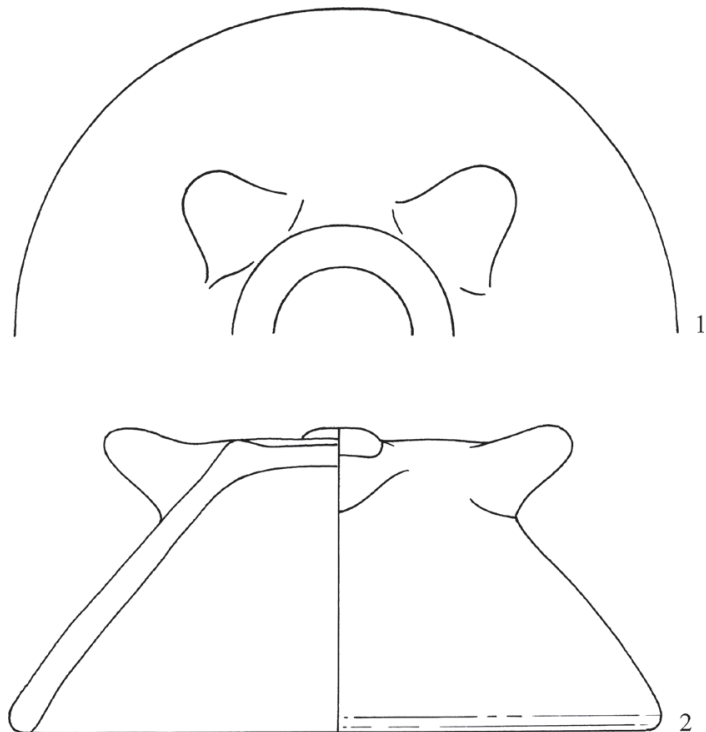

Abb. 3. Cures Sabini (nach GuIDI et al. 1996)

Acta Archaeologica Academiae Scientiarum Hungaricae 67, 2016 
Podzemelj

Backglockenhenkel

Lit.: DULAR 1978, Taf. XLII.3.

It a 1 i en

Arcevia

Backglockenfragmente, 12. Jh. v. Chr.

Lit.: RÖMER 1966, 396; VINSKI-GASPARINI 1973, 66-67.

Cures Sabini (Rieti, Lazio), 8.-7. Jh. v. Chr. (Abb. 3)

Lit.: A. Guidi et al.: Cures Sabini: lo scavo, le strutture, la cultura materiale, le attività economiche. Identità e Civiltà dei Sabini. Atti del XVIII Convegno di Studi Etruschi ed Italici, Rieti - Magliano Sabina, 30 maggio - 3 giugno 1993. Firenze 1996, 143-204.

Le Sparne di Poggio Buco (Pitigliano), Etrurien

Eine Protovillanova-Siedlung, die später in der etruskischen archaischen Periode eine bedeutende Rolle spielte (11.-10. Jh. v. Chr.).

Lit.: Museo di Preistoria e Protoistoria, Manciano. Catalogo Toscana Musei. Firenze 1994, 119.

\section{Monte la Rossa}

Lit.: D. G. LoLLinI: Tracce di stanziamento „protovillanoviano” sul Monte la Rossa presso Serrasanquinico (prov. Ancona). Studi Etruschi 27/2 (1960) 62, Abb. 10.1.

Monte Rovello, Latium

Deckel (Backglockenhenkel?), mittlere Bronzezeit

Lit.: M. A. Fugazzola-Delpino: Testimoniazione di cultura appeninica nel Lazio. Firenze 1976, Fig. 96.5-7.

\section{Narce}

Lit.: T. W. PоттеR: A Faliscan Town in South Etruria. British School at Rome. London 1976.

\section{Ripoli}

Backglocke. D: $15-18 \mathrm{~cm}$.

Lit.: S. M. PugLIESI: La civiltà Appeninica. Origine della communità pastorali in Italia. Firenze 1959, 37-38, Fig. 12.

Tolentino, Necropole de la Bura, Etrurien (Abb. 2.8)

Handgeformte Backglocke mit oberem Griff. D: $37 \mathrm{~cm}$.

Lit.: O. Montelius: La civilisation primitive en Italie. Depuis l'introduction des métaux. II.1. Stockholm 1904, 751, Pl. 157.19.

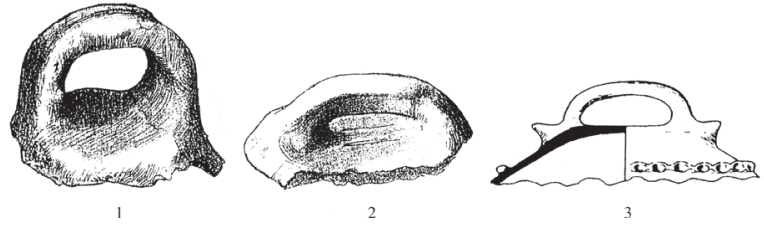

Abb. 4. Bronze- und Eisenzeit. 1-2: Donja Dolina (nach TRUHELKA 1904; ČURČIĆ 1913); 3: Maria Rast (nach MüLLER-KARPE 1959)
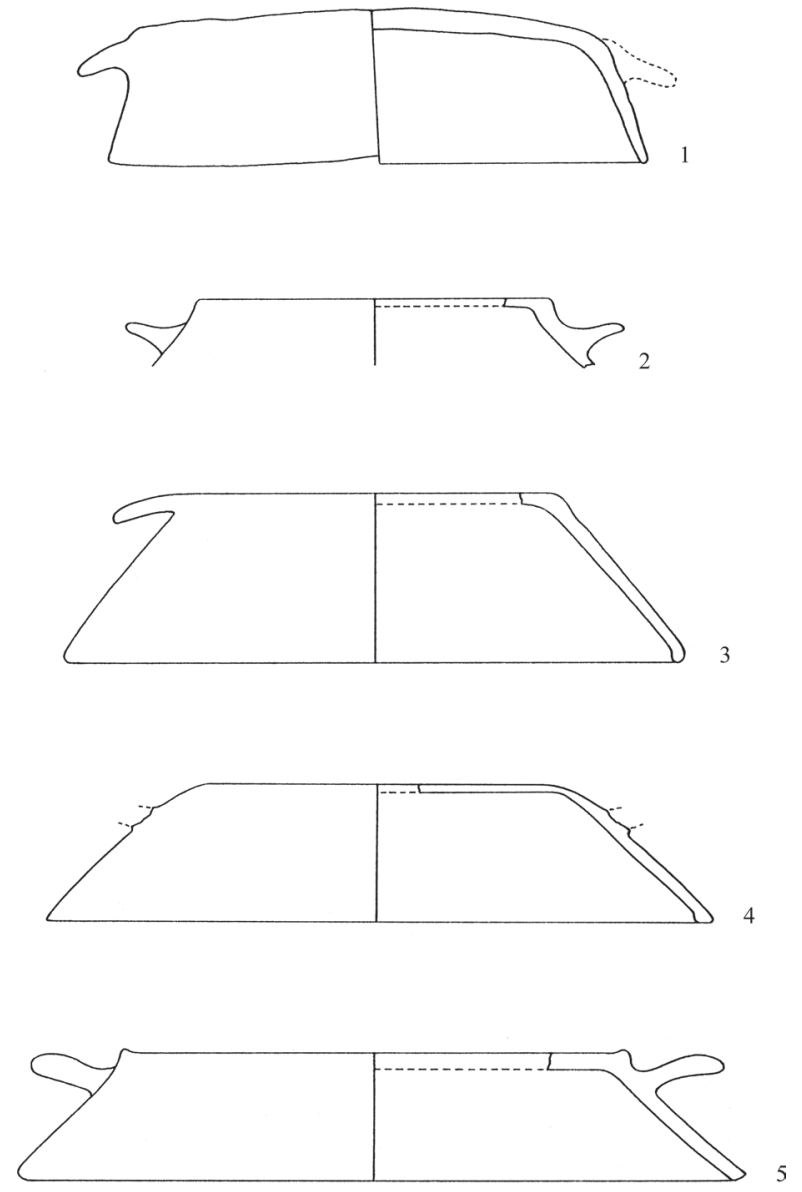

Abb. 5. Eisenzeit. 1, 5: Col de Flam III (nach LuNZ 1981); 2: Castel Sottosengia, Fumane (nach SALZANI 1981);

3: Fai della Paganella-Doss Castel (nach Marzatico 1992); 4. Sarntheim-Toldtanger (nach NIEDERWANGER 1984) 
Torrionaccio (Viterbo), Latium

Deckel (Backglockenhenkel?) aus einer Protovillanova-Siedlung Lit.: S. CASSANO-A. MANFREdI: Torrionaccio IV. (Viterbo). Scavo di un abitato protoistorico. Atti della Accademia Nazionale dei Lincei Notize degli scavi di Antichità 32 (1978 [1979]) 182; 204, Fig. 25.847-849; 214, Abb. 13

Ung a r n

\section{Regöly-Földvár}

Backglocke auf dem Fußboden eines Wohnhauses, mit auf die Urnenfelderkultur hinweisenden Fundstücken (Hallstatt B). D: $30 \mathrm{~cm}$.

Lit.: Unveröffentlicht. Ausgrabung von E. Jerem, 1970; G. T. NÉMETH: A regölyi földvár késő bronzkori periódusa [Die spätbronzezeitliche Periode der Erdburg von Regöly]. Magisterarbeit. Manuskript. Eötvös Loránd Tudományegyetem, Budapest 1989, 148, T. XXXII.1. ${ }^{283}$

Komitat Tolna, unbekannter Fundort

Drei handgeformte Backglockenhenkel. Hallstatt.

Lit: : unveröffentlichte Funde im Wosinsky Mór Museum, Szekszárd (Inv.-Nr. 59.150.1, 59.152.1, 59.158.1)

\section{Eisenzeit}

Bosnie n

Donja Dolina (Abb. 4.1-2)

Backglocken mit oberem Griff. H: $14 \mathrm{~cm}$, D: $42 \mathrm{~cm}$. 6.-3. Jh. v. Chr. Lit.: TruHELKA 1904, 34-35, Taf. XXXV, Fig. 1.2; ČURČIĆ 1913, 45; MAURIZIO 1926, 310

Kroatien

Darda

Backglockenhenkel

Lit.: K. MinichreITER: Arheološko blago Baranje. Anali Zavoda Jugoslav. Akad (Osijek) 5 (1987) 78, Sl. 32.

Griechen 1 and

Athen-Agora, spätarchaische Zeit, 520-490 n. Chr. (Abb. 29.1) Glockenförmige Backglocke mit oberem Rundstabhenkel. D: $29,5 \mathrm{~cm}$. Lit.: SPARKES-TALCOTT 1970, 233, 377, Pl. 97, Nr. 2021. Athen-Agora, klassische Zeit, 420-400 n. Chr. (Abb. 29.2) Glockenförmige Backglocke mit oberem Rundstabhenkel. D: $22 \mathrm{~cm}$. Lit.: SPARKES-TALCOTT 1970, 233, 377, Pl. 97, Nr. 2022.

${ }^{283}$ Ich bedanke mich bei Gabriella T. Németh, dass ich das Manuskript und die Daten ihrer unpublizierten Magisterarbeit hier verwenden durfte.
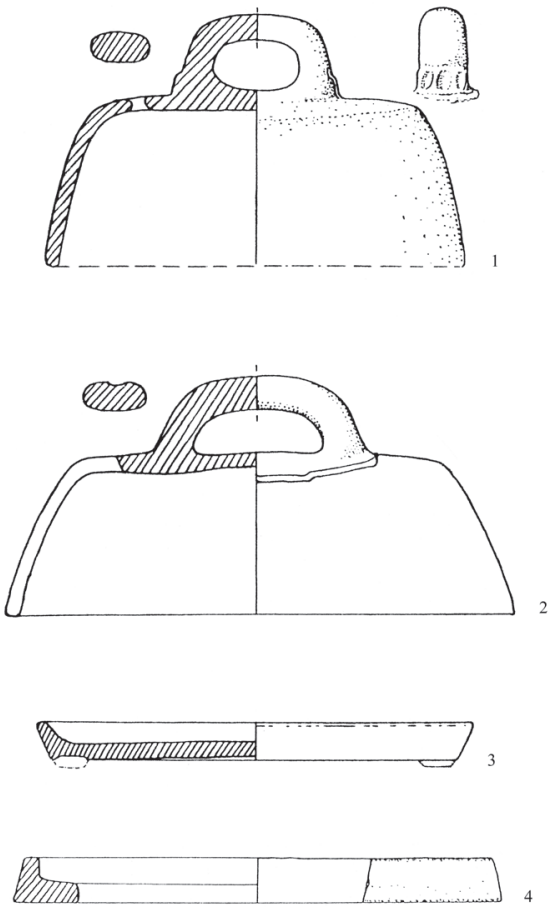

Abb. 6. Hallstattzeit. Stična, Schnitt IV (nach GABRovEC et al. 1970)
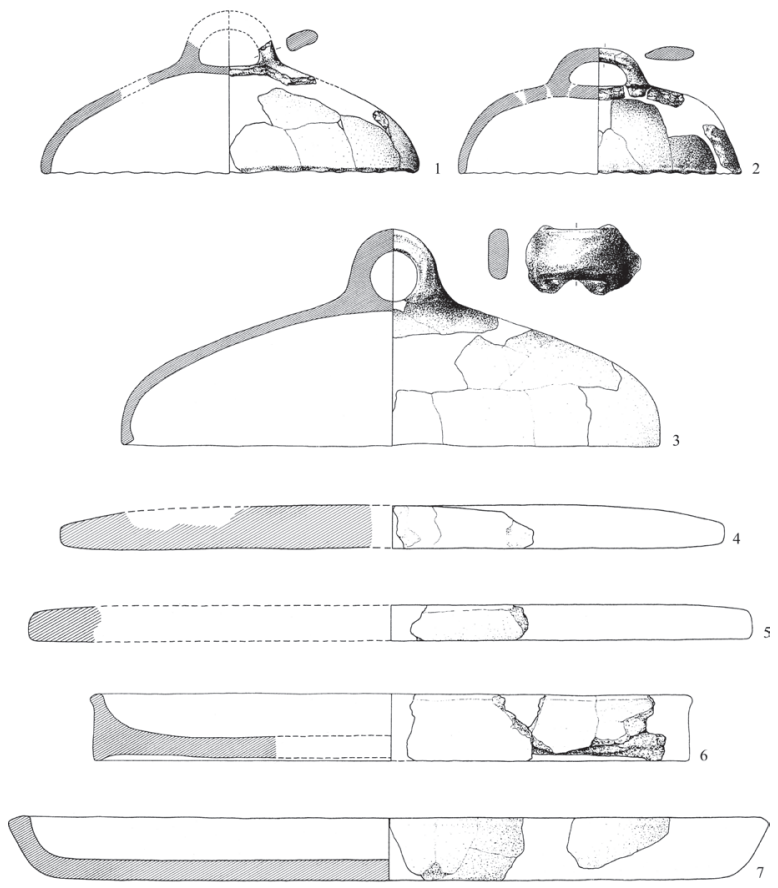

Abb. 7. Hallstattzeit. Heuneburg, Periode I-IV (nach Boom 1989) 
It a 1 i e $n$

Ardea, Etrurien

Lit.: SESTIERI 1976, Taf. IV.B3.

Murlo (Poggio Civitate) (Abb. 2.1-3, 5; Abb. 30-31)

Fragmente von vier handgeformten Backglocken mit oberem Griff. D: $19,5 \mathrm{~cm} ; 21,4 \mathrm{~cm} ; 32,0 \mathrm{~cm} ; 36,5 \mathrm{~cm}$.

Lit.: Bouloumié 1978, 125, Pl. III.

Colli Albani, Villa Cavaletti

Backdeckel (?). H: 10,5 cm, D: 19,0 cm.

Lit.: SESTIERI 1976, Taf. II.Ac.

\section{Modena-Tabina di Margareta}

Deckel mit oberem Griff. D: 22,2 cm. 6. Jh. v. Chr.

Lit.: L. MaLnATI: L'affermatione etrusca nel Modenese a l'organizzazione del territorio. In: A. Cardelli et al. (a cura di): Modena dalle origini all'anno mille studi di archeologia e storia I. Modena 1989, 141, Fig. 96.1.

De ut s ch land

Heuneburg ( $A b b .7)$

Gehenkelte, handgeformte Backhauben mit Backschüsseln und Backplatten. Hallstatt D. D: $20-30 \mathrm{~cm}$.

Lit.: Boom 1989, Taf. 33-43, Nr. 387-514.

Ung a r n

Dunaszekcső-Várhegy

Backglocke. D: $38,5 \mathrm{~cm}, \mathrm{H}: 25 \mathrm{~cm}$.

Lit.: RŐMER 1966, 410-411, Abb. 14.

S low en i e n

Stična, Schnitt IV (Abb. 6.1)

Backhaube. D: $28,8 \mathrm{~cm}$. Hallstatt C-D.

Lit.: GABRovec et al. 1970, 22, Abb. 4.13; Backschüssel: ebd. 23, Abb. 5.2.

Stična, Schnitt IV (Abb. 6.2)

Backhaube. D: $31,2 \mathrm{~cm}$. Hallstatt C-D.

Lit.: GABRovec et al. 1970, 27, Abb. 7.1; Backdeckel: ebd. Abb. 7.2.

\section{Sv. Petar bei Ludbreg}

Die Backglocke wurde von K. Vinski-Gasparini in die Stufe Hallstatt $\mathrm{C}$ datiert.

Lit.: RŐMER 1966, 394-395, Abb. 5; VINSKI-GASPARINI 1973, 66-67.
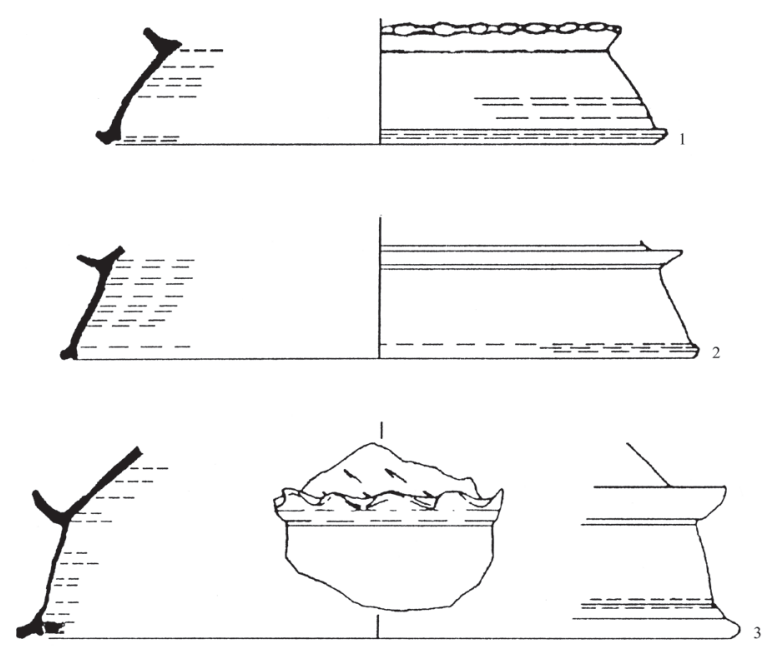

Abb. 8. Römische Republikzeit.

1-3: Molise (nach CubBerLey 1995)
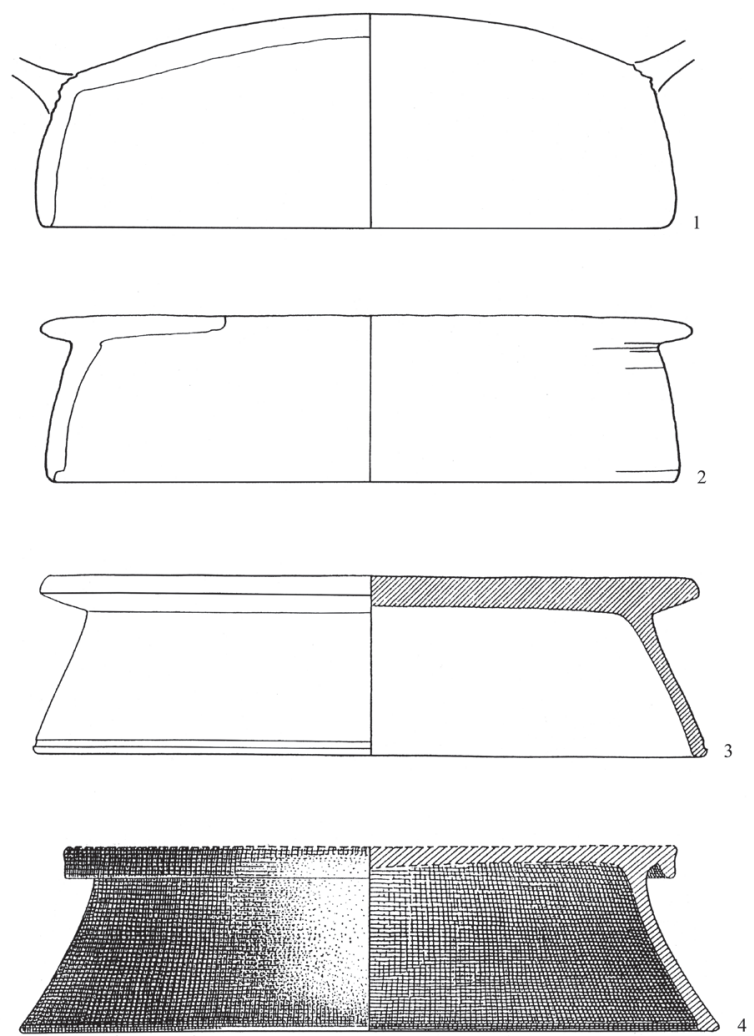

Abb. 9. Frühe römische Kaiserzeit. 1-2: Frankfurt-Domhügel (nach WAHL 1982); 3: Xanten-Fürstenberg (nach Hagen 1912); 4: Neuss/Novaesium-Ost-Eternit (nach BRUCKNER 1975) 
Slowenien, unbekannter Fundort

Lit.: J. DulaR: Hallštatska keramik v Sloveniji (Die Gräberkeramik der älteren Eisenzeit in Slowenien). Ljubljana 1982, 13, Abb. 1.23.

\section{La Tène-Zeit}

I t a 1 i e n, Ös ter re i c h, S c h we i z

S. Pietro Cariano, Archi di Castelrotto, Prov. Verona

Konische hohe und niedrige Lappenschüsseln, beide mit symmetrisch angelegten oberen Griffen. D: $22 \mathrm{~cm} ; 24 \mathrm{~cm}$.

Lit.: SAlZANi 1982, 395, Abb. 23.4, 7; GLeIRSCHER 1987, 206, Abb. 7.5.

Birgitz-Hohe Birga

Lit.: GLEIRSCHER 1987, 348, Abb. 64.17.

Buenland

Lit.: LUNZ 1981, 24

Castel Sottosenga (Fumane) (Abb. 5.2)

Lappendeckel. D: $19,5 \mathrm{~cm}$. Späte Eisenzeit.

Lit.: L. SALZANI: Preistoria in Valpolicella. Verona 1981, 100-102, Abb. 13.

Col di Flam III (Abb. 5.1, 5.5)

Zwei Lappendeckel, der eine kann ergänzt werden. D: $42 \mathrm{~cm}$.

Lit.: Lunz 1981, Taf. 99.3, Taf. 125.1-2; RodRIGUEZ 1986, Abb. 38.1.

Fai della Paganella-Doss Castel (Abb. 5.3)

Backdeckel (Lappenschüssel) mit zwei Seitenlappen. D: $24 \mathrm{~cm}$.

Lit.: MarZATICO 1992, 219, Fig. 3.4.

Ganglegg

Lit.: LuNZ 1981, 24.

Gronnsberg

Lit.: LuNZ 1981, 24.

Mazzin-Doss dei Pigui

Lappendeckelfragment mit Griff.

Lit.: LuNZ 1983, Abb. 3.11.

Moarbühel Kiens

Lit.: LuNZ 1981, 24

Ochsenbühel Aicha

Lit.: LUNZ 1981, 24

Pfatten/Vadena

Lit.: GLEIRSCHER 1987, 221.
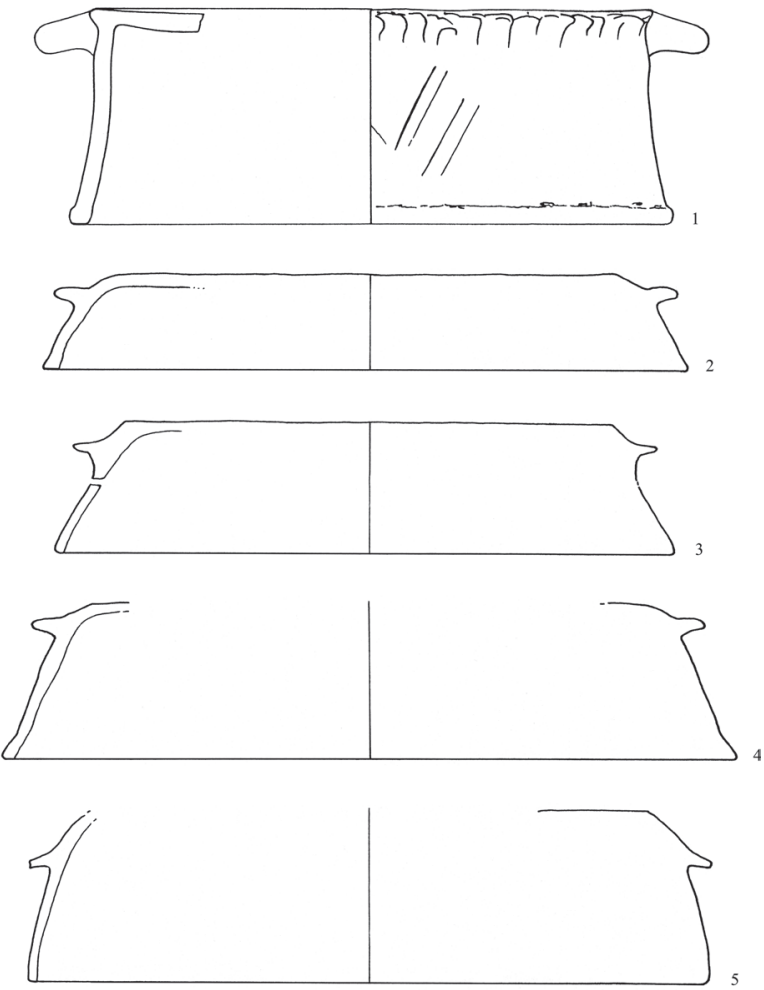

Abb. 10. Römische Kaiserzeit.

1: Rödgen (nach ScHÖNBERGER 1976); 2-4: Nave (nach JORIO 1987)
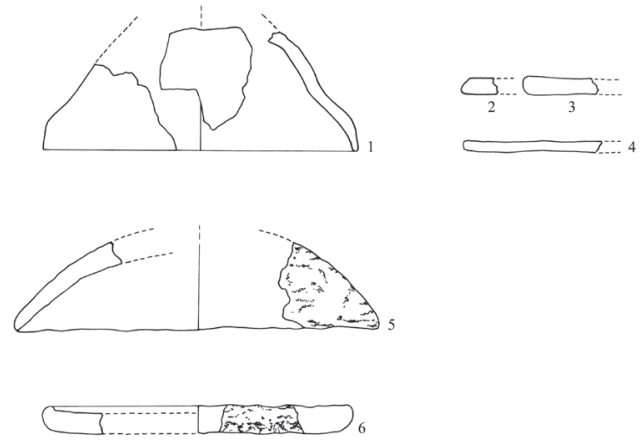

Can-

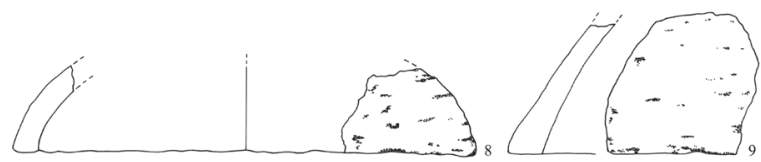

Abb. 11. Kaiserzeitlich-barbarisch. 1-4: Berezovka (nach OBLOMSKIJ 1994); Frühmittelalter.

5-7: Küllőd/Kolut-Baćan (nach TRIFUNOvić 2000); 8-9: Padé/Padej-Višnjevača (nach TRIFunOvić 2000)

Acta Archaeologica Academiae Scientiarum Hungaricae 67, 2016 
Sarnthein-Pregwies

Lit. : LuNZ 1981, 24

Sarnthein-Toldtanger (Abb. 5.4)

Lappendeckel. D: $32 \mathrm{~cm}$.

Lit.: G. NIEDERWANGER: Ur- und Frühgeschichte des Sarntales. Archäologisch-historische Forschungen in Tirol 8. Trento 1984, Taf. 80.1.

Scoul-Munt-Baselgia

Handgeformter Lappendeckel. D: $25 \mathrm{~cm}$.

Lit.: Stauffer-Isenring 1983, Taf. 46.467; L. Stauffer-M. MoGETTI-CH. MARRO: Formenwandel und Produktion der alpinen Laugeren Keramik. Archäologie der Schweiz 2 (1979) 132, Abb. 3.6.

St. Cyrill

Lit.: LUNZ 1981, 24.

Bressanone-Stufles

Lappendeckelfragmente

Lit.: DAL-RÍ-PIVA 1986, Taf. VIII: D10, B59, 60, 94, 107, 118, 175, 199.

Sonnenburger-Weinhite

Lit.: LuNZ 1981, 24

\section{Tarrenz}

Lit.: GLEIRSCHER 1987, 221

Telfes

Lit.: KALTENHAUSER 1978, Taf. 16.8-10.

\section{Römische Republik- und Kaiserzeit}

Eng 1 a n d

Castor bei Peterborough

Lit.: J. R. PERrin-G. WebSTER: Roman Pottery from Excavations in Normangate Field, Castor, Peterborough 1962-1963. Journal of Roman Pottery Studies (Oxford) 3 (1990) 35-62.

Catterick

Lit.: WiLLIAMS-EVANS 1991, 51-55.

I t a 1 i e $n$

Siehe die Fundliste und die Verbreitungskarte bei CUBBERLEY et al. 1988, 112-113, Fig. 3 mit den Daten der Backdeckel aus 30 italienischen Fundorten aus der Republik- und Kaiserzeit.

Cosa

Backdeckel. D: $20 \mathrm{~cm}$.
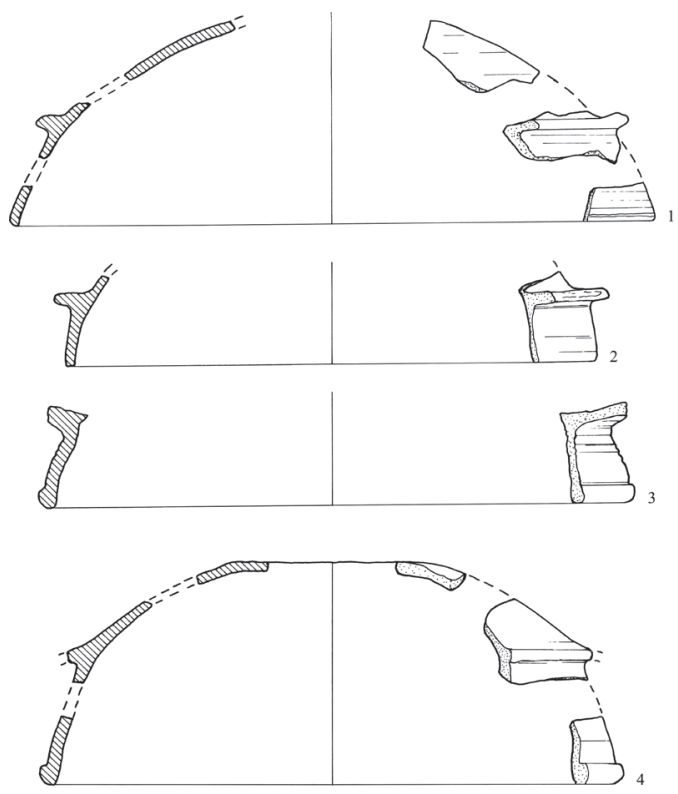

Abb. 12. Spätantike. 1-4: Milano (nach SCAVI MM3 1991)
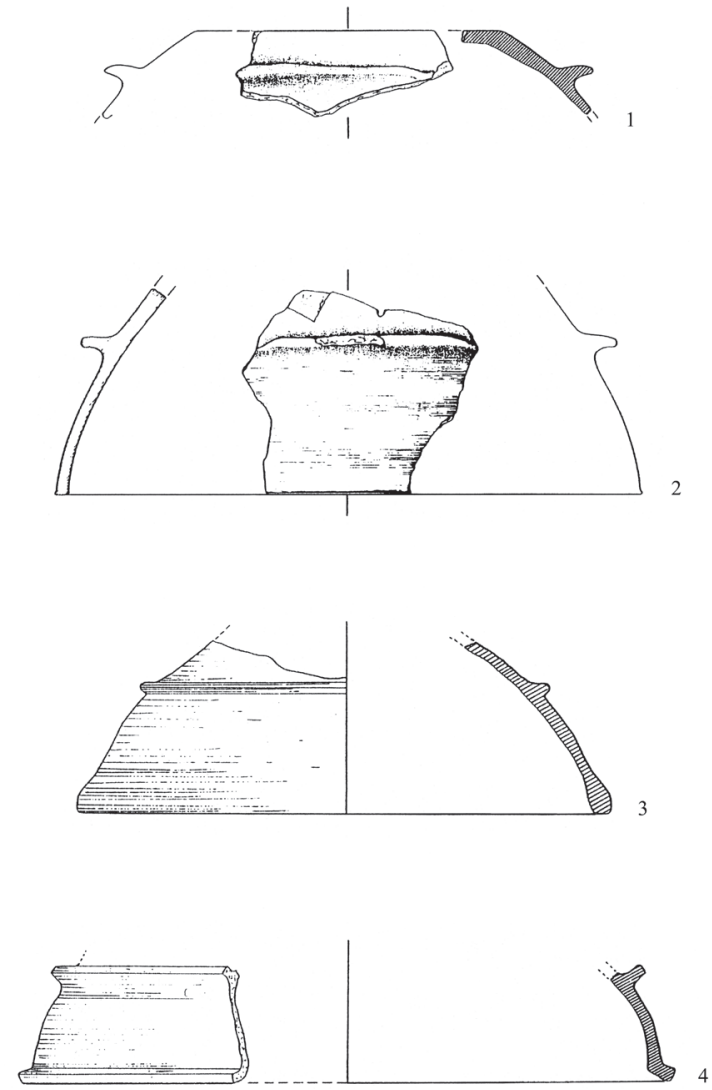

Abb. 13. Spätantike, Frühmittelalter.

1-3: Ravenna Classe (nach Brogiolo-GeLICHI 1986); 4: Brescia-Via Alberto Mario (nach PANAZZA-Brogiolo 1988) 
Lit.: S. L. Dyson: Cosa - the utilitarian pottery. Memoirs of the American Academy at Rome 33 (1976); CUBBERLEY 1995, 58.

Matrice

Backdeckel. D: $50 \mathrm{~cm}$

Lit.: J. A. LLOYD-D. W. RATHBone: La villa romana at Matrice. Conoscenze 1 (1985) 216-219.

Molise (Abb. 8.1-3)

Backdeckel mit Seitenkragen. D: $36-45 \mathrm{~cm}$.

Lit.: CuBberley 1995, 57, Fig. 5.

Nave, Grab 5, 9, 25, 27 (Abb. 10.2-4)

Große Backdeckel. D: 50-60 cm.

Lit.: JORIO 1987, 206, Abb. 37.1-4.

Tiers/Tires Grab 40, Südtirol

Backdeckel mit Seitenlappen. D: 23,8 cm. Kaiserzeitlich.

Lit.: G. RosADA-L. DAL Rí (a cura di): Tires e Aica. Necropola di Epoca romana. Materiali di Archeologia. Verona 1984, 121, Taf. 31.835; RoDRIGUEZ 1986, Abb. 38.2.

Torino-Vaude

Backdeckel. D: 36-54 cm.

Lit.: M. T. SARDo: Per pagos vicosque. In: G. C. Marrone-E. C. Gastaldi (a cura di): Torino Romana fra Orco e Stura. Torino 1985, 160, Tav. 5.38.

\section{Settefinestre}

Backdeckel. D: $20 \mathrm{~cm}$

Lit.: A. RICCI: Settefinestre III - la villa e i suoi reperti. In: A. Carandini (ed.): Settefinestre - una villa schiavistica nell'Emilia Romagna 3. Modena 1985, 246.

Deutschland

Frankfurt-Domhügel G146 (Abb. 9.1)

Backdeckel. D: $36,0 \mathrm{~cm}$

Lit.: WAHL 1982, 190-191, Taf. 33.

Frankfurt-Domhügel G147 (Abb. 9.2)

Stürze, als Backdeckel verwendet. D: $34,5 \mathrm{~cm}$

Lit.: WAHL 1982, 190-191, Taf. 33.

Neuss/Novaesium-Ost-Eternit ( $A b b$. 9.4)

Stürze, als Backdeckel verwendet. D: $29,6 \mathrm{~cm}$.

Lit.: BRUCKNER 1975, 92-93, Taf. 45.11.

Rödgen ( $A b b$. 10.1)

Stürze, als Backdeckel verwendet. D: $37,2 \mathrm{~cm}$

Lit.: SCHÖNBERGER 1976, Taf. 30.860; WAHL 1982, 191.
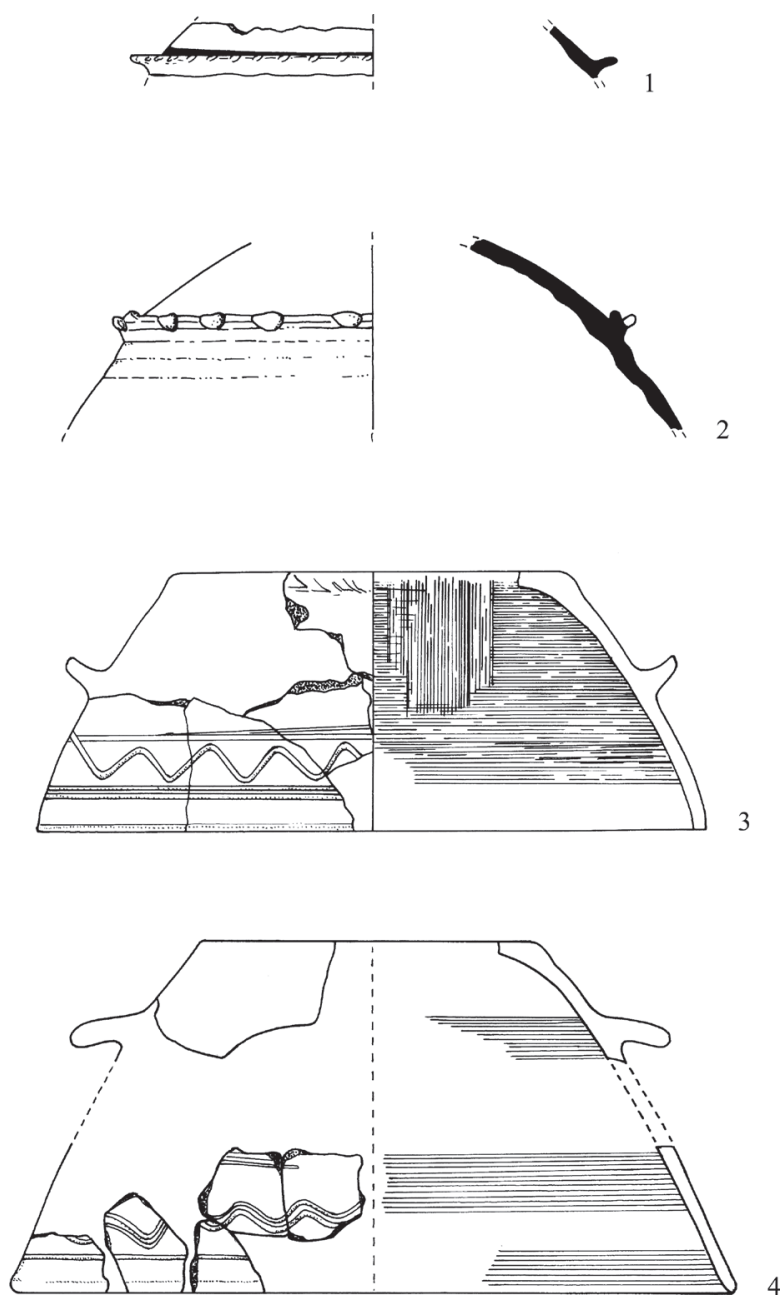

Abb. 14. Spätantike. 1-2: Ras (nach Popović 1999); 3-4: Teurnia-Bischofskirche,

St. Peter in Holz bei Spittal an der Drau (nach RodRIGUEZ 1997) 
Xanten-Fürstenberg (Abb. 9.3)

Backdeckel mit Kragengriff. D: 38,4 cm.

Lit.: Hagen 1912, 343-362, Taf. 53.3.

Ös terreich

Aguntum

Kaiserzeitlich

Lit.: RoDRIGUEZ 1986, 312

Lavant Kirchbichl

Kaiserzeitlich spätrömisch

Lit. : RodRIGUEZ 1986, Abb. 38.3.

R u s s 1 a n d

Berezovka 2 (Abb. 11.1-4)

Fragmente von glockenförmigen Backglocken oder Backschüsseln ohne Henkel oder Griff.

Lit.: OBLOMSKIJ 1994, 44, Ris. 2.15.

Spätantike, frühbyzantinische Zeit (5.-7. Jahrhundert)

T ü rke i

Anemurium (Eski Anamur)

Lit.: C. Williams: The Roman and Early Byzantine Pottery. Subsidia Mediaevalia 16. Pontifical Institut of Medieval Studies. Wetteren 1989, 73-74, Fig. 40, Nr. 32.

Ephesos (Abb. 16.1-2)

In den frühbyzantinischen Schichten in Ephesos kommen zahlreiche gewölbte, glockenförmige Gefäße, Deckel, vor, die einst zum Brotbacken geeignet waren.

Lit.: Unpubliziert. Freundliche Mitteilung von Sabine Ladstätter, Wien.

\section{A 1 b anien}

Onhezmit/Onhezmos (Abb. 15.1; Abb. 32.3)

Nicht getöpferte Backglocke mit oberem Henkel mit Seitenkragen. D: $30 \mathrm{~cm}$.

Lit.: LAKO 1984, 184, Fig. 30, Taf. VII.7-9.
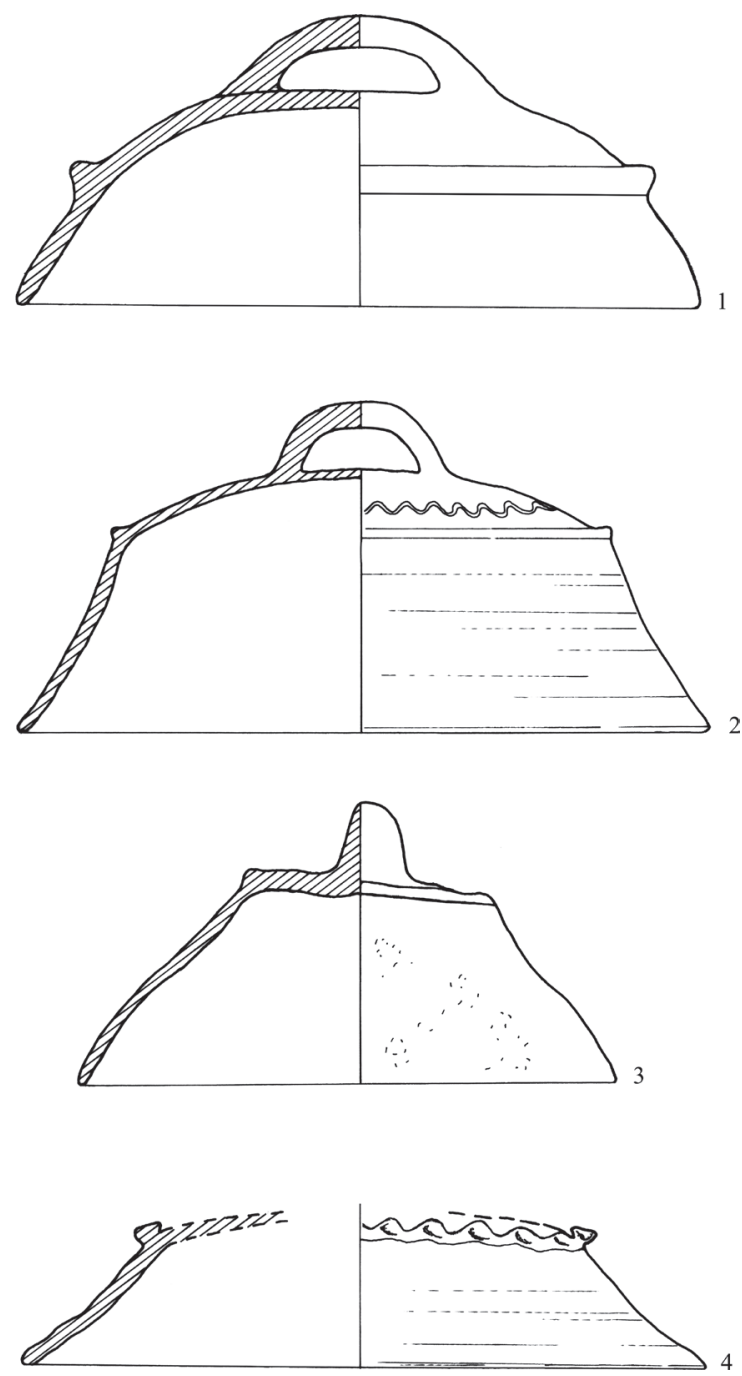

Abb. 15. Frühbyzantinisch. 1: Onhezmit/Onhezmos (nach LaKo 1987); 2-4: Čaričin Grad/Iustiniana Prima (nach BJELAJAC 1990) 
Österreich

Duel bei Festritz an der Drau

Außen rot, graubraun, innen braun, grau, rotbraun gefleckt, feine bis grobe mitteldichte Magerung. Oberfläche porös. D: $40 \mathrm{~cm}$.

Lit.: U. Steinklauber: Keramik vom Duel bei Festritz an der Drau. Archaeologia Austriaca 68 (1984) 343-345, Abb. 3.8.

Duel bei Festritz an der Drau

Lit.: STEINKLAUBER 1990, 117, 131, Abb. 19.1-2; 132, Abb. 20.

Hemmaberg, aus dem Areal der westlichen doppelten Kirche ( $A b b$ 18.4

Lappendeckel mit Verzierung. D: $28 \mathrm{~cm}$.

Lit.: SCHRETTER 1997, 56, 59, Abb. 7.

St. Peter in Holz bei Spittal a. d. Drau/Teurnia-Bischofskirche ${ }^{284}$ (Abb. 18.3, 5; Abb. 14.3-4)

Backdeckel mit Seitenlappengriff. D: $26,4 \mathrm{~cm} ; 28,6 \mathrm{~cm}$.

Lit.: H. RoDRIGUEZ: Keramikbeispiele aus der Grabungskampagne 1989 in Teurnia im Areal der Bischofskirche und ihrer Nebengebäude. Carinthia I 180/100 (1990), Taf. 2.16; RodrigueZ 1992, 171, Taf. 5.3-4; RodRIGUEZ 1997, Taf. 4.32, 36

Kroatie n

Betiga kod Barbarige / Bettica presso Barbariga (Abb. 18.1)

Backdeckel mit Wellenlinienband unten rund herum, mit oberem Lappengriff. H: $13 \mathrm{~cm}$; D: $33,0 \mathrm{~cm}$. 4.-6. Jh.

Lit.: JuRoš-MonfARDin 1986, 223-226, 227, Tab. I.1.

Brioni-Castrum (Abb. 32.2)

Lit.: MARUŠIĆ 1986, 83, 88, Fig 7.1.

Koper/Capodistria (Abb. 18.2)

Backdeckel mit Seitenlappen. D: $36 \mathrm{~cm}, \mathrm{H}: 17,3 \mathrm{~cm}$.

Lit.: R. CUNJA: Archeologia urbana in Slovenia: alcuni risultati e considerazioni dagli scavi di Capodistria. Archeologia Medievale 25 (1998) 209, Tav. I.15; Gustin-CunJA 1989, 29, Kat.-Nr. 25.

Nezakcija/Nesactium

Backdeckelfragmente mit Backschüsseln

Lit.: B. MARUŠIĆ: Prilog poznavanja kasnoantičkog Nezakcija (Beitrag zur Kenntnis des spätantiken Nesactium). Starohrvatska prosvjeta 16 (1986 [1987]) 74, S1. 11.3-4, B

${ }^{284}$ Ich bedanke mich bei Franz Glaser (Klagenfurt) für seine Daten und seine Hilfe.
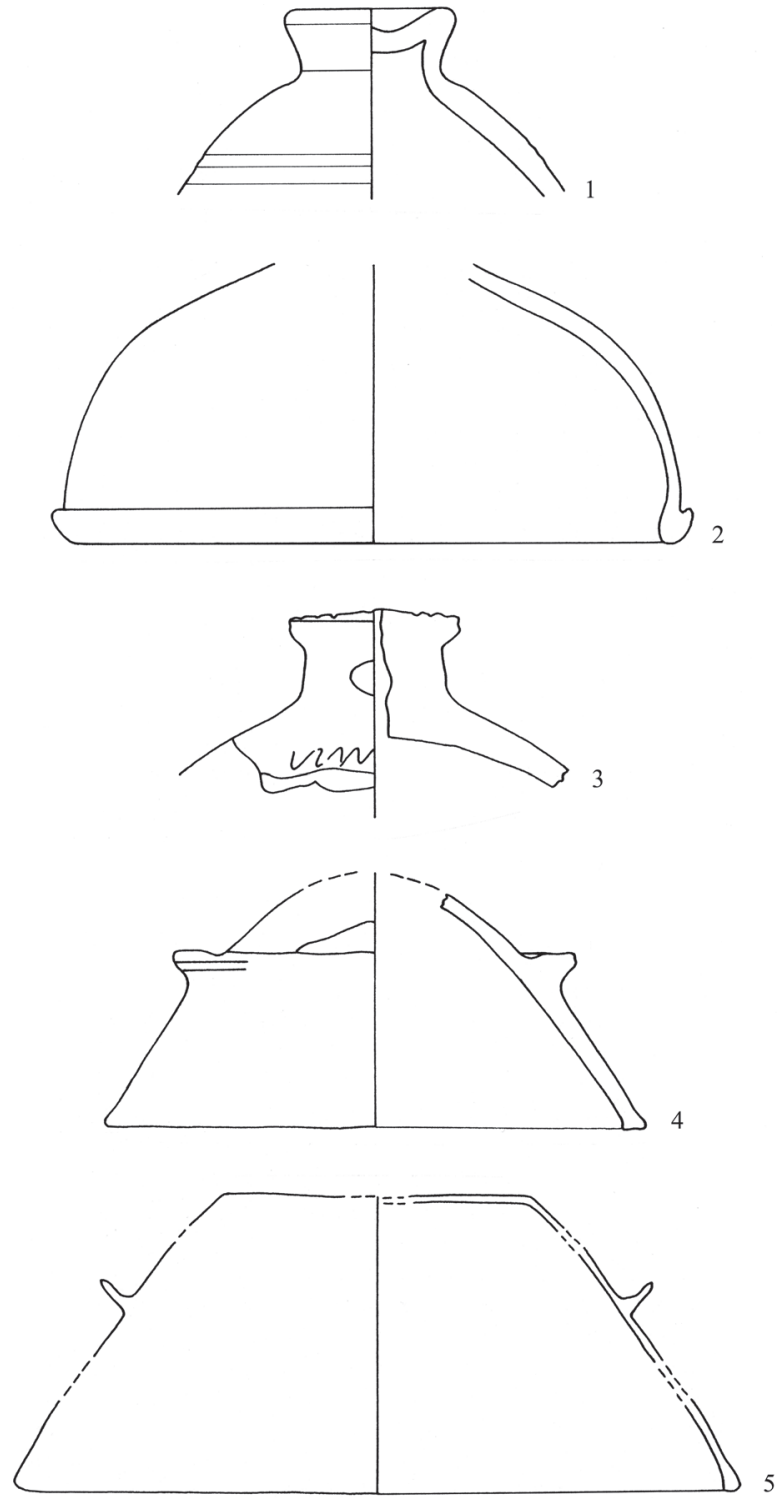

Abb. 16. Frühbyzantinisch. 1-2: Ephesos (nach S. Ladstätter) 3: Sip (nach JANKOVIĆ 1981); 4: Kovilovo-Grad (nach JANKOVIĆ 1981); 5: Svač (nach ZEČEVIĆ 1989) 
It a $l$ i e $n$

\section{Brescia-S. Giulia}

Backdeckel mit Kragen. D: 42,0 cm; 34,0 cm; 30,2 cm.

Lit.: G. P. BRogiolo-L. CASTElletti (a cura di): Insediamenti fortificati e contesti stratigrafici tardoromani e altomedievali nell'area Alpina e Padana. Como 1990, Tav. II.115.

Brescia-Via Alberto Mario (Abb. 13.4)

Backdeckel mit Seitenkragen. D: $27 \mathrm{~cm} ; 33 \mathrm{~cm}$.

Lit.: PANAZZA-Brogiolo 1988, Tav. XVI.8-9.

Castelseprio (?)

Dichtwandige Schüssel mit Seitenlappen. D: c. 32 cm. 4. (?)-6. Jh.

Lit.: S. L. Siena-M. SANNAZARO: Castelseprio (VA). In: La ceramica 1992, Abb. 1.15.

\section{Castelseprio e Torba}

Lappendeckel mit Seitenkragen, 5.-6. Jh.

Lit.: G. P. Brogiolo-S. Lusuardi SiENA: Nouve Indogini Archeologiche a Castelseprio. Milano 1980, Fig. 14.3.

\section{Finale, Finalmarina}

Backdeckelfragment mit Seitenkragen. D: 22,5 cm.

Lit.: G. MURIALDO: Liguria: La ceramica a vetrina pesante nel Finale. In: La ceramica 1992, 78, Abb. 1.3

Galbiate, Monte Barro

Lit.: G. P. Brogiolo-L. CASTelletti: Galbiate, Monte Barro. In: Notizario 1988, 81-83, Abb. 75.

Lago di Ledro bei Riva del Garda (Abb. 17)

Lappendeckel aus gut bearbeitetem Material. D: 27-37 cm.

Lit.: DAL Rí-PIVA 1987, Fig. XXI.1-8, Fig. XLI.1-5.

Mantova-Pieve di Coriano

Lit. : BRoGiolo-Gelichi 1986, 301, Fig. 4.a-e.

Milano (Abb. 12)

Backdeckel. D: $35-41 \mathrm{~cm}$

Lit.: D. CAPRUSSO (a cura di): Scavi MM3. Ricerche di archeologia urbana a Milano durante la costruzione della linea 3 della metropolitana 1982-1990. 4. I riperti. Tavole. Milano 1991, T. CVIII.1-4, 6-10; T. CVII.1, 11-13.

Monte Barro

Backdeckel. D: 26-55 cm.

Lit.: I. NoBiLE: Ceramica grezza. In: G. P. Brogiolo-L. Castelletti (a cura di): Archeologia a Monte Barro I. Il grande edificio e le torri. Lecco 1991, 63-76, Tav. XLIII-XLII, LIX.
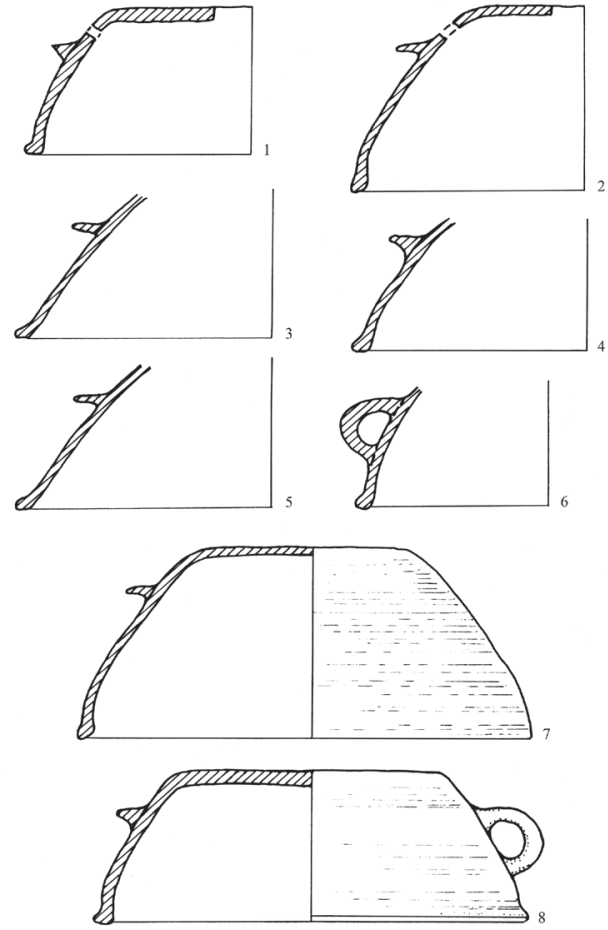

Abb. 17. Spätantike. 1-8: Lago di Ledro B (nach DAL Rí-Piva 1987)
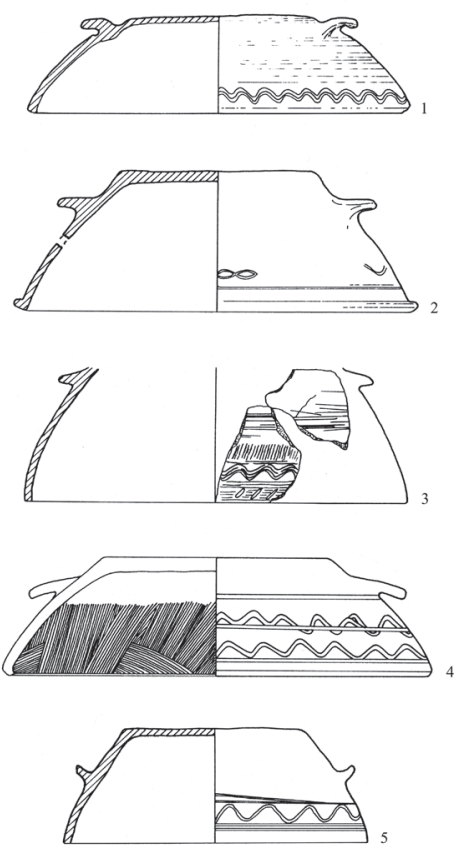

Abb. 18. Spätantike. 1: Betiga kod Barbarige/Bettica presso Barbariga (nach JUROŠ-MONFARDIN 1986); 2: Koper/Capodistria (nach Gustin 1984); 3, 5: Teurnia-Bischofskirche,

St. Peter in Holz bei Spittal a. d. Drau (nach Rodriguez 1992); 4: Hemmaberg (nach SCHRETTER 1997) 
San Vicenzo al Volturno, Colle Castellano Backdeckelfragment

Lit.: R. Hodges-H. PATTERSON: San Vicenzo al Volturno and the Origins of the Medieval Pottery Industry in Italy. In: La ceramica medievale nel Mediterraneo Occidentale. Atti del III. Congresso Internationale Siena-Faenza, 8-13 ottobre 1984. Firenze 1986, 20, Abb. 5.20.

Sesto Calende, loc. Bellaria (Varese)

Lit.: V. MariotTI-A. RozZI. In: Notizario 1988, 74-76, Abb. 69/St. $557-559$.

Ravenna-Classe (Abb. 13.1-3)

Backglockenfragmente mit Seitenkragen. D: $30 \mathrm{~cm}$.

Lit: Brogiolo-Gelichi 1986, 298, Tav. III.3.5.

S e r b i e $n$

Kovilovo-Grad (Abb. 16.4)

Backglocke mit kleinem Wulsthenkel. H: $10 \mathrm{~cm}$, D: 23,1 cm. Datierung nach 585/586.

Lit.: JANKOVIĆ 1981, 146, Fig. 60.B.

Čaričin Grad / Iustiniana Prima (Abb. 15.2; $A b b .32 .1)$

D: $22,5 \mathrm{~cm} .6 . / 7 . \mathrm{Jh}$

Lit.: BJElaJAC 1990, 182, Fig. 139, Pl. XII, Type IX, Pl. XXI.11.

Čaričin Grad / Iustiniana Prima ( $A b b$. 15.3)

D: $29,1 \mathrm{~cm} .6 . / 7 . \mathrm{Jh}$

Lit.: BJelajaC 1990, 182, Pl. XII, Type IX.1, Pl. XXI.10.

Čaričin Grad / Iustiniana Prima (Abb. 15.4)

D: $28,8 \mathrm{~cm} .6 . / 7 . \mathrm{Jh}$

Lit.: BJElaJAC 1990, 182, Type IX.2, Pl. XXI.12.

Ras-Podgrađe (Abb. 14.1-2)

Backglocke, plastischer Seitenkragen. 6. Jh.

Lit.: PoPOVIĆ 1999, 90, 106, 313, Abb. 41.2-3, Abb. 54.14-15.

Sip (Abb. 16.3)

Der obere Teil einer Backglocke mit dem runden Randlappen mit einem Loch. Nach 585/586.

Lit.: JANKOVIĆ 1981, 146, Fig. 60.A.

Svač (Abb. 16.5)

Scheibengedrehte und handgeformte Backdeckel. 1. H: 13,5 cm, D:

$33 \mathrm{~cm} ; 2 . \mathrm{D}: 43 \mathrm{~cm}$.

Lit. : ZEČEVIĆ 1989, 115, T. II.5.
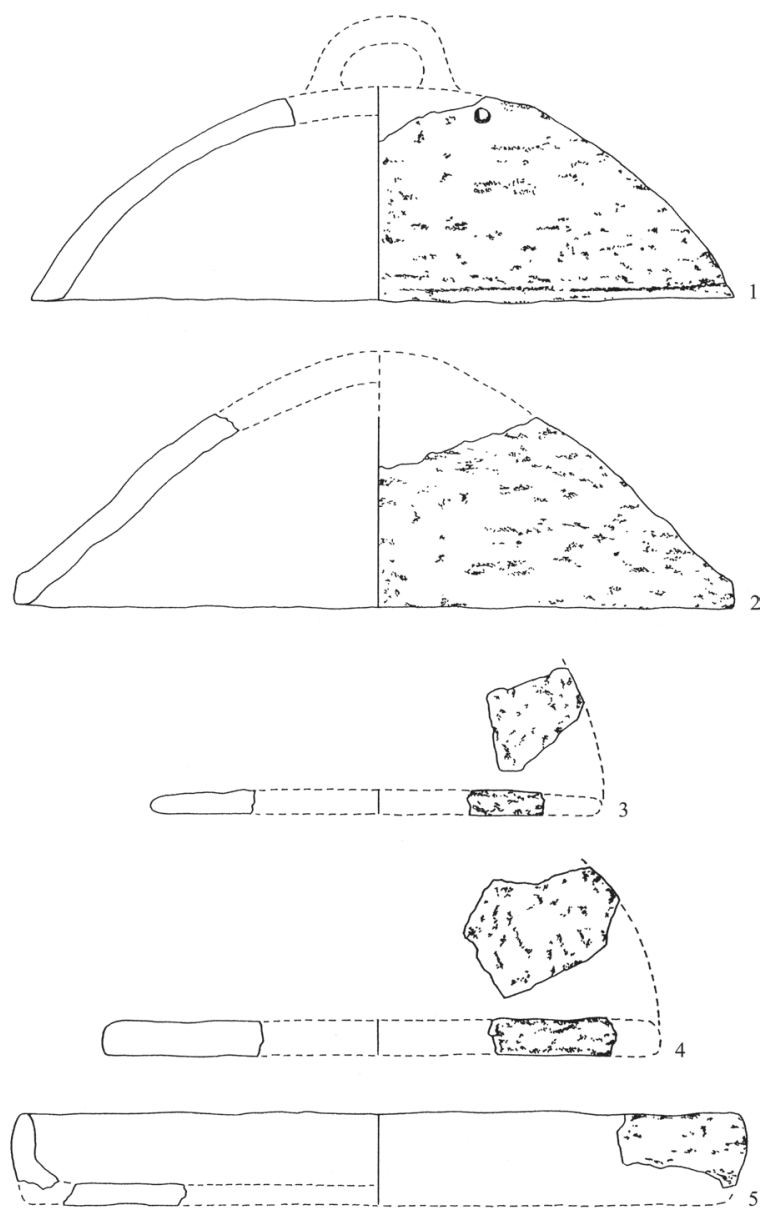

Abb. 19. Frühmittelalter.

1-5: Horgoš/Horgos (nach TRIFUNOVIĆ 2000) 
Frühmittelalter (7.-9. Jahrhundert)

Awarenzeit und 9. Jahrhundert im Karpatenbecken

(7.-9. Jahrhundert n. Chr.)

Balatonmagyaród-Hídvégpuszta

Fragmente einer rekonstruierbaren Backglocke. Auf Grund von Fundvergesellschaftung ins 9. Jh. zu datieren.

Lit.: Unveröffentlicht. Freundliche Mitteilung von Béla Miklós Szőke, 2000 (Budapest).

Bečej/Óbecse-Botra

Lit.: StAnOJEvić 1987, 125, Abb. 9.1-2; 141, Taf. X.2; FiEDLER 1994, Abb. 7.6; STANOJEVIĆ 1996, 3/7.

Belgrad

Backglockenfragmente. 9. Jh.

Lit.: M. JANKOVIć: Beograd i negova okolina od IX do XI veka. In: V. V. Sedov (Hrsg.): Problemy slavjanskoj archeologii. Trudy VI Meždunarodnogo Kongressa Slavjanskoj Archeologii 1. Moskva 1997, 42-52, 44, S1. 2a.

Bratislava-Devínská Nová Ves / Pozsony-Dévényújfalu Backteller

Lit.: L. KRASKovsKá: Slovanské sídlisko pri Devínskom Jazere. Slovenská Archeológia 9 (1961) 401, Abb. 12; ZÁBOJNíK 1988, 423, Abb. 19.3; 426, Abb. 21.4.

Budapest-Filatorigát-Baumax

Henkel- und Randfragmente mehrerer Backglocken

Lit. : Ausgrabung von P. Zsidi. L. SchILling: Avar kori telep BudapestFilatorigát lelőhelyen [Awarenzeitliche Siedlung am Fundort Budapest-Filatorigát]. Magisterarbeit, Eötvös Loránd Tudományegyetem. Budapest 2003.

Čelarevo/Dunacséb-Ciglana, Objekt 1

Backglockenfragment mit Backplattenfragment

Lit.: BunardŽıć 1985, Abb. 9; STANojević 1987, 125, Abb. 9.2; FieDLER 1994, 322, 338, Abb. 6.10; Backplatte: Abb. 6.9.

Darnózseli-Parázsszög-dülő

Backglockenfragmente, Ende 7. Jh.-8. Jh.

Lit.: Unveröffentlicht. Freundliche Mitteilung von Péter Tomka, 1994 (Győr); FIEDLER 1994, 348.

Doboz-Hajdúirtás

Henkel einer in einem Wohnhaus gefundenen Backglocke Lit.: KovalovszKi 1975, 208-209, Abb. 5.210, Abb. 6.2.

Dunaújváros-Béke Tsz.-Alsófoki patak

Lit.: Unpubliziert. FÜLÖP 1981, 253, 296.
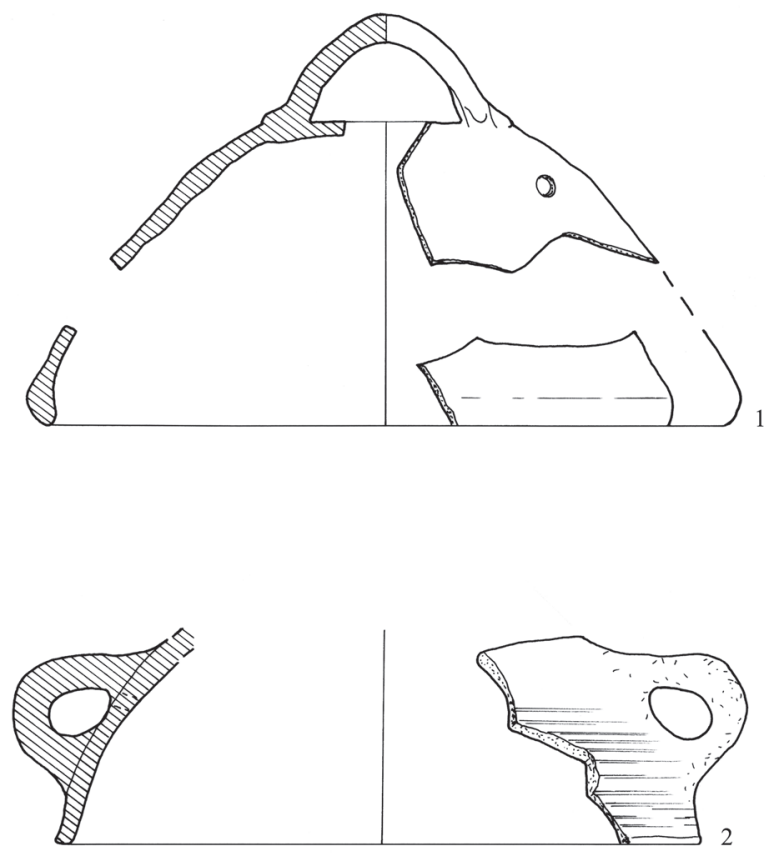

Abb. 20. Mittelalter. 1: Roma-Crypta Balbi (nach RicCI 1986); 2: Modena-Cittanova, Case Giacobazni (nach CATTANi 1988)
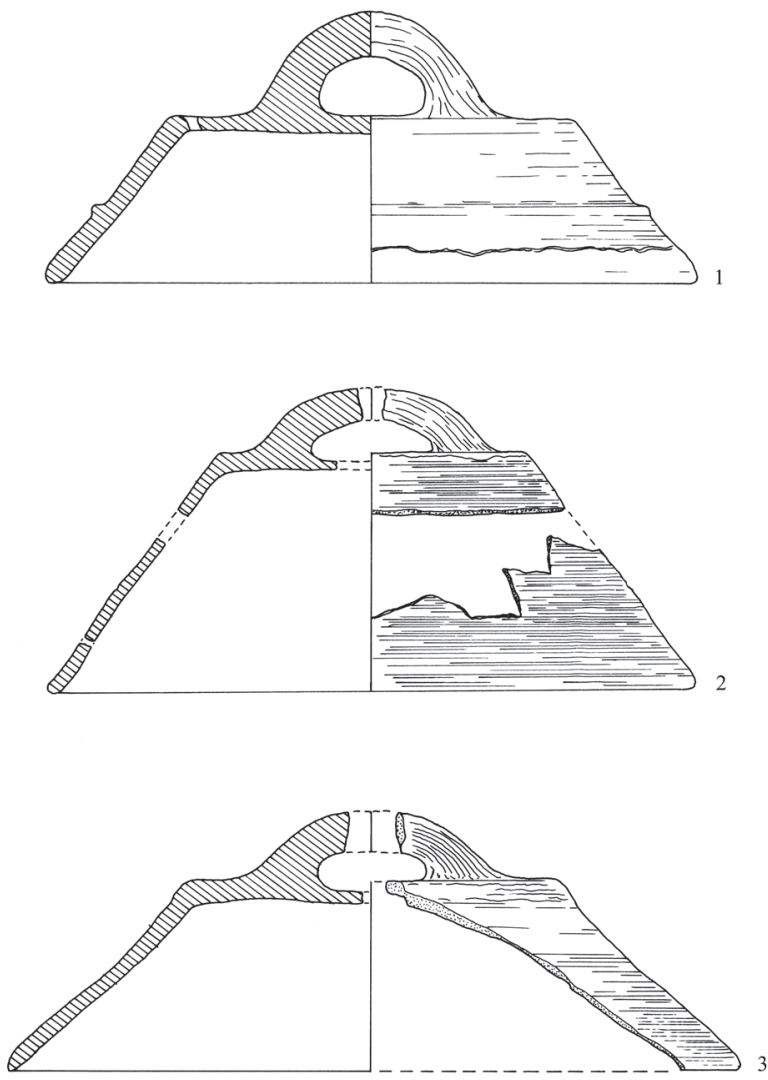

Abb. 21. Mittelalter. 1-3: Brescia (nach BRoGIOLO-GELICHI 1986) 
Eperjes-Csikóstábla

Lit.: BÁLINT 1991, 58-62, Taf. 3.9, 5.6, 9.5, 24.3, 28.16.

Gyirmót-Homokdomb

Backglocke, 8. Jh.

Lit.: Freundliche Mitteilung von Péter Tomka, 1999 (Győr).

Gyoma 133

Lit.: VIDA 1996, 334, 353, Fig. 12.5-6; 355, Fig. 14.4; 357, Fig. 16.7; 359, Fig. 18.7.

Györ-Bokányi Dezső u.

Backglocke, 7.-8. Jh.

Lit.: Freundliche Mitteilung von Péter Tomka, 1999 (Győr).

Helemba/Chl'aba

Lit.: M. HanUliaK: Praveké, včasnodejinné a stredoveké osídlenie v Chl'abe a ich význam. Archaeologia Historica (Brno) 17 (1989) 203, Taf. 10.9.

Horgoš/Horgos (Abb. 19)

Lit.: TRIFUNOVIĆ $2000,95,99$.

Hunya-Csárdavölgy

Unverzierte Fragmente einer rekonstruierbaren konischen Backglocke. D: $22,4 \mathrm{~cm}$

Lit.: SZŐKE 1980, 202, Abb. 11.7; SZŐKE 1988, 203, Abb. 4.1; MRT 8, 1989, Taf. $62.1-5,8$.

Hurbanovo/Ógyalla-Bohotá

Lit.: M. RejHOLCOvÁ: Slovanské sídliskové objekty v Hurbanove-Bohatej. Archeologické Rozhledy 29 (1977) 653, Abb. 8.1.

Ikrény-Zsajdár-dülő

Backglocke, 7. Jh.

Lit.: Ausgrabung und freundliche Mitteilung von András Figler, 1998 (Mosonmagyaróvár)

Kajárpéc-Pokolfa

Siedlung aus der frühen und mittleren Awarenzeit

Lit.: Ausgrabung und freundliche Mitteilung von Miklós Takács (Budapest) und Péter Tomka (Győr); FIEDLER 1994, 348.

Káloz-Nagyhörcsökpuszta

Randfragment

Lit.: FÜLÖP 1981, 252, Abb. 3.4

Kengyel

Lit.: CSEH J.: Késő népvándorláskori (7-9. századi) telepleletek Kengyel határából [Awarische Siedlungsfunde aus der späten Völkerwanderungszeit (7.-9. Jahrhundert) in der Gemarkung von Kengyel]. In:
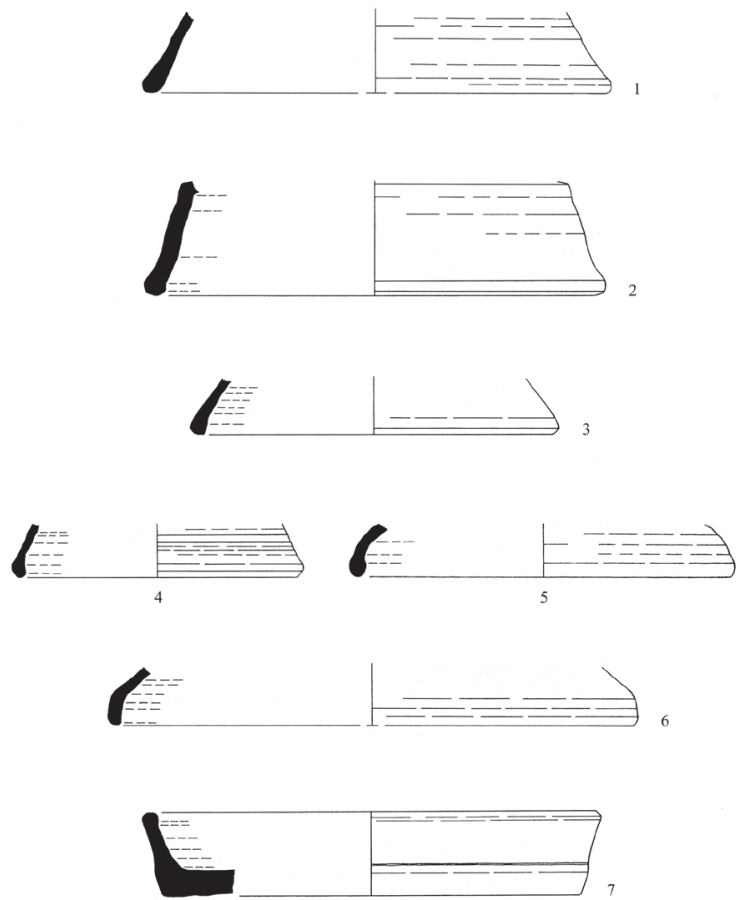

Abb. 22. Mittelalter. 1-7: Mola di Monte Gelato (nach PATTERSON 1997)
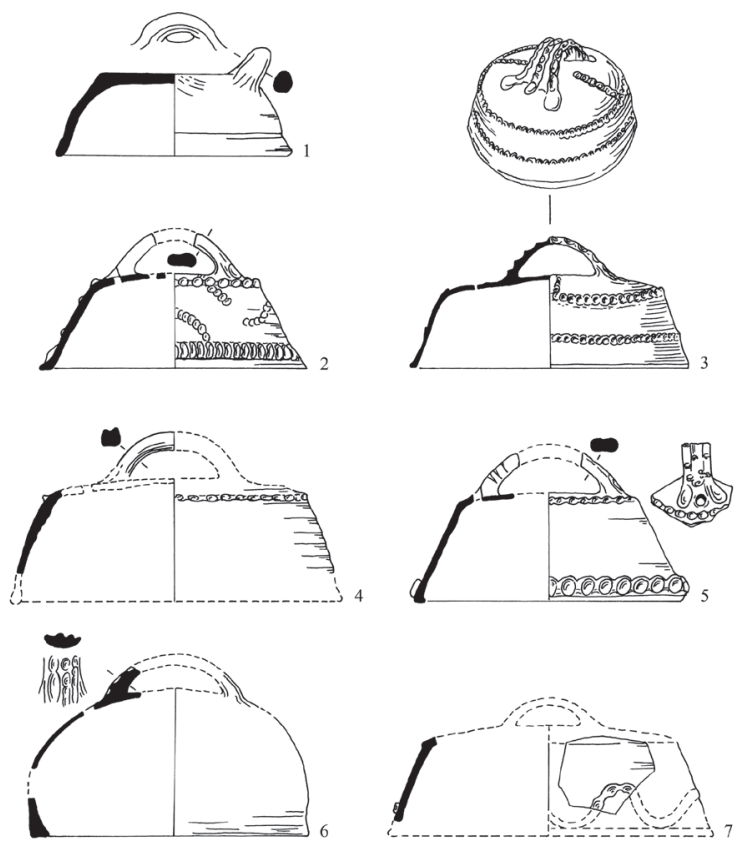

Abb. 23. Mittelalter. 1: Fulmodeston, Norfolk, 16. Jh.;

2: Thornholme Priory, Lincolnshire, 15. Jh.; 3: Laverstock, Wiltshire, 13. Jh.; 4: West Riding, Sandal Castle, Yorkshire, 15. Jh.; 5: Thornholme Priory, Lincolnshire, 13. Jh.;

6: Netherton, 13.-14. Jh.; 7: Southampton, Hampshire, 10.-11. Jh. (alle nach MCCARTHY-BROOKS 1988) 
G. Lőrinczy (Hrsg.): Az Alföld a 9. században. Szeged 1993, Abb. 4.4, $5.9-12,9.7$.

Kevermes-Bakófenék

Lit.: P. Medgyesi: Késő avar kori kemence Kevermes-Bakófenéken [Ein spätawarenzeitlicher Ofen in Kevermes-Bakófenék]. Somogyi Múzeumok Közleményei (Kaposvár) 9 (1995) 145-163, 155-161, Taf. IX-XX.

Kolut/Küllöd-Bačan (Abb. 11.5-7)

Lit.: TRIFUNOVIĆ 2000, 95, 99.

Komárom-Haus 7

Randfragment einer Backglocke, 8. Jh.

Lit.: TRugly 1996, 18, Abb. 4.

Komárom-Graben „„““

Randfragment einer Backglocke

Lit.: Trugly 1996, 19, Abb. 23.

Kölked

Lit.: HAJNAL 2008, 267.

Lébény-Kaszás

Backglockenfragmente mit Henkel, Ende 7. Jhs.-8. Jh.

Lit.: Ausgrabung und freundliche Mitteilung von Miklós Takács und Péter Tomka; FIEDLER 1994, 348.

Lébény-Bille-domb

Backglockenfragmente, 8. Jh.

Lit.: Ausgrabung und freundliche Mitteilung von Miklós Takács und Péter Tomka.

\section{Mezőkövesd}

Lit.: L. RÉvÉsZ: IX-X. századi telep nyomai Mezőkövesden [Spuren einer Siedlung aus dem 9.-10. Jahrhundert in Mezőkövesd]. A Miskolci Herman Ottó Múzeum Közleményei 24 (1986) 26, Abb. 3.6; 28, Abb. 5.8.

Mosonmagyaróvár-Mosonszolnoki pihenő

Backglockenfragmente mit Henkel, 7. Jh.

Lit.: Ausgrabung und freundliche Mitteilung von Péter Tomka (Győr); FIEDLER 1994, 348.

Nyáregyháza, 504. út

Fragmente von Backglocken und Backplatten

Lit.: A. VADAY-Á. SZEKERES: Az 504. sz. út 9-12 km szakaszának leletmentése (Nyáregyháza) [Fundrettung an der Strecke 9-12 km der Straße Nr. 504 (Nyáregyháza)]. Manuskript. 1997.

Örménykút

Lit.: BÁLINT-JANKOVICH 1983; MRT 8. 1989, Taf. 62.7.

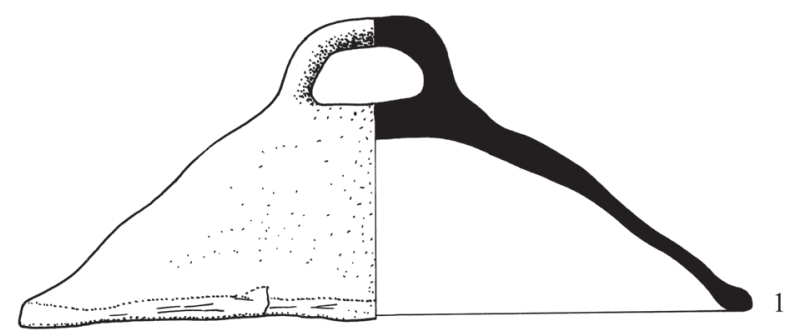

Abb. 24. Mittelalter. Szekszárd-Palánk (nach GAÁL 1981)
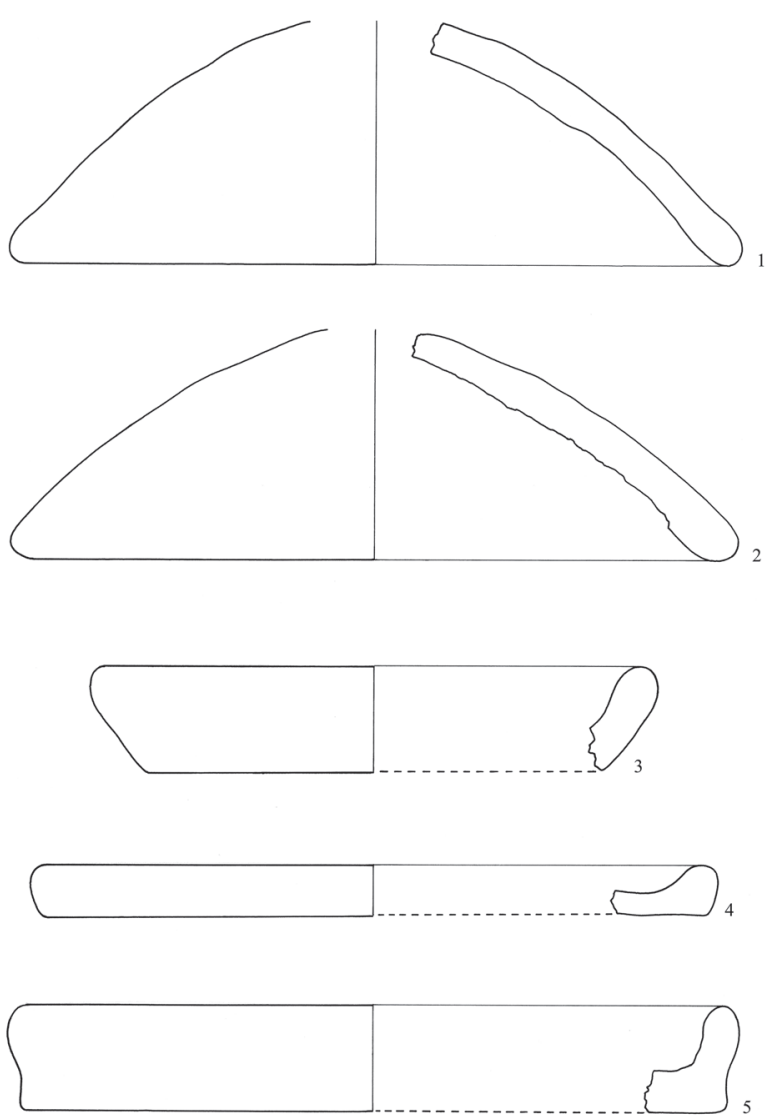

Abb. 25. Mittelalter. Székesfehérvár (nach Gy. Siklósi) 
Padej/Padé (Abb. 11.8-9)

Fragmente von nicht getöpferten Backglocken und Backplatten.

Lit.: TrifunOvić 2000, 104, Tab. XX.2-3; Backteller: ebd. Tab. XX.5, $10-12$.

\section{Prša/Perse}

Lit.: A. Točík: Pohrebisko a sídlisko z doby avarskej ríše v Prši. Slovenská Archeológia 11 (1963) 198, Taf. 20.3, 6.

Rácalmás-Régi vasútállomás

Lit. : FÜLÖP 1981, 253, 257, Abb. 8.

Ras-Podgrađe (Abb. 26)

Backschüsseln und Backdeckel ohne Griff wurden zusammen gefunden, 9.-10. Jh.

Lit.: PoPOVIć 1999, 143, Abb. 89.11; 145, Abb. 92.5-7; Backteller: ebd. 143, Abb. 89.12-13; 145, Abb. 92.8.

Sighişoara-Dealu Viilor / Segesvár-Szőlők

Fragment des Henkels einer Backglocke

Lit.: F. PUSKÁs KoLOZSVÁRI: Dél-Erdély a VIII-IX. században [SüdSiebenbürgen in den 8.-9. Jahrhunderten]. Manuskript. Magisterarbeit, Eötvös Loránd Tudományegyetem. Budapest 2002, VI. tábla.

\section{Simoneşti/Siménfalva}

Fragmente von Backglocken und niedrigen Tontellern, 7.-9. Jh.

Lit.: BENKŐ 1992, 146, Taf. 22.8-9, 11.

Štúrovo-Obid / Párkány-Ebed

Lit.: ZÁвоJNík 1988, 417, Abb. 15.5.

Szarvas-Fo. 162

Lit.: MRT 8. 1989, Taf. 62.6.

Tatabánya-Alsógalla

Lit.: SZATMÁRI 1982/1983, 73, 77, Abb. 18.

Tatabánya-Dózsakert

Lit.: G. VÉKONY: Késő népvándorláskori és Árpád-kori települések Tatabánya-Dózsakertben [Spätvölkerwanderungszeitliche und árpádenzeitliche Siedlungen in Tatabánya-Dózsakert]. In: G. Gombkötő (Hrsg.): Komárom megye története I. Tatabánya 1985, 284.

\section{Tiszabercel}

Lit.: Freundliche Mitteilung von Katalin Tóth (Hódmezővásárhely).

Tiszafüred

Mehrere Bruchstücke von Backdeckeln, erste Hälfte des 8. Jhs.

Lit.: Madaras 1991, 303, Taf. 16.2; 304, Taf. 17.6; 305, Taf. 18.2; 307, Taf. 20.1.
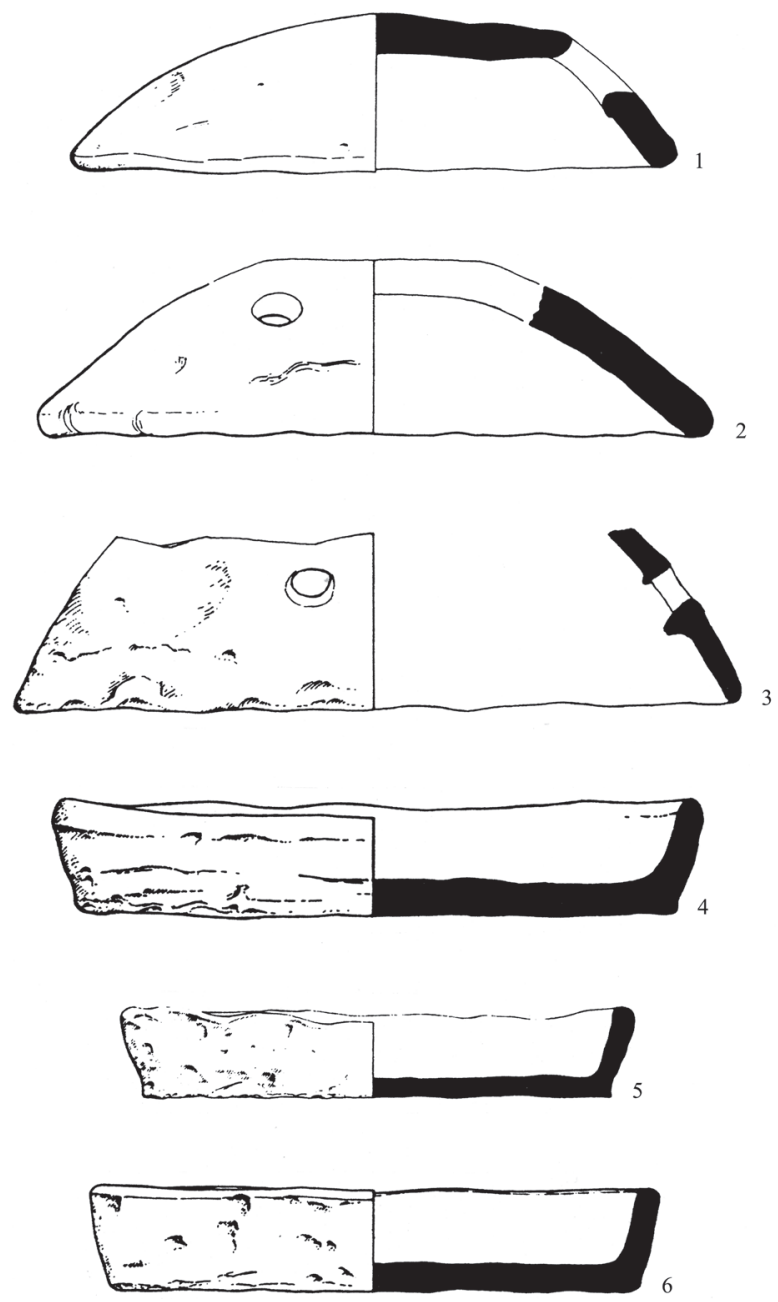

Abb. 26. Mittelalter. Ras (nach PoPOVIć 1999)
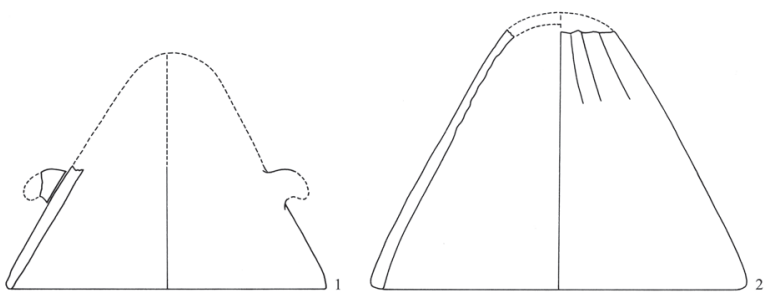

Abb. 27. Mittelalter. Marseille (nach MARCHESI et al. 1997) 
Veresegyháza

Bruchstücke von Backdeckeln, 8. Jh.

Lit.: Mesterházy-HoRváth 1983, 121, Abb. 7.1, 7.

Zillingtal/Völgyfalu

Mehrere Teile von Backglocken, 8. Jh.

Lit.: Unveröffentlicht. Ausgrabung von F. Daim. H. Herold: Die Keramik der Randgebiete des Awarischen Khaganats unter besonderer Berücksichtigung der Siedlung und des Gräberfeldes von Zillingtal. Manuskript. Dissertation. Wien 2002.

Zimony/Zemun, Objekt 4, 5

Randfragmente einer Backglocke, 9. Jh.

Lit.: JANKović 1996, 134-135, Taf. V.8, VI.7.

\section{Ungarische Landnahmezeit und Árpádenzeit (10.-14. Jahrhundert)}

Békés-Ditér

In situ, 12. Jh

Lit.: PARÁDI 1966, 50.

\section{Endrőd-182}

Lit.: D. Jankovich-BÉSÁN: Szondázó ásatás Endrőd 182. sz. lelőhelyen. Manuskript. 1998, Taf. I.1.

Lébény-Bille-domb

Lit.: TAKÁCS 1996, 170, 168, Abb. 14.

Moreşti/Malomfalva, Haus 9

Lit.: HoREDT 1984, 18, Abb. 7.17-18.

Mosonszentmiklós-Egyéni földek

Lit.: TAKÁCS 1996, 170, 168, Abb. 14.

\section{Szarvas-Rózsás}

Lit.: KovaLovszKi 1960, 37, Taf. VIII.4-5.

\section{Tiszalök-Rázom}

Lit.: KovalovsZKi 1960, 37; I. MÉRI: Egy Árpád-kori magyar falu leletmentő ásatása Tiszalök-Rázom, 1950-53. [Die Rettungsgrabung eines árpádenzeitlichen ungarischen Dofes Tiszalök-Rázom, 195053] Opuscula Hungarica II. Budapest 2000, 124, Abb. 62.

\section{Tiszavalk-Tetes}

Lit.: Ausgrabung von Pál Patay. KovALovszKi 1995, Anm. 10; FodoR 1984, 106
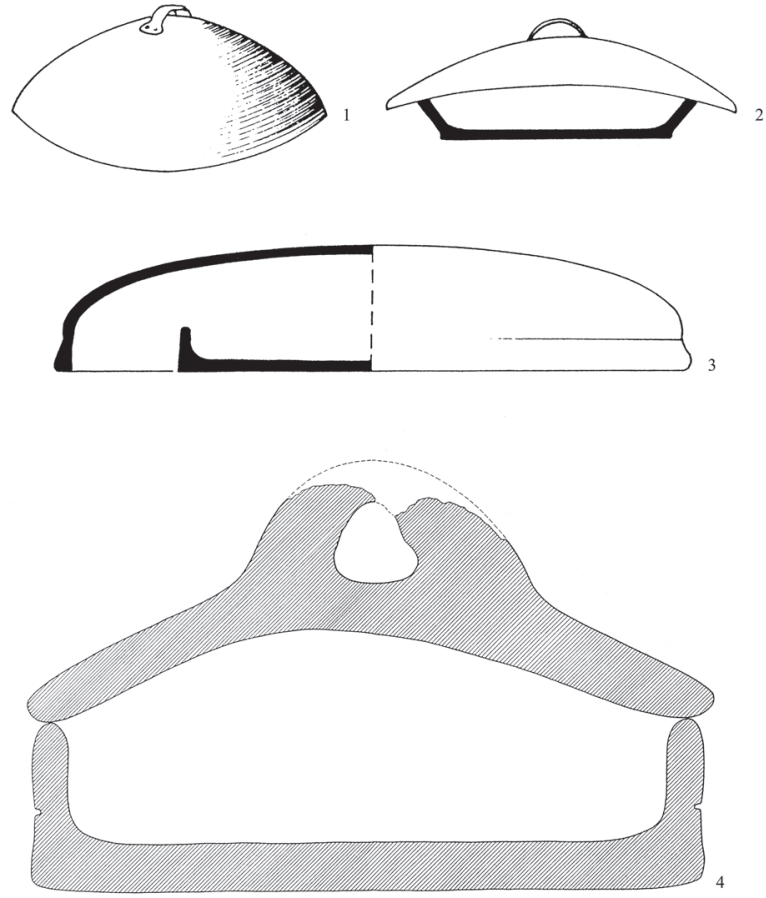

Abb. 28. Spätbyzantinisch. 1-2: Gehenkelte Backdeckel aus Metall (nach BAKIRTZES 1989); Spätarchaische Zeit.

3: Athen-Agora, einfache Backdeckel (nach SPARKES-TALCOTT 1970); 4: Rezente Backdeckel und Backschüsseln in Komotini, Griechenland (nach EFSTRATIOU 1987, 1988)
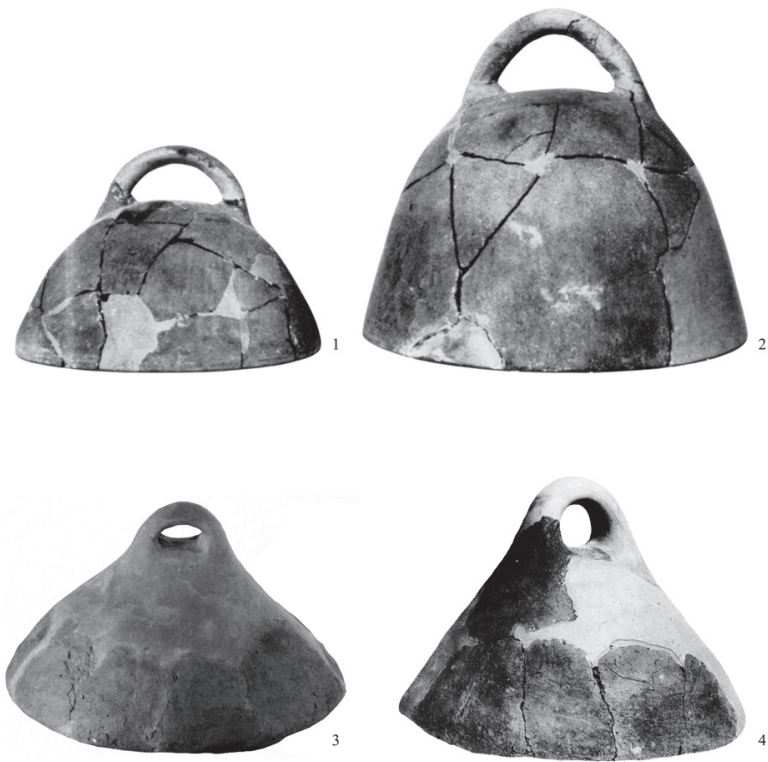

Abb. 29. Spätarchaische, klassische Zeit.

1-2: Athen-Agora (nach SPARKES-TALCOTT 1970) Awarenzeit 3. Érsekújvár / Nové Zámky, ZABOJNíK 1988,

4. Horgos (Horgoš) nach TRIFUNOvić 2000 
Visegrád-Lepence

Lit. : P. GRÓF: Újabb adatok Visegrád kora Árpád-kori topográfiájához [Neuere Daten zur árpádenzeitlichen Topographie von Visegrád]. Herman Ottó Múzeum Évkönyve 30-31/2 (1993) 521, Abb. 4, unten.

\section{Mittelalter, Neuzeit (10.-17. Jahrhundert)}

Eng 1 and

Fulmodeston, Norfolk (Abb. 23.1)

Backglocke, 16. Jh.

Lit.: MCCARTHY-BRooKs 1988, 418, Fig. 261, Nr. 1916.

King's Lynn

Lit.: H. Clarke-A. CARTER: Excavation in King Lynn 1963-1970. Society for Medieval Archaeology Monograph Series 7. London 1977, 306-309.

Laverstock, Wiltshire (Abb. 23.3)

Backglocke (curfew). 13. Jh.

Lit.: MCCARTHY-BRoOKS 1988, 339, Fig. 205, Nr. 1384.

Southampton, Hampshire (Abb. 23.7)

Backglocke (curfew), 10.-11. Jh.

Lit.: MCCARThy-Brooks 1988, 188, Fig. 100, Nr. 393.

Netherton (Abb. 23.6)

Backglocke (curfew), 13.-14. Jh.

Lit.: MCCARTHY-BrooKs 1988, 118, Fig. 59.4.

Sandal Castle, Yorkshire (Abb. 23.4)

Backglocke (curfew), 15. Jh.

Lit.: McCARThY-BrooKs 1988, 407, Fig. 252, Nr. 1815.

Thornholme Priory, Lincolnshire (Abb. 23.2, 23.5)

Backglocke, frühes 13.-14. Jh.

Lit.: McCarthy-Brooks 1988, 264, Fig. 153, Nr. 896; 414, Fig. 258, Nr. 1869.

Österreich

Wien

Lit.: Keramische Bodenfunde 1982, 81, Fig. 100.

I $t$ a $1 \mathrm{i}$ en

Brescia-Via Alberto Mario (Abb. 21.1-3)

Backglocken oder Gluthauben mit oberem Henkel. D: $37-46 \mathrm{~cm}$. 10. Jh. Lit.: Brogiolo-Gelichi 1986, 306, Tav. VII.1-4; PANAZZA-Brogiolo 1988, Tav. XVI.8-9, Tav. XVII.3-6.
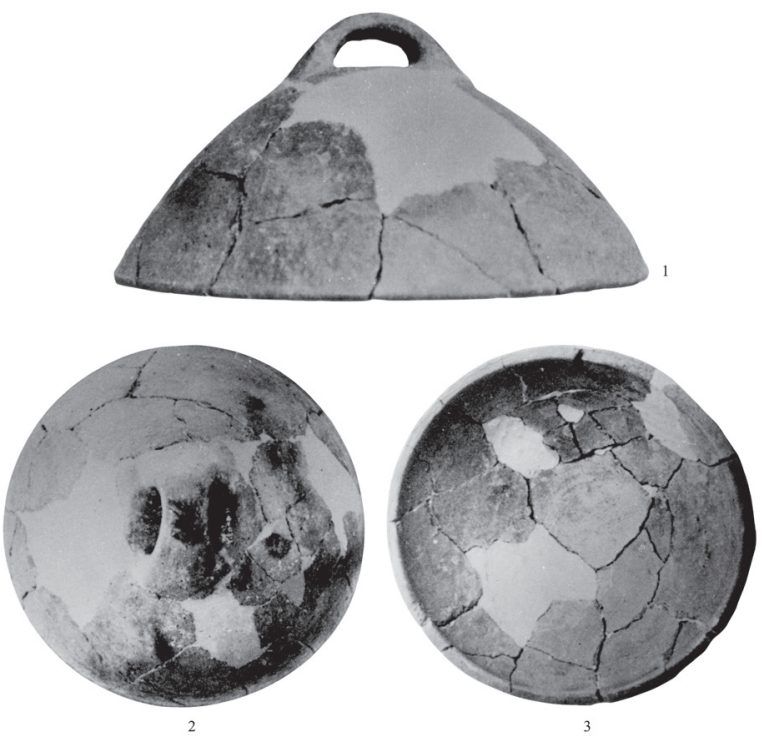

Abb. 30. Eisenzeit. Murlo, Poggio Civitate (nach Bouloumié 1978)
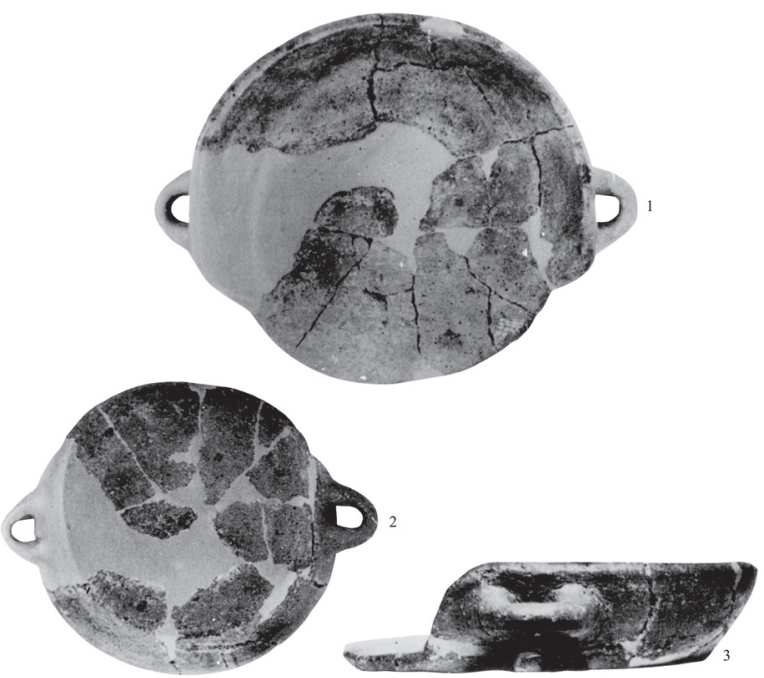

Abb. 31. Eisenzeit. Murlo, Poggio Civitate, Backschüssel (nach Bouloumié 1978) 
Cremona-Piadena, Loc. Castello

Backglocke oder Gluthaube mit zwei runden, seitlichen Henkeln. D: $32 \mathrm{~cm}, 41 \mathrm{~cm}$.

Lit: Brogiolo-Gelichi 1986, 300, Fig. 3a; 302, Tav. V.3-4.

\section{Ferrara}

Backdeckel aus grauem, körnigem Material. Ein schmales Lüftungsloch, Gluthaube (?). H: $12 \mathrm{~cm}, \mathrm{D}: 33 \mathrm{~cm} .13 .-14$. Jh.

Lit.: G. RegGr: Ceramiche delle Civiche Collezioni, Commune di Ferrara 1972. Das Reich der Salier 1024-1125. Ausstellungskatalog. Sigmaringen 1992, 14-15, Nr. 1.1.

\section{Forli-Cattolica}

Backglocke oder Gluthaube mit seitlichen Henkeln. D: $45 \mathrm{~cm}$. 10.-14. Jh. Lit: Brogiolo-Gelichi 1986, 304, 313, Tav. XI.4.

Modena-Cittanova, Case Giacobazzi ( $A b b$. 20.2)

Backglocke oder Gluthaube. D: $36 \mathrm{~cm}$. 10. Jh.

Lit.: M. CATTANI: Recenti ricerche archeologiche di superficie. In: A. Cardelli et al. (a cura di): Modena dalle origini all'anno mille. Studi di archeologia e storia I. Modena 1989, 580, 582, Fig. 526.1.

Mola di Monte Gelato (Abb. 22.1-7)

Backdeckel. D: 19-35 cm. Backteller. 9.-12. Jh.

Lit.: PATTERSON 1997, 371-372, 382, Fig. 248, Nr. 116-123.

Rom-Crypta Balbi (Abb. 20.1)

Getüpfelte Backglocken mit oberem Henkel. D: 29-33 cm. Ende des 10.-12. Jh.

Lit.: RICCI 1986, 537, Tav. XI.7-8; 539, Tav. XII.8-9.

\section{Santa Cornelia}

Randfragmente eines Backdeckels

Lit.: H. Patterson: Early medieval and medieval Pottery. In: N. Christie (ed.): Three South Etrurian Churches: Santa Cornelia, Santa Rufina and San Liberato. Archaeological Monographs of the British School at Rome 4. London 1991, 122-124.

Grie che n land

\section{Mikroprespa}

Große Backglocke mit Knopfgriff, 10. Jh.

Lit.: Moutsopoulos 1992, 27, T. 1, das linke Foto innen.

Ung a r n

\section{Barcs-Palánkvár}

Rand- und Henkelfragmente von 256 Backglocken. Der durchschnittliche Durchmesser des Randes: 35-50 cm; Durchmesser des rekonstruierten Exemplars: $49-50 \mathrm{~cm}$. 16.-17. Jh.
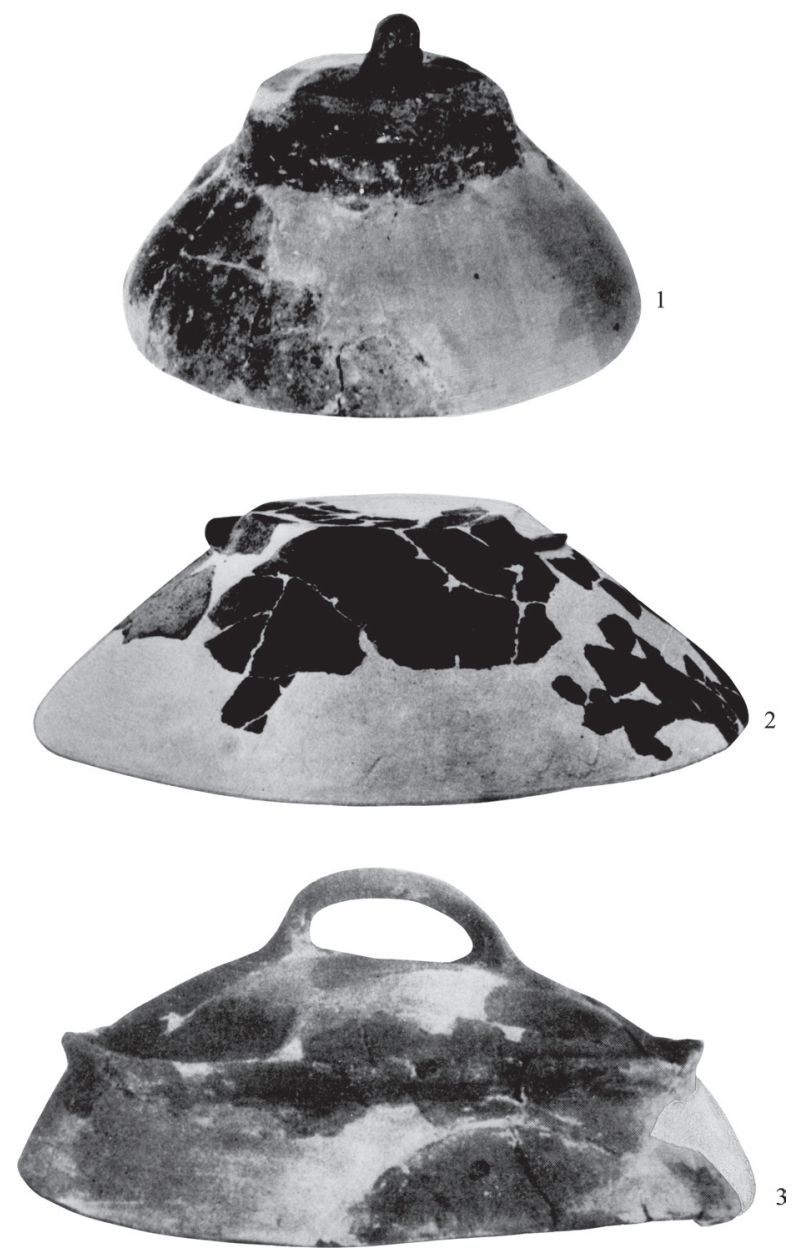

Abb. 32. Spätantike, frühbyzantinisch.

1: Čaričin Grad/Iustiniana Prima (nach BJELAJAC 1990); 2: Brioni-Castrum (nach MARUŠIĆ 1986); 3: Onhezmit/Onhesmos (nach LAKO 1987) 
Lit.: Gy. KovÁCs-M. RózsÁs: A barcsi török palánkvár [Die türkische Palisadenburg von Barcs]. Somogyi Múzeumok Közleményei 12 (1996) 175, T. 15.7; KovÁcs 1998, 155-156, Fig 1.1-5.

Buda

Lit.: Freundliche Mitteilung von András Végh (Budapest).

\section{Köszeg}

Rote Tonbackglocke. D: $50 \mathrm{~cm}$. Zweite Hälfte des 15. Jhs.

Lit.: I. HoLL: Kőszeg vára a középkorban [Die Burg von Kőszeg im Mittelalter]. Fontes Archaeologici Hungariae. Budapest 1992, 171, Abb. 136.1.

\section{Nagykanizsa-Vár}

Lit.: Gy. KovÁcs: Jegyzetek a kanizsai vár 16-17. századi leleteihez [Bemerkungen zu den Funden der Burg von Kanizsa aus den 16.-17. Jahrhunderten]. Zalai Múzeum 12 (2003) 192, Anm. 14.

Szekszárd-Újpalánk (Abb. 24)

Backglocke mit oberem Henkel. D: $50 \mathrm{~cm}$

Lit.: GAÁL 1981, 145, Fig. 4.16; A. GAÁL: Török palánkvár a Budaeszéki út Tolna megyei szakaszán [Türkische Palisadenburg an der Strecke der Straße Buda-Eszék im Komitat Tolna]. In: Magyar és török végvárak 1663-1684. Studia Agriensia 5 (1985) 185-197.

Székesfehérvár - Hirmer-ház 43. sz. árok, emésztőgödör ( $A b b .25)$ Backglocken mit Backschüsseln, 17. Jh.

Lit.: Ausgrabung und freundliche Mitteilung von Gyula Siklósi (Székesfehérvár). Szent István Király Museum, Inv.-Nr. 92.600-604.

\section{Szolnok}

Lit.: GY. KovÁcs: Török kerámia Szolnokon (Türkische Keramik in Szolnok). Szolnok Megyei Múzeumi Adattár 30-31 (1984), Taf. 34.1.

Törökkoppány

Backglocken- und Backschüsselfragmente, 17. Jh.

Lit.: KovÁCs 1991, 172, 359, T. VIII.7-8.

Vál

Lit.: HathÁZI-KovÁcs 1996, 41, 31, Abb. 1, 5; 34, Abb. 8; 35, Abb. 4.

Ös terreich

Wien

Backglocke oder Gluthaube

Lit.: Keramische Bodenfunde 1982, 81, Nr. 100-101.
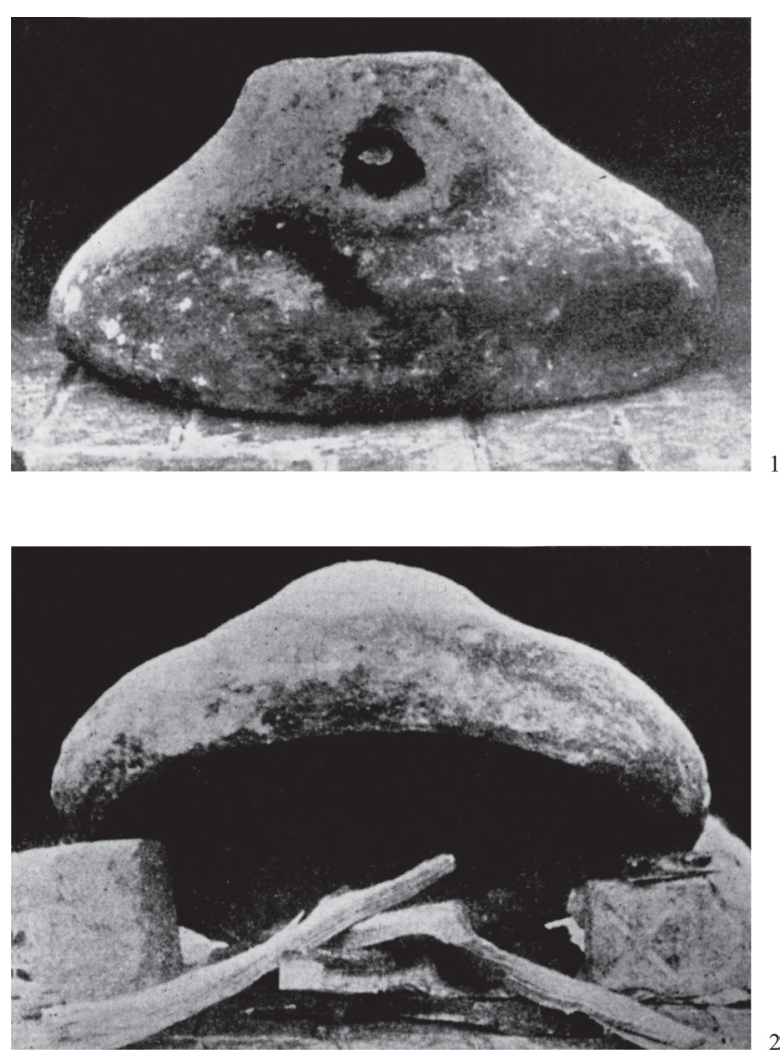

Abb. 33. Backglocke in Gebrauch am Anfang des 20. Jahrhunderts in Rumänien. 1: Backglocke zest beim Fladenbrotbacken;

2: Die Backglocke ist aufgestellt zum Erhitzen

(Fotos von Prof. A. Zaharia, nach MAURIZIO 1924, 313-314, Abb. 75.a-b) 
Rumänien(S i e be n bürge n)

Cechesti/Csekefalva

Backglockenfragment. 13.-14. Jh.

Lit.: BENKŐ 1992, 56-57, Taf. 35.3.

\section{Lăpuşel/Hagymáslápos}

Lit.: Freundliche Information von Ion Stanciu (Cluj).

\section{Lazuri/Lázári}

Mehrere Backglockenfragmente aus der Siedlung, Anfang des 8. Jhs. Lit.: I. STANCIU: Aşezarea slavă timpurie de la Lazuri - „Lubi tag“, jud. Satu Mare (cercetările arheologice din anii 1977, 1993-1995). Contribuţii la cunoaşterea secolelor 6-7 în zona Tisei superioare. Satu Mare. Studii şi Communicări XV-XVI (1998-1999) 244, Pl. XXXIII.

\section{Sarasău-Zapodie / Aszó}

Backglockenfragmente mit Backschüsseln, 9.-11. Jh.

Lit.: R. POPA: Noi cercetări de arheologie medievală în Maramureş. Şantierul Sarasău. Studii ši cercetãri de istorie veche ši arheologie (Bucureşti) 22/4 (1971) 615, Fig. 12.a-b; PoPA-HARHOIU 1989, 267, Fig. 10.1-3.

Frankreich

Marseille (Abb. 23.1-2)

Zwei konische Backformen mit Bleiguss (moule), die umgekehrt verwendet wurden. D: $25 \mathrm{~cm}$.

Lit.: MARCHESI et al. 1997, 79-80, Fig. 52; 289-290, Fig. 258.

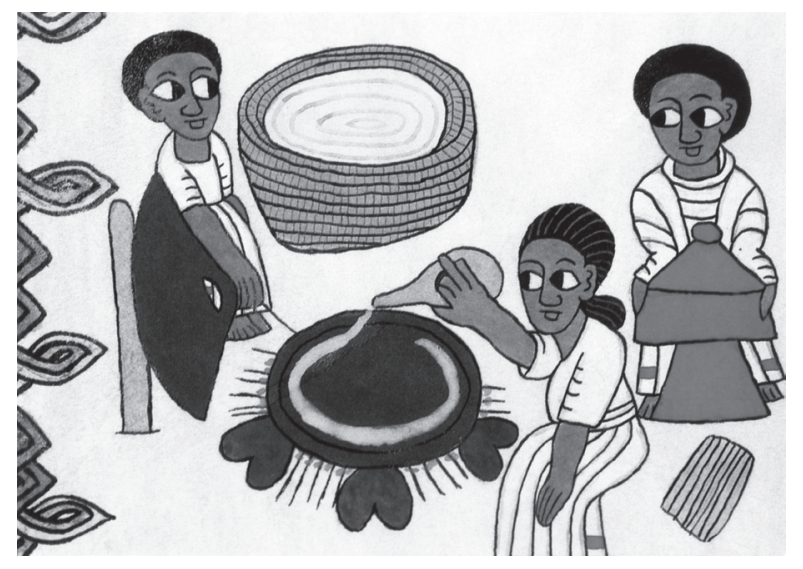

Abb. 34. Der Teig wurde von einer Frau auf den gehitzten Tonbackplatte gelegt, während eine andere Frau eine Backglocke aus Ton hält. Lebensbild in Etiopien, 1970-er Jahren. Ausstellung im Staatlichen Museum für Völkerkunde in München in 2002.

\section{LITERATUR}

BABIĆ 1972

BABIĆ 1986

BAJALOVIĆ-HADŽI-PEŠIć 1981

BAKIRTZES 1989

BÁLINT 1989

BÁLINT 1990

BÁLINT 1991

BÁLINT 1993
= B. BABIĆ: Črepulja, črepna, podnica - posebno značajan oslonac za atribuciju srednjevekovnih arheoloških nalazišta Balkanskog poluostrva Slovenima poreklom sa istoka [Črepulja, črepna, podnica - Besonders wichtiger Stützpunkt für die Attribution der mittelaterlichen Fundstellen des Balkans an Slawen, die aus Osten abstammen]. In: D. Dimitrijević (Hrsg.): Materijali IX. Simpozijum srednevekovne Sekcije Arheološko Društvo Jugoslavije, Prilep 1970. Beograd 1972, 101-123.

= B. BABIĆ: Materijalnata kultura na makedonskite Sloveni vo svetlinata na arheološkite istraživanja vo Prilep [Die materielle Kultur der Slawen Makedoniens im Lichte der archäologischen Forschungen in Prilep]. Prilep 1986.

= M. BAJALOviĆ-HADŽI-PEŠIĆ: Keramika u srednjovekovnoj Srbiji (Les céramiques en Serbie au Moyen Age). Beograd 1981.

$=$ CH. BAKIRTZES: Byzantine tsoukalolagena (A contribution to the study of the names, shapes and uses fireproof cooking pots, transport vessels and storage containers). Athen 1989.

= Cs. BÁlint: Die Archäologie der Steppe. Wien-Köln 1989.

= Cs. BÁLINT: Über einige Tonkessel aus der Umgebung von Šarkel. In: Cs. Bálint (Hrsg.): Die Keramik der Saltovo-Majaki-Kultur und ihrer Varianten. Varia Archaeologica Hungarica 3. Budapest 1990, 9-21.

= Cs. BÁLINT: Die spätawarenzeitliche Siedlung von Eperjes (Kom. Csongrád). VAH 4. Budapest 1991.

= Cs. BÁLINT: Probleme der awarischen Landnahme. In: M. Müller-Wille-R. Schneider (Hrsg.): Ausgewählte Probleme europäischer Landnahmen des Früh- und Hochmittelalters. Methodische Grundlagendiskussion zwischen Archäologie und Geschichte I. Vorträge und Forschungen 41. Sigmaringen 1993, 195-273. 
BÁLINT-JANKOVICH 1983

BATOVIĆ 1987

BENAC 1979

BENKŐ 1992

BICHIR 1973

BIKIĆ 1994

BJELAJAC 1990

BOMMER-BOMMER 1943

Bоoм 1989

Bouloumié 1978

BROGIOLO-GELICHI 1986

BROGIOLO-GELICHI 1997

BRUCKNER 1975

BRUKNER 1981

BUNARDŽIĆ 1985

BUTURA 1989

ChAPMAN-BINTLIFF-GAFFNEY-SLAPSAK 1988

Chelcea 1968

ChIrILA-GudeA-LuCACEL-PoP 1972

Čović 1962

CRISAN 1959

Cs. Sós 1970

CubBerley 1995

CubBerley et al. 1988

ČURČIĆ 1912

Dal Rí-Piva 1986

DANKÓ 1893

DANKÓ 1963

DonČEVA-PETKOVA 1977

Drevnjaja Rus'

DUHN 1924

DULAR 1978

EFSTRATIOU 1987
= Cs. BÁLINT-D. Jankovich: Örménykút MRT 54. sz. lelőhely. RégFüz I/36 (1983) 83.

= Š. BATOvić: Liburnska grupa [Liburnische Gruppe]. In: S. Gabrovec (Hrsg.): Praistorija jugoslavenskih zemalja. V.: Železno doba Sarajevo 1987, 372

= A. BenaC: Prelazna zona [Die Übergangszone]. In: A. Benac (Hrsg.): Praistorija jugoslavenskih zemalja II, neolitsko doba. Sarajevo 1979, 434.

= E. BENKŐ: A középkori Keresztúr-szék régészeti topográfiája (Die archäologische Topographie des mittelalterlichen Stuhles Keresztúr). VAH 5. Budapest 1992

$=$ G. BICHIR: Cultura Carpica. Bucureşti 1973 .

= V. Bikıć: Srednjovekovna keramika Beograda [Die mittelalterliche Keramik Belgrads]. Arheološki Institut Beograd, Posebna izdanja 24. Beograd 1994.

= LJ. BJelajaC: La céramique et lampes. In: B. Bavant-V. Kondić-J.-M. Spieser (ed.): Caričin Grad II. Collection de l'École Française de Rome 75. Belgrade-Rome 1990, 161-190.

= S. BOMMER-L. BOMMER: Die Ernährung der Griechen und Römer. Planegg 1943.

$=\mathrm{H}$. vAN DEN BOOM: Keramische Sondergruppen der Heuneburg. Heuneburgstudien VIII. RömischGermanische Forschungen 47. Mainz am Rhein 1989.

= B. BouloumiÉ: Nouveaux instrumentes culinaires (?) en céramique de Murlo (Poggio Civitate). MEFR 1978, 113-131.

= G. P. Brogiolo-S. Gelichi: La ceramica grezza medievale nella pianura padana. In: La ceramica medievale nel Mediterraneo Occidentale. Atti del III. Congresso Internationale Siena-Faenza 8-13 ottobre 1984. Firenze 1986, 293-316.

= G. P. Brogiolo-S. GeliChI: Ceramiche, technologia ed organizzazione della produzione nell'Italia settentrionale tra $\mathrm{VI}^{\mathrm{e}} \mathrm{X}$ secolo. In: G. D. d'Archimbaud (Hrsg.): La céramique médiévale en méditerranée. Actes du VI ${ }^{\mathrm{e}}$ Congrès de l'AIECM2, Aix-en-Provence (13-18 novembre 1995). Aix-enProvence 1997, 139-145.

= A. BRUCKNER: Gebrauchskeramik aus zwei augusteischen Töpfereien von Neuss. In: Novaesium VI. Limesforschungen 14. Berlin 1975, 77-118.

$=$ O. BRuKner: Rimska Keramika u Jugoslovenskom Delu provincije Donje Panonije [Die Keramik im jugoslawischen Teil der Provinz Unterpannonien]. Dissertationes et Monographie 24. Beograd 1981.

$=$ R. BunARDŽIĆ: Celarevo. Risultati delle ricerche nelle necropoli dell' alto medioevo. Ausstellungskatalog. Roma 1985.

= V. Butura: Stravechi marturii de civilizatie romaneasca Transilvania. Studiu etnografic [Angaben zur alten rumänischen Zivilisation in Transylvanien. Etnographische Studien]. Bucureşti 1989.

= J. C. Chapman-J. Bintliff-V. Gaffney-B. SlapsaK: Recent Developments in Yugoslav Archaeology. BAR IntSer 431. Oxford 1988.

= I. ChelceA: Testul de copt pîine. RMuz 2, 1968, 172

= E. Chirila-N. Gudea-V. LuCacel-C. Pop: Das Römerlager von Buciumi. Cluj 1972, T. XIXXXIV.

= B. Čović: Gradinsko naselje- na Kekića glavica (Die Wallburgsiedlung auf der Kekića glavica). Glasnik Zemaljskog Muzeja u Sarajevu (Sarajevo) 17 (1962) 41-61.

= I. H. CRISAN: Ceramica daco-getica. Bucureşti 1959, 153-160.

= Á. Cs. Sós: Frühmittelalterliche slawische Siedlungsreste im Zagyvatal. S1A 18/1 (1970) 97-112.

= A. CubBerley: Bread backing in Ancient Italy. Clibanus und sub testu in the Roman world: Further thoughts. In: J. Wilkins-D. Harvey-M. Dobson (eds): Food in Antiquity. Exeter 1995, 55-68.

= A. L. Cubberley-J. A. Lloyd-P. C. Roberts: Testa and clibani: The backing Covers of Classical Italy. PBSR 56 (1988) 98-119.

= V. ČURČIĆ: Rezente Pfahlbauten von Donja Dolina in Bosnien. Zeitschrift für österreichische Volkskunde, Ergänzungsheft IX. Wien 1912, 45.

$=$ L. DAL Rí-G. PIVA: Ledro B: Una stazione del primomedioevoa Volta di Besta sul Lago di Ledro nel Trentino. Atti dell'Accademia Roveretana degli Agiati VI/26/A 236 (1986) 265-347.

= J. DANKó: Vetus hymnarium ecclesiasticum Hungariae. Budapest 1893, 372.

= I. DANKó: A magyarhertelendi női fazekasság (Die Töpferarbeit der Frauen in Magyarhertelend). JPMÉ 6 (1963) 123-133.

= LJ. DončEvA-PetKovA: Bălgarska bitova keramika [Bulgarische Siedlungskeramik]. Sofija 1977.

= Drevnjaja Rus'. Byt i kul'tura. Hrsg. von B. A. Kolčin, T. I. Makarova. Arheologija 16. Moskva 1997.

= F. VON DuHN: Italische Gräberkunde I. Heidelberg 1924

= J. DulaR: Podzemelj. Katalog najdb [Podzemlj. Katalog der Funde]. Ljubljana 1978, Taf. XLII.3.

$=$ N. EFSTRATIOU: Ethnoarchaiologikes eregnes stogs oreinogs oinismogs tz Rodope. To Archaiologikó 'Ergo etl Makedonía kai Thráki 1 (1987) 479-483. 
EFSTRATIOU 1988

EIBNER-PERSEY 1980

EILMANN 1944

ETTLINGER-SIMONETT 1952

FABER 1994

FIEDLER 1994

FILIPOVIĆ 1951

FISCHER 1957

FISCHL-KISS-KULCSÁR 2001

FISCHL-KISS-KULCSÁR 2001

FISSEHA 2002

FODOR 1984

FORT-LINKSFEILER 1989

FRANCO 1982

FRAYN 1978

FREIHERR VON MISKE 1907

FugazZola Delpino 1977

FÜLÖP 1979

FÜLÖP 1981

FUSEK 1994

FuSEK-ZÁBOJNÍK 2006

GAÁL 1981

GABROVEC et al. 1970

GAVAZZI 1965

GAVAZZI 1978

GLEIRSCHER 1987

GLODARIU-Moga 1989

GolubOVIĆ 1999

GUNDA 1966
= N. EFSTRATIOU: Excavation of a Herding Iron Age site in Highland Rhodope. To Archaiologikó 'Ergo et Makedonía kai Thráki 2 (1988) 517-521.

= A. EIBNER-PERSEY: Hallstattzeitliche Grabhügel von Sopron (Ödenburg). Wissenschaftliche Mitteilungen aus dem Burgenland 62. Eisenstadt 1980, Taf. 86/1, Taf. 88/1.

$=$ R. EILMAnN: Kochgeschirr. In: E. Kunze-U. Jantzen (Hrsg.): IV. Bericht über die Ausgrabungen in Olympia. Berlin 1944, 96-104.

$=$ E. Ettlinger-Chr. Simonett: Römische Keramik aus dem Schutthügel von Vindonissa. Basel 1952, Taf. 8, Nr. 133, 134.

= A. FABER: Das römische Auxiliarkastell und der Vicus von Regensburg-Kumpfmühl. MBV 49. München 1994, Taf. 17.

= U. FIEDLER: Zur Datierung der Siedlungen der Awaren und der Ungarn nach der Landnahme. Ein Beitrag zur Zuordnung der Siedlung von Eperjes. ZfA 28 (1994) 307-352.

= C. M. Filipović: Ženska keramika kod balkanskih naroda (Primitive Ceramics Made by Women among the Balkan Peoples). Beograd 1951.

= U. FISCHER: Cambodunumforschungen 1953. II: Keramik aus den Holzhäusern zwischen der 1. und 2. Querstraße. MhBV 10. München 1957, Taf. 27. 11-12.

= K. FISCHL-V. KISS-G. KULCSÁR: Beiträge zum Gebrauch der tragbaren Feuerherde (puraunoi) im Karpatenbecken II. (Spätbronzezeit - Früheisenzeit). In: C. Kacsó (Hrsg.): Der nordkarpatische Raum in der Bronzezeit. Symposium Baia Mare, 7.-10. Oktober 1998. Baia Mare 2001, 125-156.

= K. P. FISCHL-V. KISS V-G. KULCSÁR: A hordozható tűzhelyek használata a Kárpát-medencében (The use of portable stoves in the Carpathian Basin I. The Middle Bronze Age). M $\mathrm{MO} \Sigma$ 1. „Fiatal Őskoros Kutatók” I. Összejövetelének konferenciakötete. Debrecen, 1997. november 10-13. Debrecen 2001, 163-193.

$=$ G. FISSEHA (Hrsg.): Äthiopien. Christentum zwischen Orient und Afrika. Ausstellungskatalog. Staatliches Museum für Völkerkunde. München 2002.

= I. FodOR: Kazárok, bolgárok, magyarok. Széljegyzetek Peter B. Golden könyvéhez [Chasaren, Bulgaren, Ungarn. Randbemerkungen zum Werk von P. B. Golden]. ArchÉrt 111 (1984) 100-109.

= D. FORT-LiNKSFEILER: Die Schüsseln und Schalen der Heuneburg. Heuneburgstudien VIII. RömischGermanische Forschungen 47. Mainz am Rhein 1989.

= M. CR. Franco: L'insediamento preistorico del Lago di Mezzano. Roma 1982, 128-129, Tav. XXXVIII, Fig 92.

= J. FRAYN: "Home baking in Roman Italy: A footnote". Antiquity 52 (1978) 28-33.

= K. FreiHerr von Miske: Die prähistorische Ansiedlung Velem St. Vid I. Wien 1907, Taf. LX. 11.

= M. A. Fugazzola Delpino: Testimonianze di cultura appenninica nel Lazio. Firenze 1977, Fig. 80. 1, Fig. 97.11.

= Gy. FüLÖP: VIII-XI. századi telepnyomok Rácalmás-Régi vasútállomáson (Siedlungsreste aus dem VIII-XI. Jh. in Rácalmás-Régi vasútállomás). Alba Regia 17 (1979) 267-274.

= Gy. FÜLÖP: Avarkori kemence Káloz-Nagyhörcsökön [Awarenzeitlicher Ofen in Káloz-Nagyhörcsök]. Alba Regia 19 (1981) 252.

$=$ G. FUSEK: Slovensko vo včasnoslovanskom období [Slowakei in der frühslawischen Zeit]. ASM Studia Instituti Archaeologici Nitriensis ASS. 3. Nitra 1994.

= G. FuSEK-J. ZÁBojNíK: Experiment s modelováním zvonov na pečenie [Ein Versuch der Herstellung der Backglocken]. In: J. Zábojník (Hrsg.): Aevum Medium. Zborník na počest’ Jozefa Hošša. Bratislava 2006, 19-22.

= A. GAÁL: Az ólommegmunkálás eszközei az újpalánki (Tolna megye) török palánkvár régészeti anyagában (Tools of plumb processing in the archaeological material of the Turkish palisade fortress Újpalánk). In: Iparrégészet. Égetőkemencék (Industrial archaeology. Kilns and furnaces). Veszprém 1981, 143-148.

= S. Gabrovec-O. H. FreY-St. Foltiny: Erster Vorbericht über die Ausgrabungen im Ringwall von Stična (Slowenien). Germania 48 (1970) 12-33.

= M. GAVAZZI: Zur Frage der Backglocke im südpannonischen Raum. In: Europa et Hungarica Congressus Ethnographicus in Hungaria. Budapest 1965, 79-93.

= M. GavaZZI: Uz pojavu pekve u južnom Podunavlju (Zur Erscheinung der „Pekva“ in der südlichen Donauebene). Vrela i sudbine narodnih tradicija. Zagreb 1978.

= P. GLEIRSCHER: Die Kleinfunde von der Hohen Birga bei Birgitz. BRGK 68 (1987) 181-351.

= I. GlodariU-V. Moga: Cetatea dacica de la Capilna [Dakische Festung in Capalna]. Bucureşti 1989, 174, Fig. 28-29.

$=$ S. Golubović: A grave in the shape of a well from the necropolis of Viminacium. Archaeologia Bulgarica 3/3 (1999) 9-22.

= B. GUNDA: Ethnographica Carpatica. Budapest 1966. 
Gustin-Cunja 1989

HAJNAL 2008

HatHÁZI-KovÁCs 1996

Hensel 1987

HERRMANN 1981

HERRMANN 1986

HILGERS 1969

HOREDT 1978

HOREDT 1983

HOREDT 1984

JANKOVIĆ 1981

JANKOVIĆ 1996

JORIO 1987

JUNKELMANN 1997

JUROŠ-MONFARDIN 1986

KALTENHAUSER 1978

KARADŽIĆ 1818

Keramische Bodenfunde 1982

Kolias 1984

KovÁCs 1991

KovÁCs 1998

KovALOVSZKI 1960

KovAlovszKi 1975

La ceramica 1992

LAKO 1984

LARIONESCU-ARMASESCU 1973

LECHNER 1962

LEONARDI 1979

LuNZ 1981

LuNZ 1983

MADARAS 1991

MANNONI 1965
= M. Gustin-R. Cunja: Koper. Med Rimom in Benetkami (Capodistria. Tra Roma e Venezia). Ljubljana 1989.

= Zs. HAJNAL: Adatok az avar kori cserépbográcsok és sütőharangok időrendjéhez (Angaben zur Chronologie der awarenzeitlichen Tonkessel und Backglocken). ComArchHung 2008, 267-293.

= G. HATHÁZI-Gy. KovÁcs: A váli gótikus templomtorony [Der gotische Kirchenturm in Vál]. SzIKMK B/45. Székesfehérvár 1996

= W. HENSEL: Słowianszczyna wczesnosredniowieczna. Zarys kultury materialnej [Die frühmittelalterlichen Slawen. Abriss der materiellen Kultur]. Warszawa $1987 .^{4}$

= J. HerRmanN: Zwischen Hradschin und Vineta. Frühe Kulturen der Westslawen. Leipzig-Jena-Berlin 1981.

= J. HeRrmanN: Getreidekultur, Backteller und Brot-Indizien frühslawischer Differenzierung. In: Zbornik posveten na Boško Babić. Prilep 1986, 267-272.

=W. HilgERS: Lateinische Gefäßnamen. Bezeichnungen, Funktion und Form römischer Gefäße nach den antiken Schriftsquellen. BJ-Bh 31. Düsseldorf 1969.

= K. HoREDT: Backteller und Tonkessel in Moreşti. SlA 26/1 (1978) 59-68.

= K. HoREDT: Zur Verwendung der dakischen Henkelschalen. AKorr 13 (1983) 233-234

= K. HoREDT: Moreşti 2. Grabungen in einer mittelalterlichen Siedlung in Siebenbürgen. Bonn 1984.

= D. JANKović: Podunavski deo oblasti Akvisa u VI i početkom VII veka [La partie Danubienne de la région d'Aquis au $\mathrm{VI}^{\mathrm{e}}$ et au début du $\mathrm{VII}^{\mathrm{e}}$ siècle]. Arheološki Institut, Gradja 5. Institut Archéologique, Matériaux 5. Beograd 1981.

= M. JANKović: Slovensko naselje kod Zemuna (Slav settlement near Zemun). RMV 37-38 (1995/1996 [1996]), 123-137.

$=$ ST. JorIO: Ceramiche di tradizione locale. In: L. P. Pitscher (a cura di): Sub ascia una necropoli romana a Nave. Modena 1987

= M. Junkelmann: Panis militaris. Die Ernährung des römischen Soldaten oder der Grundstoff der Macht. Kulturgeschichte der Antiken Welt 75. Mainz 1997.

$=$ F. JuRoš-Monfardin: Pokušaj sistematizacije kasnoantičke i ranobizantske keramike grube fakture iz profanog objekta u Betigi kod Barbarigi (Tentativo di sistemazione della ceramica tardoantica e paleobizantina proveniente dell'edificio profano di Bettica presso Barbariga). In: Arheološka istraživanja v Istri i Hrvatskom primorju. Izdanja Hrvatskog Arheološkog Društva (Pula) 11/2 (1986) 223-226

= G. Kaltenhauser: Die urzeitliche Zisterne von Telfes im Stubac. Veröffentlichungen des Tiroler Landesmuseum Ferdinandeum Innsbruck 58 (1978) 23-45.

= ST. V. KARADŽıć: Srpski rječnik [Serbisches Wörterbuch]. Wien 1818.

= Keramische Bodenfunde am Wien. Mittelalter - Neuzeit. Ausstellungskatalog. Hrsg. von O. Harl. Wien 1982.

= T. Kolias: Eßgewohnheiten und Verpflegung im byzantinischen Heer. In: W. Hörandtner et al. (Hrsg.): Byzantios. Festschrift für Herbert Hunger. Wien 1984, 193-202.

$=$ GY. KovÁCs: $16^{\text {th }}-18^{\text {th }}$ century Hungarian pottery types. Antaeus 19-20 (1990-91) 169-180.

= Gy. KovÁcs: A barcsi török palánkvár kerámialeletei (The Ceramic finds from the Turkish palisade fort at Barcs). ComArchHung 1998, 155-180.

= J. Kovalovszki: Ásatások Szarvas környéki Árpád-kori falvak helyén (Die Ausgrabungen an der Stelle árpádenzeitlicher Dörfer in der Umgebung von Szarvas). ArchÉrt 87 (1960) 32-40.

= J. KovALovszKi: Előzetes jelentés a dobozi Árpád-kori faluásatásról 1962-1974 (Vorbericht über die Ausgrabungen im árpádenzeitlichen Dorf bei Doboz). ArchÉrt 102 (1975) 204-223.

$=$ L. PARoli (ed.): La ceramica invetriata tardoantica e altomedievale in Italia. Atti del Seminario Certosa di Pontignano (Siena) 1990. Firenze 1992.

= K. LAKO: Kështjella e Onhezmit (La forteresse D’Onhezmos). Iliria 14/2 (1984) 153-205.

= S. LARIONESCU-I. ARMASESCU: Ţestul - un “cuptor mobil” [Ţestul - ein mobiles Ofen]. RMuz 10/3 (1973) 245-247.

$=$ ZD. LECHNER: Proizvodnja poklujka u Pozeskom Novom Selu (Die Erzeugung der Backdeckel). OZ 8 (1962) 255-278.

= G. LEONARDI: Il bronzo finale nell'Italia nord-orientale. Proposte per una suddivisione in fasi. Atti della XXI riunione scientifica dell'istituto italiano di preistoria e protoistoria. Firenze 1979

$=\mathrm{R}$. LunZ: Archäologisch-historische Forschungen in Tirol 7. Trento 1981.

$=$ R. LunZ: Scavi archeologici sul Doss dei Pigui in Val di Fassa. Beni culturali nel Trentino 4 (1983) 65-79.

= L. MAdaras: Az avar falu [Das awarische Dorf]. In: L. Tálas-L. Madaras (Hrsg.): Régészeti ásatások Tiszafüred-Morotvaparton. SzMME 1991, 227-316.

$=$ T. MANNONI: 'Il testo e la sua diffusione nella Liguria del Levante. Bolletino Linguistico 17 (1965) $49-64$ 
MANNONI 1970

MARCHESI et al. 1997

MARUŠIĆ 1986

MARZATICO 1992

MAU 1896

MAURIZIO 1927

MCCARTHY-BROOKS 1988

MCNICOLL et al. 1992

MesterháZY-HoRvÁTH 1983

Microregion 1966

MILOJČIĆ 1961

Moutsopoulos 1992

MRT 8

MRT 9

MÜLLER-KARPE 1959

NoPCSA 1925

Notizario 1988

OBLOMSKIJ 1994

OCHSENSCHLAGER 1974

OMURA 1998

ONUZI 1980

PANAZZA-BROGIOLO 1988

PARÁdi 1966

PATTERSON 1997

PEACOCK 1977

PERC 1962-63

POPA-HARHOIU 1989

Popović 1956, 1957

POPOVIĆ 1999
$=$ T. MAnNOnI: La ceramica di uso commune in Liguria prima del secolo XIX. Atti del Convegno Internazionale della Ceramica (Albisola) III (1970) 297-319.

$=$ H. Marchesi-J. Thiriot-L. VAllauri: Marseille, les ateliers de potiers du XIII ${ }^{\mathrm{e}} \mathrm{s}$. et le quartier Sainte-Barbe $\left(V^{\mathrm{e}}-\mathrm{VII}^{\mathrm{e}}\right.$ s.). Documents d'Archéologie Française 65. Paris 1997.

= B. MARUŠIć: Materijalna kultura Istre od 5. do 9. stolječa (La cultura materiale dell'Istria dal $\mathrm{V}$ al IX secolo). Arheološka istraživanja v Istri i Hrvatskom primorju. Izdanja Hrvatskog Arheološkog Društva (Pula) 11/1 (1986-1987) 81-105.

= F. MARZATICO: Il gruppo Fritzes-Sanzeno. In: I. R. Metzger-P. Gleirscher (Hrsg.): Die Räter. Bozen 1992, 213-246.

= A. MAU: Bäckerei. PWRE II. Stuttgart 1896, 2735, 2738.

= A. MAuRIZIO: Die Geschichte unserer Pflanzennahrung von den Urzeit bis zur Gegenwart. Berlin 1927.

= M. R. McCARThY-C. M. Brooks: Medieval Pottery in Britain AD 900-1600. Leicester 1988.

= A. W. McNicoll-P. C. Edwards-J. Hanbury-Tenison-J. B. Hennessy-T. F. Potts-R. H. SmithA. WALMSLEY-P. Watson: Pella in Jordan 2. The second interim report of the Joint University of Sydney and College of Wooster Excavations at Pella, 1982-1985, 1-16.

= K. MesterházY-L. HorvÁth: Településtörténeti kutatások Veresegyház határában (Siedlungsgeschichtliche Forschungen in der Gemarkung von Veresegyház). ArchÉrt 109 (1983) 112-124.

= A. Vaday-L. Bartosiewicz-K. Berecz-A. M. Choyke-Zs. Medzihradszky-S. PusztaB. SzÉKELY-M. ViCZE-T. VIDA: Cultural and Landscape Changes in South-East Hungary. 2. Prehistoric, Roman Barbarian and Late Avar Settlement at Gyoma 133 (Békés Country Microregion). Archaeolingua 5. Budapest 1996.

= V. Milojčıć: Samos I. Die prähistorische Siedlung unter dem Heraion. Grabung 1953-1955. Bonn 1961, 50-51.

= N. K. Moutsopoulos: Excavations in Byzantine castles of Western Macedonia. To arhaioxopiko erpo ethe Makedonia kai Trake 6 (1992) 1-34.

= J. MAKKAY (Hrsg.): Békés megye régészeti topográfiája. IV/2: A szarvasi járás [Archäologische Topographie von Komitat Békés. IV/2: Kreis Szarvas]. Magyarország régészeti topográfiája 8. Budapest 1989

= I. TORMA (Hrsg.): Pest megye régészeti topográfiája. XIII/2: A szobi és a váci járás [Archäologische Topographie von Komitat Pest. XIII/2: Die Kreise von Szob und Vác]. Magyarország régészeti topográfiája 9. Budapest 1993.

$=$ H. MÜLLER-KARPE: Beiträge zur Chronologie der Urnenfelderzeit nördlich und südlich der Alpen. RGF 22. Berlin 1959.

= F. NopCSA: Albanien. Leipzig 1925.

= R. Poggiani-Keller-D. CAPrusso-S. Jorio (eds): Notizario 1987. Soprintendenza Archeologica della Lombardia. Milano 1988.

= A. M. OBlomskis: Etničeskie processy v mezždureče Suly i Vorskly v I-V. vv. n. e [Ethnische Prozesse im Zwischenflunssgebiet von Sula und Vorskla im 1.-5. Jh. n. Chr.]. RA 1994/2, 42-55.

= E. Ochsenschlager: 'Mud objects from Al-Hiba. A study in ancient and modern technology. Archaeology 27 (1974) 162-174.

$=\mathrm{S}$. OMURA: Preliminary report of the excavation at Kaman-Kalehöyük in Türkei (1995). In: T. Mikasa (ed.): Essays on Ancient Anatolia in the Second Millennium B.C. Wiesbaden 1998.

= A. OnUZI: Le métier domestique de la poterie. Ethnographie Albanaise 10 (1980) 133-146.

= G. Panazza-G. P. Brogiolo: Gli studi fino al 1978. Lo scavo di via Alberto Mario. Ricerche su Brescia altomedievale 1. Brescia 1988.

= N. PARÁDI: Békés-Ditér. RégFüz 19 (1966) 50.

$=$ H. PATERSON: The early medieval and medieval pottery. In: T. W. Potter-A. C. King: Excavations at the Mola di Monte Gelato. A Roman and Medieval Settlement in South Etruria. Archaeological Monographs of the Britisch School at Rome 11. Roma-London 1997, 366-383.

= D. P. S. PeAcock: Pompeian red ware. In: D. P. S. Peacock (ed.): Pottery and Early Commerce. Characterization and Trade in Roman and Later Ceramics. London-New York-San Francisco 1977, 147-162.

= B. PERC: K stratigrafiju žarnogrobišče naselbine v Ormožu [Über die Stratigraphie der urnenfeldzeitlichen Siedlung von Ormož]. AV 13-14. (1962-63) 375-381.

$=$ R. POPA-R. HARHOIU: Marturii arheologice din Maramureş apartinînd mileniului I. e. n. (Archäologische Zeugnisse aus Maramuresch aus dem I. Jahrtausend u. Z.). SCIV 40 (1989) 266-267.

= C. Popović: Lončarstvo u Bosni i Hercegovini [Die Töpferei im Bosnien und Herzegowina]. Glasnik Zemaljskog Muzeja Istorija i etnografija I. 11 (1956) 95-122; II. 12 (1957) 17-46.

= M. Popović: Tvrđava Ras (The fortress of Ras). Arheološki Institut, Posebna izdanja 34. Archaeological Institute, Monographies 34. Beograd 1999. 
RADIMSKÝ 1895

RADIMSKÝ 1897

RAPAICS 1934

RATTI 1966

RICCI 1986

RITTATORE-VONWILLER 1984

RITTERLING 1913

RODRIGUEZ 1986

RODRIGUEZ 1992

RODRIGUEZ 1997

RŐMER 1966

RosADA-DAL Rí 1984

Roth-RuBi 1986

RusanOva 1973

RÜTIMEYER 1924

SALZANI 1981

SANDERS 1999

SCHEFFER 1981

SCHÖNBERGER 1976

SCHRETTER 1997

SEDOV 1982

SESTIERI 1976

SIMON 1976

SIVIERO 1975

Slavjane 1993

SPARKES 1962

SPARKES-TALCOTT 1970

StANOJEVIĆ 1987

STANOJEVIĆ 1996

STAUFFER-ISENRING 1983

STOKAR 1951

STEINKLAUBER 1990
= W. RADIMSKÝ: Prehistoricka sejenica kod Ripča u Bosni [Der prähistorische Bau im Ripač in Bosnien]. Glasnik Zemaljskog Muzeja Bosne i Hercegovine 1895, 309, 483.

= W. RADIMSKÝ: Der prähistorische Pfahlbau von Ripač bei Bihać. WMBH 5, 1897.

$=\mathrm{R}$. RAPAICS: A kenyér és a táplálékot szolgáltató növényeink története [Die Geschichte des Brotes und unserer nahrunggebenden Pflanzen]. Budapest 1934.

= E. RATTI: Ricerche sul luxus alimentare romano fra il I. sec. a.c. e il I. sec. d.c. Rendiconti Istituto Lombardo - Accademia di scienze e lettere CI. 100 (1966) 194-199.

= M. Ricci: Ceramica da fuoco. In: D. Monacorda-L. Paroli-A. Molinari- M. Ricci-D. Romei (ed.): La ceramica medievale di Roma nella stratigrafia della Crypta Balbi. In: La ceramica medievale nel Mediterraneo Occidentale. Atti del III. Congresso Internationale Siena-Faenza 8-13 ottobre 1984. Firenze 1986, 511-544.

= F. RitTATORE-VonwiLler: L'importanza della fase Protovillanoviana del Polesine nei suoi rapporti con gli ambienti Transadriatici e del Mediterraneo Orientale. Preistoria i protoistoria nel Polesine 20 (1984) 131.

= E. RITTERLING: Das frührömische Lager bei Hofheim im Taunus. Wiesbaden 1913.

$=$ H. RodRIGUEZ: Die vor- und frühgeschichtlichen Kleinfunde vom Lavanter Kirchbichl in Osttirol. Dissertation. Innsbruck 1986. ${ }^{285}$

$=$ H. RoDRIGUEZ: Bemerkungen zur relativchronologischen Gliederung der südostalpinen spätrömische-spätantiken Gebrauchskeramik. In: G. P. Brogiolo-L. Castelletti (a cura di): Il territorio tra tardoantico e altomedioevo. Metodi di indagine e risultati. Firenze 1992, 159-178.

$=$ H. RodRIGUEZ: Die Zeit vor und nach der Schlacht am Fluvius Frigidus (394) im Spiegel der südostalpinen Gebrauchskeramik. AV 48 (1997) 153-178.

= B. RŐMER: A sütőharang a történelem elötti időktől napjainkig (Der Backdeckel von der Urzeit an bis zur Gegenwart). Ethnographia 1966, 390-420.

= G. RosADA-L. DAL Rí (Hrsg.): Tires e Aica. Necropola di Epoca romana. Materiali di Archeologia. Verona 1984.

= K. Roth-Rubi: Die Villa von Stutheien/Hüttwilen TG. Ein Gutshof der mittleren Kaiserzeit. Antiqua 14 (1986) 32-37, 129-133.

= I. P. Rusanova: Slavjanskie dervnosti VI-IX. vv. meždu Dneprom i Zapadnym Bugom [Slawische Altertümer im 6.-9. Jh. zwischen Dnepr und Westbug]. Archeologija SSSR, SAI E 1-25. Moskva 1973.

= L. RÜTIMEYER: Ur-Ethnographie der Schweiz. Basel 1924.

= L. SALZANI: Preistoria in Valpolicella. Verona 1981, 100-102.

= G. D. R. SANDERS: A Late Roman bath at Corinth. Excavations in the Panayia field 1995-1996. Hesperia 64/4 (1999) 441-480.

$=$ CH. SCHEFFER: Cooking and cooking stands in Italy, 1400-400 B.C. In: Aquarossa Fol. II, Part 1. Acta Instituti Romani Regni Sueciae, Ser. 4, 38. Stockholm 1981.

= H. SCHÖNBERGER: Römerlager Rödgen. Limesforschungen 15. Berlin 1976

= S. SCHRETTER: Die westliche Doppelkirchenanlage auf dem Hemmaberg. Archäologie in Österreich 8/1 (1997) 54-61.

= V. V. Sedov: Vostočnye slavjane v VI-XIII vv. [Die Ostslawen im VI.-XIII. Jh.]. Moskva 1982.

= A. M. B. Sestieri: Tomba II. In: Civiltà del Lazio primitivo. Katalog. Rom 1976.

= H.-G. Simon: Die Funde aus den frühkaiserzeitlichen Lagern Rödgen, Friedberg und Bad Nauheim. In: Römerlager Rödgen. Limesforschungen 15. Berlin 1976, 51-156.

= G. B. Siviero: Ceramica dal XIII al XVII secolo. Este. Museo Nazionale Atestino 1975.

= I. P. RuSANOvA-E். A. SymONOviČ (eds): Slavjane i ich sosedi v konce I. t. do n è. - pervoj polovine I. t. n. è. [Slawen und ihre Nachbarn vom Ende des I. Jahrtausend v. Chr. - bis zur ersten Hälfte des I. Jahrtausend n. Chr.]. Moskva 1993.

= B. A. SPARKES: The Greek Kitchen. JHS 82 (1962) 121-137.

$=$ B. A. Sparkes-L. TalcotT: The Athenian Agora. XII/2: Black and Plain Pottery of the $6^{\text {th }}, 5^{\text {th }}$ and $4^{\text {th }}$ Centuries B.C. New Jersey 1970.

$=$ N. Stanojević: Naselja VIII-IX. veka u Vojvodini [Siedlungen im VIII-IX. Jh. in der Wojnodina, Neusatz]. RMV 30 (1987) 119-146.

= N. Stanojević: Srednovekovna nasela od V do XV veka u Vojvodini (Mittelalterliche dörfliche Siedlungen vom 5. bis zum 15. Jh. in der Wojwodina). Novi Sad 1996.

= L. Stauffer-Isenring: Die Siedlungsreste von Scuol-Munt Baselgia (Unterengadin GR). Ein Beitrag zur innenalpinen Bronze- und Eisenzeit. Antiqua 9. Veröffentlichungen der Schweizerischen Gesellschaft für Ur- und Frühgeschichte. Basel 1983.

= W. vON STOKAR: Die Urgeschichte des Hausbrotes. Ein Beitrag zur Entwicklungsgeschichte der Nahrung. Leipzig 1951.

= U. Steinklauber: Der Duel und seine Kleinfunde. Carinthia 180/100 (1990) 109-136. 
SZATMÁRI 1982-83

SZŐKE 1980

SZŐKE 1988

SZŐNYI 1996

TAKÁCS 1986

TAKÁCS 1996

TÁTRAI 1981

TENGSTRÖM 1974

ToMIĆ 1958

ToMIĆ 1966

TOMIĆ 1970

TOMIĆ 1983

TRIFUNOVIĆ 1997

TRIFUNOVIĆ 2000

TRUGLY 1996

TRUHELKA 1904

TRUHELKA 1914

VADAY 1980-81

VADAY 1989

VADAY 1996

VAKARELSKI 1977

VÁRI 1917, 1922

VIDA 1996

VIDA 1999

VIDA 2011

VINSKI-GASPARINI 1954

VINSKI-GASPARINI 1973

VROOM 2008

WAALE 1989

WAHL 1982
$=$ S. B. SZATMÁRI: Avar temető- és telepásatás Tatabánya-Alsógalla mellett (Awarische Gräberfeldund Siedlungsausgrabung bei Tatabánya-Alsógalla). SzMMÉ 1982-83, 67-79.

= B. M. SzŐKE: Zur awarenzeitlichen Siedlungsgeschichte des Körös-Gebietes in Südost-Ungarn. ActaArchHung 32 (1980) 181-203.

= B. M. SzŐKE: Südost-Ungarn im 9. Jahrhundert im Lichte der Siedlungsforschungen. In: Trudy V. Meždunarodnogo Kongressa Archeologov-Slavistov. Kiev 1985. Tom 1. Kiev 1988, 199-204.

= E. T. SzŐNYI: Römerzeitliche Altansässigensiedlung von Ménföcsanak (Umgebung von Győr). AV 47 (1996) 254-255.

= M. TAKÁCS: Die árpádenzeitlichen Tonkessel im Karpatenbecken. VAH 1. Budapest 1986.

= M. TAKÁCS: Formschatz und Chronologie der Tongefäße des 10.-14. Jahrhunderts der Kleinen Tiefebene. ActaArchHung 48 (1996) 135-195.

= Zs. Tátrai: Sütőbura (Backhaube). In: Gy. Ortutay (Hrsg.): Magyar néprajzi lexikon 4. Budapest $1981,510$.

= E. Tengström: Bread for the People. Studien of the Corn Supply during the Late Empire. Skrifter Utgivna of Svensk Institutet i Rom, 8 12 . Stockholm 1974.

= P. Tomić: Črepuljarstvo u selo Vrnjcima [Herstellung von Backglocken im Dorf Vrnjci]. Glasnik Etnografskog Muzeja u Beogradu 21 (1958) 209-220.

= P. Tomić: Narodna keramika u Jugoslaviji [Volkstümliche Keramik in Jugoslawien]. Beograd 1966.

= P. Tomić: Črepulje i vršnici u Severoistočnoj Srbiji - sa osvrtom na ove sudove i u drugim krajevima Jugoslavije (Črepulja et vršnik - récipients de terre pour la cuisson du pain dans le nord-est de la Serbie y compris des appréciations sur les autres régions de la Yugoslavie). Glasnik Etnografskog Muzeja u Beogradu 33 (1970) 43-54.

= P. Tomić: Gončarstvo u Srbiji [Töpferhandwerk in Serbien]. Beograd 1983.

= S. Trifunović: Slovenska naselja V-VII veka u Bačkoj i Banatu [Slawische Siedlungen des 5-7. Jhs. in der Batschka und Banat]. In: I. I. Sedov (red.): Problemy slavjanskoj arheologii. Trudy VI Meždunarodnogo Kongressa slavjanskoj arheologii. Moskva 1997, 173-185.

$=\mathrm{S}$. TRIfunović: Nasela limiganata i slovena u Banatu i Bačkoj (Settlements of Limigantes and Slavs in Banat and Bačka). Glasnik Srpskog Arheološkog Drštva 15-16 (1999-2000 [2000]) 43-106.

= S. TRugly: A komáromi avar telep (Die awarische Siedlung von Komárom/Komárno). ComArchHung 1996, 125-150.

= Ć. TRuHELKa: Der vorgeschichtliche Pfahlbau im Savenbette bei Donja Dolina. WMBH 9 (1904) 3-156.

= Ć. TRUHELKA: Kluturme prilike Bosne i Hercegovine u doba prehistorijsko [Kulturelle Verhältnisse Bosniens und der Herzegowina in der Urgeschichte]. Glasnik Zemaljskog Muzeja u Bosni-Hercegovini 26/1 (1914) 43, 67, 83

= A. H. VADAY: Késő szarmata agyagbográcsok az Alföldön (Spätsarmatenzeitliche Tonkessel von der Tiefebene). MFMÉ 1980-81, 23-34.

= A. H. VADAY A.: Die sarmatischen Denkmäler des Komitats Szolnok. Ein Beitrag zur Archäologie und Geschichte des Sarmatischen Barbaricums. Antaeus 17-18 (1989) 176-177, 344, Abb. 52.

= A. VADAY: Roman Period Barbarian settlement at the site of Gyoma 133. In: Microregion 1996, 51-306.

$=$ H. VAKARELSKI: Etnografija na Bălgarija [Ethnographie Bulgariens]. Sofija 1977.

= E. VÁri (Hrsg.): Sylloge Tacticorum Graecorum 3. Taktika Kaiser Leons VI. Budapest 1917, 1922.

$=$ T. VIDA: Avar Period settlements remains and graves at the site of Gyoma 133. In: Microregion 1996, 323-364.

= T. VIDA: Die awarenzeitliche Keramik I. (6.-7. Jh.). VAH 8. Budapest 1999.

$=$ T. VIDA: Sütőharangok és sütőfedők - régészeti adatok Dél- és Közép-Európa étkezési kultúrájához [Backglocken, Backdeckel und Backhauben. Archäologische Angaben zur Ernährungskultur Südund Mitteleuropas]. In: B. Kolozsi-Kr. Szilágyi (Hrsg.): Sötét idők falvai. 8-11. századi települések a Kárpát-medencében. Tempora Obscura 1/2. Debrecen 2011, 701-817.

$=$ K. VINSKI-GASPARINI: Neke pojave kontunuiteta s područja arheologije u nasšim krajevima (Einige Kontinuitätserscheinungen aus dem Gebiet der Archäologie in unseren Ländern). Peristil 1 (1954) 119-127.

= K. VINSKI-GASPARINI: Kultura polja sa žarama u sjevernoj Hrvatskoj [Die Urnenfelderkultur im nördlichen Kroatien]. Zadar 1973.

= J. VROOM: Dishing up history. Early medieval ceramic finds from the Triconch palace in Butrint. MEFR 120/2 (2008) 291-305.

= E. DE WAALE: La ceramica d'impasto. In: La civita di Artena. Scavi belgi 1979-1989. Roma 1989, 68, 74, Abb. 21.

= J. WAHL: Der römische Militärstützpunkt auf dem Frankfurter Domhügel. Schriften des Frankfurter Museums für Vor- und Frühgeschichte 6. Bonn 1982. 
WÄHREN 1960a

WÄHREN 1960 b

WÄHREN 1978

WÄHREN 1989

WÄHREN 2000

WEINBERG 1988

WHITEHOUSE 1978

WIEGELMANN 1973

WILLIAMS-EvANS 1991

ZÁвоJNík 1988

ZÁBOJNík 2006

ZAJCEV-PUZDROVSKIJ 1974

ZEČEVIĆ 1989
= M. WÄHREN: Die Backvorrichtungen des Altertums im Orient unter Berücksichtigung ihres Weiterlebens in der Gegenwart. Brot und Gebäck 14 (1960) 86-96.

= M. WÄHREN: Die Backvorrichtungen vom sechsten bis ersten Jahrtausend vor Christus. Brot und Gebäck 14 (1960). In: WÄHREN 2000, 377-388.

= M. WÄHREN: Brot. In: RGA 3. Berlin-New York 1978

= M. WÄHREN: Brot und Gebäck von der Jungsteinzeit bis zur Römerzeit. HelvA 20 (1989).

= M. WÄHREN: Gesammelte Aufsätze und Studien zur Brot- und Gebäckkunde und -geschichte 1940-1999. Deutsches Brotmuseum. Ulm 2000.

= G. D. WeInBERG: Excavations at Jalame. Site of Glass Factory in Late Roman Palestine. Columbia 1988.

= D. B. Whitehouse: "Home baking in Roman Italy: A footnote“. Antiquity 52 (1978) 146-147.

= G. WiEgELmanN: Backen. In: RGA 1. Berlin-New York 1973, 573-576.

= D. Williams-J. Evans: A fragment from a probable Roman clibanus from Catterick, North Yorkshire. Journal of Roman Pottery Studies 4 (1991) 51-55.

= J. ZÁволNíк: On the problems of Settlements of the Avar Khaganate Period in Slovakia. AR 40 (1988) 401-437, 480.

= J. ZÁвoJNík: Nálezy tzv. zvonov na pečenie na lokalitách z obdobia avarského kaganátu na území Slovenska (Backglocken auf den Fundstellen vom Awarischen Khaganat in der heutigen Slowakei). In: J. Zábojník (Hrsg.): Aevum Medium. Zborník na počest' Jozefa Hošša. Bratislava 2006, 133-147.

= Ju. P. ZAJCEV-A. E. PuZDrovskis: Neapol'skifskij v ejpochu diofantovych vojn [Skythische Neapolis in der Zeit der diophantischen Krieger]. In: Severo-zapadnyj Krym v antičnuju ėpochu. Kiev 1994, 217-237.

= E. ZEČEVIĆ: Rezultati istraživana srednevekovnog Svača (The results of the exploration of medieval Svač). Glasnik Srpskog Arheološkog Drštva. Beograd 1989. 